IFN Working Paper No. 1030, 2014

\title{
Sweden's School Choice Reform and Equality of Opportunity
}

\author{
Karin Edmark, Markus Frölich and \\ Verena Wondratschek
}




\title{
Sweden's School Choice Reform and Equality of Opportunity
}

\author{
by \\ Karin Edmark ${ }^{1}$, Markus Frölich ${ }^{2}$ and Verena Wondratschek ${ }^{3}$ \\ ${ }^{1}$ Research Institute of Industrial Economics (IFN), IFAU, UCLS, CESifo \\ ${ }^{2}$ University of Mannheim, IFAU, IZA, ZEW \\ ${ }^{3}$ Centre for European Economic Research (ZEW), IFN
}

27 June 2014

This study analyses whether the Swedish school choice reform, enacted in 1992, had different effects on students from different socio-economic backgrounds. We use detailed geographical data on students' and schools' locations to construct measures of the degree of potential choice. This allows us to study the effects of choice opportunities among public schools, whereas previous studies have focused on newly opened private schools. Our results suggest small positive or no effects of choice opportunities, depending on specification and outcome. We find no strong evidence of differences between subgroups; if anything, effects tend to be slightly more positive for disadvantaged groups, such as students from low-income families. Taken together, the results indicate that students from a socio-economically disadvantaged or immigrant background were not harmed by the reform.

Keywords: school choice, school competition, treatment evaluation, cognitive and noncognitive skills

JEL-codes: I24, C21

Acknowledgements:

We thank Florian Böser, Louise Johannesson, Aline Schmidt, Lennart Ziegler and Nina Öhrn for excellent research assistance. We also thank Mikael Lindahl, Anders Böhlmark, Jonas Vlachos, Peter Fredriksson, Christina Gathmann, Helena Holmlund, and seminar participants at IFAU, IFN, ZEW, Södertörns högskola, the Ratio Institute, the Uppsala Center for Labor Studies, Stockholm University, Helsinki Center of Economic Research, Gothenburg University, University of Mannheim, the CESifo Area Conference on The Economics of Education in Munich 2013, the 2013 Congress of the IIPF, the 2013 Conference of the EALE, and the Second Lisbon Research Workshop on Economics, Statistics and Econometrics of Education 2013, for valuable comments. We gratefully acknowledge project funding from The Swedish Research Council. The third author would furthermore like to thank IFAU and IFN for kindly hosting her as guest researcher on several occasions. The first author is grateful for financial support from the Jan Wallander and Tom Hedelius foundation, and from Marianne and Marcus Wallenberg Foundation. The second author acknowledges support from the Research Center SFB 884 "Political Economy of Reforms" Project B5, funded by the German Research Foundation (DFG). The third author gratefully acknowledges financial support from the Leibniz Association in the research network "Non-Cognitive Skills: Acquisition and Economic Consequences" and from the "College for Interdisciplinary Educational Research. A Joint Initiative of the BMBF, the Jacobs Foundation and the Leibniz Association". For further information on other projects of the third author and ZEW see www.zew.de/staff_vnl and www.zew.de/jahresbericht. 


\section{Introduction}

The school choice reform that was introduced in Sweden in the early 1990s has dramatically changed the possibilities of choosing a school within the Swedish compulsory education system. In addition to new choice options among public schools, a voucher system for private schools was introduced such that students could attend private schools without having to pay additional tuition fees. Due to this reform, the system has gone from one where students with few exceptions attended the public school of their catchment area, to one where many students opt for another school than the default school, and where there exist privately run but publicly funded alternatives alongside the traditional public schools.

In a companion paper (Wondratschek, Edmark \& Frölich 2013a, hereafter abbreviated WEF13), we investigated the average effects of school choice as introduced by the 1992 reform, and found them to be rather modest. In particular, we found that more choice options had a positive but small effect on final grades from compulsory school, and non-existent or very small effects on long-term outcomes. However, given the importance of the principle of "equivalent quality" ${ }^{1}$ in the Swedish school system, not only the average effect on the whole population is of interest, but also whether the school choice reform has affected students of different background differently. This is also an important issue in the context of the Swedish policy debate, where the fear that children from a socio-economically disadvantaged background would be harmed in absolute or relative terms has been one of the main arguments against the reform. ${ }^{2}$

Whether school choice is "a rising tide that lifts all boats", to quote from the title of Hoxby (2003), or rather a policy that is beneficial only for a subset of students, is also a

\footnotetext{
${ }^{1}$ Chapter 1, §9 of the Swedish school law (Law 2010:800) states that all students shall have access to education of equivalent quality. In Swedish: ’Utbildningen inom skolväsendet ska vara likvärdig inom varje skolform och inom fritidshemmet oavsett var i landet den anordnas."

2 The National Board of Education (2003), p. 45, points to the risk of increased ethnical and social segregation as one of the most common arguments against the choice reforms in the political debate. A descriptive analysis, that is available in the appendix, shows no evidence for an overall increase in school segregation in lower secondary education in the period after the reform, compared to before the reform. It shall however be emphasized that this is a rough description, and a more thorough analysis would be needed to answer the question of whether the school choice reform has caused more segregation.
} 
topic of interest in the international policy discussion and research literature. For example, Hastings, Kane and Staiger (2006) report positive effects of gaining access to the most preferred schools on test scores among white students and students of higherincome families in the U.S., while there are no statistically significant effects among African Americans and children of lower-income families. Hoxby (2000) finds a similar pattern in the effects of competition between U.S. public school districts on student educational attainment: white non-Hispanics, males and those whose parents have at least a high school degree are the ones who gain from more competition, but no group seems to lose. Deming (2011), on the other hand, finds that gaining access to a firstchoice school through a randomised lottery decreases the crime rates, but that the effect is concentrated among African-American male students who are defined as high risk based on ex ante characteristics. Previous studies of the Swedish school choice reform, with the exception of the companion paper of this study, WEF13, have focused exclusively on the expansion of privately run but publicly funded schools. The results of these studies (see Ahlin (2003), Sandström and Bergström (2005), Björklund, Clark, Edin, Fredriksson and Krueger (2005)) suggest that students from a better-off socioeconomic background gain a bit more, but importantly, no group seems to be negatively affected by the choice reforms. Overall, however, there are no large differences between students of different socio-economic background. ${ }^{3}$

To date there has been no study that evaluates the effects of the full Swedish 1992 choice reform, including the increased possibilities to choose between public schools, on outcomes of different groups of students. Our study serves to fill this gap. As the Swedish reform changed the institutional setting for the complete population and not just for certain target subgroups, it is especially suited to study the effects of school choice on different subpopulations. Moreover, given the long time since the introduction of the reform, we are able to evaluate long-run effects over and above mere short-run outcomes. We will focus our analysis on the following issues:

First, we will investigate Quantile Treatment Effects of the reform, that is whether the degree of school choice affected different parts of the distribution of outcomes

\footnotetext{
${ }^{3}$ Böhlmark and Lindahl (2012) also find positive overall effects of the private school expansion, but do not test for
} 
differently. We will centre our analysis on distributional effects on marks at the end of $9^{\text {th }}$ grade. To this end, we focus on two thresholds which are of special interest when looking at marks: the probability of receiving a passing grade and the probability of receiving a high grade. ${ }^{4}$ Second, we will analyse whether the reform has had heterogeneous effects on student outcomes with respect to the socio-economic background, based on parents' education, income and immigrant status as well as the crime rate of the residential area.

The dataset that we use for our analysis comprises detailed administrative data for the complete Swedish population born between 1972 and 1990. As the first five of these cohorts had already left compulsory education when the reform was introduced in autumn 1992, we observe both students that have and that have not been affected by the reform.

We use very detailed geographical information about students' and schools' locations to construct measures of the potential degree of school choice that is available to each student, based on the number of schools near the students' home. Our identification strategy to deal with the potential endogeneity of choice options available to students after the reform (due to mobility of students and schools) is to measure the potential degree of school choice just before the reform, that is before parents and schools potentially reacted to the school choice reforms with a decision on where to live or open a school. This means that, for a student who chooses a school after the introduction of the reform, we will measure choice by counting the number of schools near her home in 1991. For cohorts that make their choice before 1992, we will use the actual year in which they choose a school, as the rules of the new school choice regime cannot have affected the place of residence of these cohorts.

Nevertheless, even for these unaffected cohorts, that is for students in a situation without free school choice, the number of schools nearby may be correlated with

\footnotetext{
heterogeneous effects with respect to student background.

${ }^{4}$ In 1997 the grading system was changed from a grade 1-5 scale (with 5 as the top grade), to the four categories: Fail, Pass, Pass with distinction and Pass with special distinction. We construct our indicator variable of receiving a passing grade (or higher) as receiving at least a " 3 " in the older system, or at least a "Pass" in the later system. As indicator of receiving a high grade, we use receiving at least a "4" in the old system, and at least a "Pass with distinction" in the later system. It shall be noted that the two grading systems follow different scales, and the indicator variables for "Pass grade" and "High grade" will hence have a slightly different meaning for the different cohorts.
} 
student outcomes via observable and unobservable factors ${ }^{5}$. For this reason, we include regional- and individual-level covariates in the estimations. Moreover, we use the five student cohorts that left compulsory education before the reform was enacted to control for the effect of having many schools nearby before the reform. This allows us to net out all time constant correlation - due to both observable and, most importantly, unobservable factors - between outcomes and having many schools close-by in a situation without free school choice. The identifying assumption is thus that the cohorts that are unaffected by the reform are a good control group for later cohorts, and that the correlation between the number of schools nearby and student outcomes would have stayed constant over time if there had been no reform. We provide suggestive evidence on the validity of this assumption by testing for placebo treatment effects.

Applying this empirical strategy, we identify the differential effect of more school choice, measured at the time of the introduction of the reform, on student outcomes. Since the results are based on a pre-reform measure of school choice, the estimated effect, which can be characterized as an "intention-to-treat" effect, will include all dynamic processes, like the opening or closing of schools, which are a direct result of the degree of school choice that was present at the outset of the reform ${ }^{6}$. It shall also be clear that we estimate the effects of the variation in the choice options available to the student, and not the effect of whether the student in fact makes an active choice or not. ${ }^{7}$

As a result of students' choice options, and budgets of schools being tied to the number of students in one way or the other ${ }^{8}$, the reform simultaneously led to choice for students and competition among schools in many areas ${ }^{9}$. These two concepts, as well as

\footnotetext{
${ }^{5}$ For example, it may be that areas with a higher school density have different employment opportunities which result in different educational levels in the neighbourhood and thus different schooling outcomes of children, independently of the educational quality of schools. Also, it may be that Tiebout choice moves before the reform, where parents move into catchment areas of good schools, have affected school density in the long run.

${ }^{6}$ In Section 8.1.2 in the appendix we show that the degree of school choice in 1991 and at the time when the children make an active school choice are closely related.

${ }^{7}$ As will be discussed in Section 3 there are several channels through which increased school choice options could affect students, both when they make active choices and when they do not.

${ }^{8}$ Due to the voucher that private schools get for each student, the school budget of private schools has a direct connection to the number of students. For public schools, the way in which the budget is tied to the number of students is specified at the municipal level. The corresponding rules have varied over time and across Sweden, from systems where the idea of vouchers has also been used for public schools to systems that have specified only broadly that the number of students should be taken into account when deciding about schools' budgets.

${ }^{9}$ The degree to which schools compete against each other depends on several factors, such as the specific way that school finances are tied to the number of students, which is specified on the municipal level, the degree to which
} 
indicators measuring competition and choice, are naturally closely linked, as there would be no competition without student choice. We will not attempt to separate between the two in this study but measure choice on the student level. The estimated effects will thus comprise both choice and related competition effects. ${ }^{10}$

Our results suggest small positive or no effects of choice opportunities, depending on specification and outcome. We find no strong evidence of differences between subgroups; if anything, effects tend to be slightly more positive for disadvantaged groups, such as students from low-income families. Taken together, the results indicate that students from a socio-economically disadvantaged or immigrant background were not harmed by the reform.

As some placebo tests fail, especially for the adult outcomes, we do not overinterpret such results but focus on the more robust estimates.

The remainder of the paper is organised as follows: Section 2 gives an overview of the Swedish compulsory school system and the 1992 school choice reform, and Section 3 discusses why the effects of the reform may differ across groups of students. Section 4 describes the data and explores how different subgroups behaved in terms of their school choice behaviour before and after the reform. Section 5 explains and discusses our empirical strategy. Section 6 then presents the results, and Section 7 concludes.

\section{Swedish compulsory school and the 1992 school choice reform}

Before we turn to the empirical analysis of the paper, this section will give a short overview of the Swedish compulsory school system and the 1992 school choice reform ${ }^{11}$. Swedish compulsory schooling comprises grades 1-9, with students starting

students actually choose other than the default schools, which is likely to be related to the amount of free capacity of school slots in an area, and other factors. Moreover, a qualitative study conducting interviews in a central area of Stockholm for example reports that some head masters of public schools have agreed to not actively compete for students from each other's catchment area schools (Waslander, Pater and van der Weide (2010)).

${ }^{10}$ In a companion paper (Wondratschek et al. 2013b), we attempted to disentangle the choice effect, i.e. the individual matching effect, from the competition effect. While our estimates gave some indications of positive choice effects and negative competition effects especially shortly after the reform, the close relation between the two indicators of choice opportunities faced by students and competition from other schools faced by schools made it difficult to empirically separate estimates of the two effects.

${ }^{11}$ Wondratschek et al. 2013b includes a more detailed description. 
grade one the year they turn seven. ${ }^{12}$ Since elementary school (grades 1-6) and lower secondary school (grades 7-9) are often organised in different schools, it is common to change the school when starting grade 7 , at the age of 13 . Following previous studies on the Swedish school choice reform, we will focus on grades 7-9. After compulsory school, which has a comprehensive curriculum with some choice options like studying a second language, most students go on to upper secondary school, which is voluntary and is organised in several educational tracks.

Since 1990, the municipalities are the responsible administrative entities for organising compulsory education. The main sources of finance are the local income taxes and central government grants. ${ }^{13}$ The central government, however, steers compulsory schooling through providing rules and regulation.

Following the election of a right-wing coalition in the fall of 1991, the large compulsory school choice reform that is studied in this paper was implemented in the autumn of 1992. The reform had two parts: first it opened up for attending another public school than the one in the catchment area, and second, it allowed for privately run but publicly funded schools to operate alongside the ordinary public schools. In 1994, the law was amended by also allowing for choice among public schools outside of the home municipality, which was previously only possible in very special cases. ${ }^{14}$ If the demand for a given public school exceeded the number of available slots, priority was given to students living in the catchment area. Private schools were not allowed to select their students on the basis of ability or other characteristics but only on a firstcome-first-served basis. ${ }^{15}$

The reform has had substantial effects on the workings of the educational sector, at least in more urban areas. Before the reform, students were, with few exceptions,

\footnotetext{
${ }^{12}$ From the year 1997 on, the vast majority of children also attend a voluntary 1-year school preparatory year, which is usually offered at the compulsory school.

${ }^{13}$ The central government grants have been completely general since 1993, i.e. not tied to specific sectors, and they are set so as to compensate for differences in tax base as well as in structural costs, in order to ensure that all municipalities have roughly equal economic conditions. Between 1991-1993, a sector specific grants system was in place, and before that, when the central government was responsible for the provision of education, central government grants were classified for different purposes. The largest among these, the "basic resource", consisted mainly of teacher salaries (see pp. 67f von Greiff (2009)).

${ }^{14}$ See Law 1985:100 Chapter 4 §8a.

${ }^{15}$ Sibling priority, geographical proximity, or having attended a school run by the same provider, are also valid selection criteria.
} 
referred to the school of their catchment area. Some alternative schools existed, such as Waldorf schools or schools with a special profile, like music, but they were rare. After the 1992 reform, as more and more private schools were established and as choice between the already existing schools became more and more common, this gradually changed, and now, 20 years after the reform, school choice is a normal phenomenon in many parts of the country. According to the National Board of Education ${ }^{16}$, almost 13 per cent of all students in compulsory school attended an independent school in the school year 2011/12. For the public schools, there is no comprehensive information available on how common it is to choose another school than the catchment area school, but survey information from school year 2000/01 suggests that choosing another public school is at least as common as choosing a private school (The National Board of Education (2003)).

For the sake of the empirical analysis, it is worth to point out that the expansion of choice both in terms of private schools, and in terms of choice between the public schools, has been gradual: in the mid 1990s, a couple of years after the reform, choosing another school than the default school was still rare (see the National Board of Education (1996)). This means that we expect the choice reform to have more and more of an impact over time, something that we will take into account in the empirical analysis.

\section{Why may effects differ across groups of students?}

This section will discuss theoretical arguments for why there might be heterogeneous effects for children with different socio-economic or migration backgrounds. We choose to focus especially on groups that may be considered more vulnerable or disadvantaged since the effects of school choice policies on these groups are often of particular interest in the public debate. In particular, we will focus on students with low-educated parents, defined as both parents having at most a compulsory education degree; students living

\footnotetext{
16 See information at the webpage of the National Board of Education: http://www.skolverket.se/statistik-ochanalys/2.1862/2.4290/2.4292.
} 
in a low income household, defined as disposable household income being in the lowest quartile of the income distribution; students with both parents having been born outside of Sweden; and students living in high-crime areas. ${ }^{17}$ Each of these groups will be compared with their respective counterpart.

Before we turn to why the effects of school choice would be expected to differ across groups of students, we briefly outline the channels through which free school choice might affect educational outcomes in general. ${ }^{18}$ First, being able to choose a school that suits one's preferences and character may result in a better match between students and schools, which would improve learning among those who actively make a choice. Second, more choice for students, and schools budgets being tied in some way to the number of students, may introduce competitive pressure and lead head masters and teachers to increase teaching quality in order to attract students to their school ${ }^{19}$. This may lead to good schools attracting more students, and bad schools either improving or having to close down. Thereby, the overall quality of the education system may increase in the long-run, which would then be beneficial also for students who do not make an active school choice. Third, when students are free to attend another school than the one of the catchment area, the composition of students within a school may change, which results in different peer effects ${ }^{20}$.

However, to what extent these channels work in reality is not clear, as they are related to a number of issues. One of them is the informational asymmetry between parents and schools, as the former may not always be able to observe educational quality or base their choices solely on this. Moreover, transportation costs to different schools and capacity limits of schools may decrease the forces of the above explained channels. Also, parents with different characteristics may react differently to the choice reform, both in their propensity to make an active school choice and the characteristics on which they base their choice. As a result, children with different background may be

\footnotetext{
${ }^{17}$ See Section 4.2 for a closer definition.

${ }^{18}$ WEF13 presents a more detailed discussion.

${ }^{19}$ See for example Hoxby (2003) on the relation between school choice and school productivity.

${ }^{20}$ See for example Epple and Romano (1998) on this issue, who model peer effects of sorting as a results of school choice. See also De Giorgio et al (2009) for a study on the effects of class composition.
} 
affected differently by the choice reform. In the following, we will discuss potential reasons for such differences for the subgroups that we analyse in this study.

We organise our thoughts on this matter by asking: how do we expect that students reacted to and were affected by the expanding possibilities to choose school after the Swedish choice reform of 1992 ?

First of all, we expect that some students reacted by choosing another school than the default school. Some may have chosen to attend another public school than the one of their catchment area, while others may have chosen a private school. ${ }^{21}$ Survey information from the National Board of Education (2003) suggests that making an active school choice (in Sweden in school year 2000/01) was more common among students whose parents had higher education or were immigrants. One can also speculate that the possibility of choosing another than the closest school might be more interesting for students of low-income background, as these may be financially restricted from getting into a good school by moving near it, i.e. from exerting Tiebout choice. Students from high-income families, on the other hand, have always had better economic means to move near the desired school, and might thus not have been as restricted in their school choice by the assignment system that was in place before the reform. A related hypothesis is that students living in more disadvantaged areas may be more likely to choose another school than the neighbourhood school, for example to get access to a school with less social problems. Students of different socio-economic or immigrant background, or students living in areas with more or less social problems, may hence differ in the likelihood of choosing another school than the default school.

Second, those who make use of the option to attend another school than the default one, will naturally be subject to another school environment, including other teachers and peers, than would otherwise have been the case. ${ }^{22}$ How the new school differs from the old one in turn depends on the factors that determined the choice of school. Burgess et al. (2009) show that families in Britain do not only value academic performance when they choose schools, but also other factors such as the student composition and

\footnotetext{
${ }^{21}$ See for example Nechyba (2006) for an overview of the literature on the mechanisms of sorting of students with respect to income and peer quality.
} 
travel distance. The results of Hastings et al. (2006), who study U.S. families, furthermore suggest that getting access to the most desired school has positive effects on student outcomes only for those who named academic quality as an important choice factor. In addition, Hastings and Weinstein (2008) find that the likelihood of choosing a high-performing school was increased when low-income families were given information about school test scores. This suggests that, at least in the U.S., parents from low- and middle-income families did not have sufficient information on the quality of the school, since providing such information changed their choice of school towards educationally better schools. Hastings and Weinstein (2008) also find a positive effect on student test scores of attending a higher-scoring school.

The results of these studies illustrate that, in order to benefit from the option to choose a school, it is important to have and use information about factors that actually are important for students' school results, such as academic quality. This means that even though all students may make an active school choice, the factors influencing this choice may be very different, which may in turn lead to heterogeneous effects of school choice. For the Swedish case, Böhlmark and Lindahl (2007) provide some evidence that parents with higher education and those born in another country were more likely to send their children to a private school, while they find no such difference with regard to parental income. This might in turn lead to different effects for the corresponding subgroups if attending a private school is on average more or less beneficial than attending a public school ${ }^{23}$.

Third, not only the students who make an active school choice may be affected by increased choice possibilities, but also the students who remain in the default school. That is, they may be affected by the other students' choices if the characteristics of the peer group change and, in relative terms, by possibly staying at a not so good school that other students opted to leave. In their study, Östh, Andersson and Malmberg (2010) suggest that school choice in Sweden has led to increased between-school dispersion in

\footnotetext{
${ }^{22}$ See Sacerdote (2011) for a recent survey of the empirical literature on peer effects. See also De Giorgi and Pellizzari (2011) for a study on peer effects which models and tests for different mechanisms of peer interactions.

${ }^{23}$ Böhlmark and Lindahl (2007) find some evidence for a beneficial effect of attending a private school, though they also show that most of their estimated positive effects of higher private school shares stems from the competition effects that affect all pupils, not just those in private schools.
} 
$9^{\text {th }}$ grade marks, on top of the dispersion that stems from residential segregation. Böhlmark and Lindahl (2007), who also study the 1992 choice reforms but focus on the introduction of private schools, find that a higher share of private school students within a municipality is related to higher segregation in terms of parental education and immigrant status between public and private schools. Comparing schools offering grades 7-9 in the years before and after the reform, we do not find any indication for an overall increase in segregation, measured in terms of the between-school variation in the share of students with a disadvantaged socio-economic background or immigrant background (see Section 8.1.1 in the appendix). This measure does however not disentangle the effects of the choice reform from other factors that changed over time and thus does not show that the choice reform has not increased segregation.

In sum, given that previous studies have indicated systematic differences in the way that students of different background react to reforms that expand school choice, and given the many channels through which school choice may affect student outcomes, it is important to test empirically whether the effect of the Swedish 1992 school choice reform differs across groups of students, and in particular, whether some groups were harmed by school choice as it evolved after the reform.

\section{Data and descriptive statistics}

Before we turn to the econometric analysis, we will check, in this section, if there is any indication in our data that students of different background reacted differently to the choice reform. To this end, we look at descriptive statistics for student outcomes as well as at indicators of actual school choices made, namely travel distance to school and attending a private versus public school. First however, the subsection below gives a short overview of the data sources.

\subsection{Data}

This study uses the same data set as employed in the companion paper; the following section thus heavily builds on the corresponding one in WEF13. We use data from Statistics Sweden, the Swedish National Council for Crime Prevention, the Military Archives and the Swedish Defence Recruitment Agency. The data set contains 
information on final grades from compulsory school for all individuals in Sweden born in 1972-1990, and on the longer term outcomes “criminal convictions by age 22”, “university education at age 25" and “employment at age 25" for those who had achieved the corresponding age by 2009. For men, we also observe the cognitive score from the military draft test ${ }^{2425}$. The data furthermore include a broad set of individual level background variables, including detailed parental background information on education and income level, country of birth and family structure. In addition, we have access to geographical information on the location of schools (for years 1988-2006) and students’ residences (for years 1985-2006), measured as 100*100 square meter boxes. These data allow us to construct detailed measures of the choice options available to each student.

Moreover, we have information on a set of municipality level characteristics like the population density and income tax base which we collected from the webpage of Statistics Sweden (www.scb.se) and from the webpage of the Swedish Association of Local Authorities and Regions (www.skl.se). On a finer regional level, we constructed a set of parish level characteristics from individual register data, including population density, education and income level and immigrant share. A full list of these variables, used as covariates in the estimations, is given below Table 5. Table 25 displays the corresponding descriptive statistics.

\subsection{Descriptive statistics}

Table 1 shows average student outcomes separately for the pre- and post-reform cohorts, that is for cohorts born between 1972 and 1976, and between 1977 and 1990, respectively, and separately for the different subgroups ${ }^{26}$. We can see that the higher the household income and parental education, the better is the average value of most outcomes, that is of the percentile rank in marks, cognitive skills, the share receiving a passing or a high grade in math or holding a university degree at age 25 , and having

\footnotetext{
${ }^{24}$ See also Lindqvist and Vestman (2011) for a detailed description of this test. Note that the share of men taking the military test drops significantly for the younger cohorts. See WEF13 for an analysis showing that the selection effects are only mildly related to our choice measure and outcomes, on average.

${ }^{25}$ The cognitive score and information on whether the individual has been convicted for a crime are available only for cohorts born in 1972 to 1987, while the information on university education and employment, measured at age 25, is only available for individuals born between 1972 and 1984.
} 
been convicted for a crime until age 22. A similar pattern holds when comparing children whose parents have both been born abroad with those who have at least one native Swedish parent. Comparing these numbers pre- and post-reform, the most remarkable changes are the increase in the percentage receiving a passing grade in all subgroups ${ }^{27}$ and the increase in the share of those having obtained a university degree at age 25. Both of these changes are more pronounced among children with high compared to low-educated parents and immigrants as compared to native Swedes. The change in obtaining a university degree at age 25 is with 10 percentage points twice as large for children of high-income as compared to low-income families. Apart from this, students from middle and high income households have similar or improved outcomes in all dimensions except for the share of those being employed at age 25, while students from low-income families have similar outcomes and a slight decrease in the probability of receiving a high grade in math at the end of $9^{\text {th }}$ grade. Children from parents who both have at most a compulsory education experience a decrease in the percentile rank in marks by 2 percentage points and an increase in the share having committed a crime until age 22 by 1.5 percentage points.

Lastly, we split the sample according to the local crime rate in 1990-91. We think that this is an interesting additional characteristic since, as was discussed in Section 3, school choice gives students of areas with social problems the possibility of leaving their neighbourhood for the time they are at school and to get in touch with other peers. If, for some reason, their families were stuck in a neighbourhood with high crime and potentially bad influences while growing up, being given the opportunity of going to a school outside of this neighbourhood might be especially beneficial.

In order to analyse empirically whether this is the case, we split the sample according to whether the student's home municipality or, for the larger municipalities, parish, had

\footnotetext{
${ }^{26}$ The corresponding standard deviation and number of observations are reported in tables in Section 8.2.3.1.

${ }^{27}$ This is in line with Vlachos (2010) who finds that the final average grade point averages from Swedish lower as well as upper secondary school increased between 1998 and 2008. Vlachos' analysis contributes only a small share of this increase to competition effects, and suggests that a large share can rather be attributed to other factors such as the introduction of a new grading system in 1997, based on absolute knowledge goals, instead of the previous more relative grading system. In WEF13, we find that there is, on average, a modest increase in the percentile rank of $9^{\text {th }}$ grade GPA as a result of having more school choice. We further present suggestive evidence that this is not explained by grade inflation only.
} 
a crime rate in the top quartile of the distribution both in 1990 and 1991, or not. ${ }^{28} \mathrm{We}$ use the crime rate among 15-18-year-olds, as this is likely to be more important in terms of influences on adolescents than the adult crime rate.

Table 1: Pre- and post-reform averages of student outcomes for different subgroups

\begin{tabular}{|c|c|c|c|c|c|c|c|c|}
\hline & $\begin{array}{l}\text { cohort } \\
\text { is ...- } \\
\text { reform }\end{array}$ & 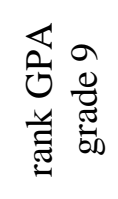 & 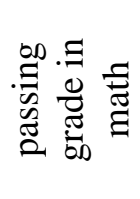 & 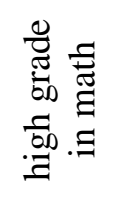 & 莺 & 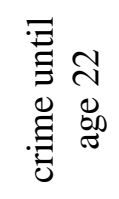 & 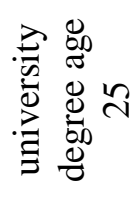 & 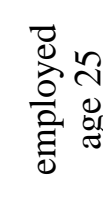 \\
\hline \multicolumn{9}{|c|}{ household income is... } \\
\hline \multirow[t]{2}{*}{ low income } & Pre & 40.87 & 0.713 & 0.308 & 4.72 & 0.204 & 0.244 & 0.678 \\
\hline & Post & 40.55 & 0.835 & 0.294 & 4.64 & 0.203 & 0.292 & 0.671 \\
\hline \multirow[t]{2}{*}{ medium income } & Pre & 47.59 & 0.773 & 0.356 & 4.98 & 0.147 & 0.331 & 0.729 \\
\hline & Post & 48.11 & 0.885 & 0.370 & 4.92 & 0.134 & 0.389 & 0.714 \\
\hline \multirow[t]{2}{*}{ high income } & Pre & 55.92 & 0.821 & 0.429 & 5.50 & 0.129 & 0.472 & 0.695 \\
\hline & Post & 59.82 & 0.929 & 0.511 & 5.60 & 0.104 & 0.576 & 0.654 \\
\hline \multicolumn{9}{|c|}{ parents highest educational degree is ... education } \\
\hline \multirow[t]{2}{*}{ compulsory } & Pre & 36.37 & 0.684 & 0.275 & 4.14 & 0.186 & 0.159 & 0.740 \\
\hline & Post & 34.01 & 0.763 & 0.220 & 4.00 & 0.201 & 0.191 & 0.728 \\
\hline \multirow{2}{*}{$\begin{array}{l}\text { more than } \\
\text { compulsory }\end{array}$} & Pre & 50.34 & 0.788 & 0.380 & 5.22 & 0.150 & 0.381 & 0.702 \\
\hline & Post & 50.68 & 0.895 & 0.403 & 5.14 & 0.137 & 0.440 & 0.684 \\
\hline \multicolumn{9}{|l|}{ parents are... } \\
\hline \multirow[t]{2}{*}{ both immigrants } & Pre & 43.00 & 0.686 & 0.276 & 4.20 & 0.242 & 0.249 & 0.631 \\
\hline & Post & 44.42 & 0.824 & 0.304 & 4.20 & 0.226 & 0.346 & 0.607 \\
\hline \multirow{2}{*}{$\begin{array}{l}\text { at least one } \\
\text { Swedish }\end{array}$} & Pre & 48.52 & 0.777 & 0.369 & 5.10 & 0.150 & 0.353 & 0.713 \\
\hline & Post & 49.78 & 0.889 & 0.396 & 5.10 & 0.136 & 0.420 & 0.695 \\
\hline \multicolumn{9}{|c|}{ Residential area 1990-91. } \\
\hline \multirow[t]{2}{*}{ high crime } & Pre & 46.99 & 0.741 & 0.338 & 4.89 & 0.197 & 0.306 & 0.684 \\
\hline & Post & 49.46 & 0.871 & 0.382 & 4.93 & 0.170 & 0.387 & 0.666 \\
\hline \multirow{2}{*}{$\begin{array}{l}\text { low/medium } \\
\text { crime }\end{array}$} & Pre & 48.41 & 0.777 & 0.369 & 5.09 & 0.148 & 0.354 & 0.712 \\
\hline & Post & 49.41 & 0.887 & 0.391 & 5.06 & 0.138 & 0.419 & 0.693 \\
\hline
\end{tabular}

Note: Sample contains only observations with full information on all covariates $X$ given below Table 5.

\footnotetext{
${ }^{28}$ The high crime areas are defined as the local areas that were in the top quarter of the distribution of youth crime in both 1990 and 1991, and where youth crime is measured as the share of 15-18-year-olds that were convicted for a crime during the year. (The reason for using both 1990 and 1991 to determine high crime areas is to get a more stable measure.) As local area, we used the municipality of residence, measured in 1991, in the cases where the municipality population was less than 50 000. For larger municipalities, we deemed the municipality to be too large to constitute a relevant local unit and instead used the parish level information. Finally, in many cases the resulting parishes were too small to be meaningful and we then merged several geographically adjacent parishes to one unit. For more detailed information on this procedure, please contact the authors.
} 
Table 2 displays which kinds of crimes are most commonly committed in high vs. low or medium crime areas in 1991. Listing only those crimes that make up more than 3 per cent of all crimes, we can see that the composition of crimes in low/medium and high-crime areas is very similar, so it is mostly the quantity that varies: the average crime rate in the high crime municipalities is 6.1 per cent, while it is only 3.7 per cent in the low and medium level crime areas.

The last rows in Table 1 display that there are no strong differences in outcomes of students living in the different areas, except that the share of those having committed a crime until age 22 is higher in high crime areas and that the share holding a university degree at age 25 and those receiving a passing or a high grade is slightly lower for prereform cohorts in these areas. However, after the reform, students in high crime areas perform slightly better in terms of marks compared to students in low or medium crime areas.

Table 2: High crime areas based on criminal convictions of individuals aged 15-18 years in year 1990 and 1991.

\begin{tabular}{lcc} 
type of crime & high crime & low or medium crime \\
\hline Assault & 6.2 & 5.8 \\
Illegal driving & 13.7 & 17.48 \\
Drunk driving & $<3 \%$ & 3.72 \\
Reckless driving & $<3 \%$ & 3.41 \\
Damage & 5.44 & 5.48 \\
Petty theft /pilfering & 16.31 & 15.05 \\
Theft & 18.67 & 17.04 \\
Car/ bike theft & 6.98 & 5.95 \\
& & \\
Average crime rate & $6.11 \%$ & $3.68 \%$ \\
Number & 50 & 320 \\
\hline
\end{tabular}

Note: High crime refers to areas that have a criminal conviction rate among 15-18-year-olds that is in the upper quartile in both 1990 and 1991. "Low or medium crime" refers to the complementary group. Local areas are defined as the municipality for municipalities with a population below 50000 , and is defined as the parish or a set of adjacent parishes, for municipalities with a population at or above 50000 .

These descriptive comparisons of subpopulations and cohorts that have been affected and not affected by the reform show that children from low-income and less educated households experienced, for some outcomes, a small relative drop after the reform compared to more advantaged students. Before we turn to an econometric assessment of 
whether these differences are related to the school choice reform, we first investigate in the next section whether there is any indication in the data that students from different subgroups changed their school choice behaviour in different ways after the reform.

\subsection{Differences in choice behaviour of students with different background}

In this section we investigate whether students of a different socio-economic or immigrant background reacted differently to the choice reform in terms of making an active school choice. As we lack information on whether students choose to attend another public school than the assigned one, we instead make use of indirect information in terms of distance to school of attendance and whether students attend a private or public school, to get an idea of how the choice reform affected school choicerelated behaviour.

The travel distance to school can be seen as an approximate indicator of school choice in general - to public as well as private schools, since students that opt out of the school of their catchment area are likely to increase their travel distance, as the catchment area school is in general the nearest one. With new schools opening up and old ones possibly closing down, an increased travel distance is not a perfect measure of choosing another than the default school but only an approximation. Moreover, any changes in travel distance over time may of course be related to other factors and general trends too. On the contrary, attending a private school is clear evidence for active school choice, as opting out of the public school system requires parents to act.

Columns 1-4 in Table 3 show the mean of the travel distance to school for the different subgroups, separately for the pre- and post-reform cohorts. ${ }^{29}$ The first two columns show the unconditional mean, while the last two columns show the mean conditional on all covariates included in the estimation ${ }^{30}$, i.e. net of all differences in covariates. The numbers for the cohorts not affected by the reform indicate that the unconditional mean travel distance to school was larger among low-income than among

\footnotetext{
${ }^{29}$ Note that we measure travel distance "as the crow flies", i.e. by computing the distance between the mid points of the coordinate for the students home and the students' school of attendance in $9^{\text {th }}$ grade.

${ }^{30}$ This is calculated using coefficient estimates from an OLS regression with distance to school as the outcome and all covariates, an indicator for „affected by the reform“, an indicator for the subgroup and an interaction of the two included as right hand side variables.
} 
mid- and high-income households, and was larger among households with Swedishborn parents or households living in high-crime areas. However, conditioning on covariates (Columns 3 and 4) almost completely eliminates these differences except for households with different incomes. When we compare the conditional pre- and postreform means, we see that the distance to school increases over time for all groups, but the increase is largest, both for the unconditional and the conditional means, for lowincome households. We furthermore see that the conditional travel distance increases a bit more between the pre- and post-reform cohorts if both parents are Swedish-born parents or if the child lives in a high crime area.

Columns 5-6 in Table 3 show the unconditional and conditional share of students attending a private school in $9^{\text {th }}$ grade. Here, we only report the shares for post-reform cohorts, as it was extremely uncommon to attend a private school before the reform. The unconditional means in the fifth column of Table 3 show that children of immigrant, higher-education and higher-income background, as well as children from high crime areas, are more likely to attend a private school. When conditioning on all covariates that we use in the main estimations (see note to Table 5 for a list), the differences with respect to household income are negligible, while the qualitative results for the other subgroups stay the same.

In sum, the descriptive statistics suggest that travel distances have increased for all groups after the choice reform, but the increase is larger for students whose parents have lower income, who live in high crime municipalities or have Swedish-born parents, which in turn could suggest that choosing another school than the catchment area school after the reform was more common among these groups of students. Of course, when interpreting these purely descriptive statistics it has to be kept in mind that other factors like trends in living in different residential areas and not school choice itself may be behind these results. Our data on private school attendance furthermore shows that private school attendance was more common among students of immigrant background, students in high-crime areas or students with high-educated parents. 
Table 3: Mean travel distance and the share attending a private school for different subgroups

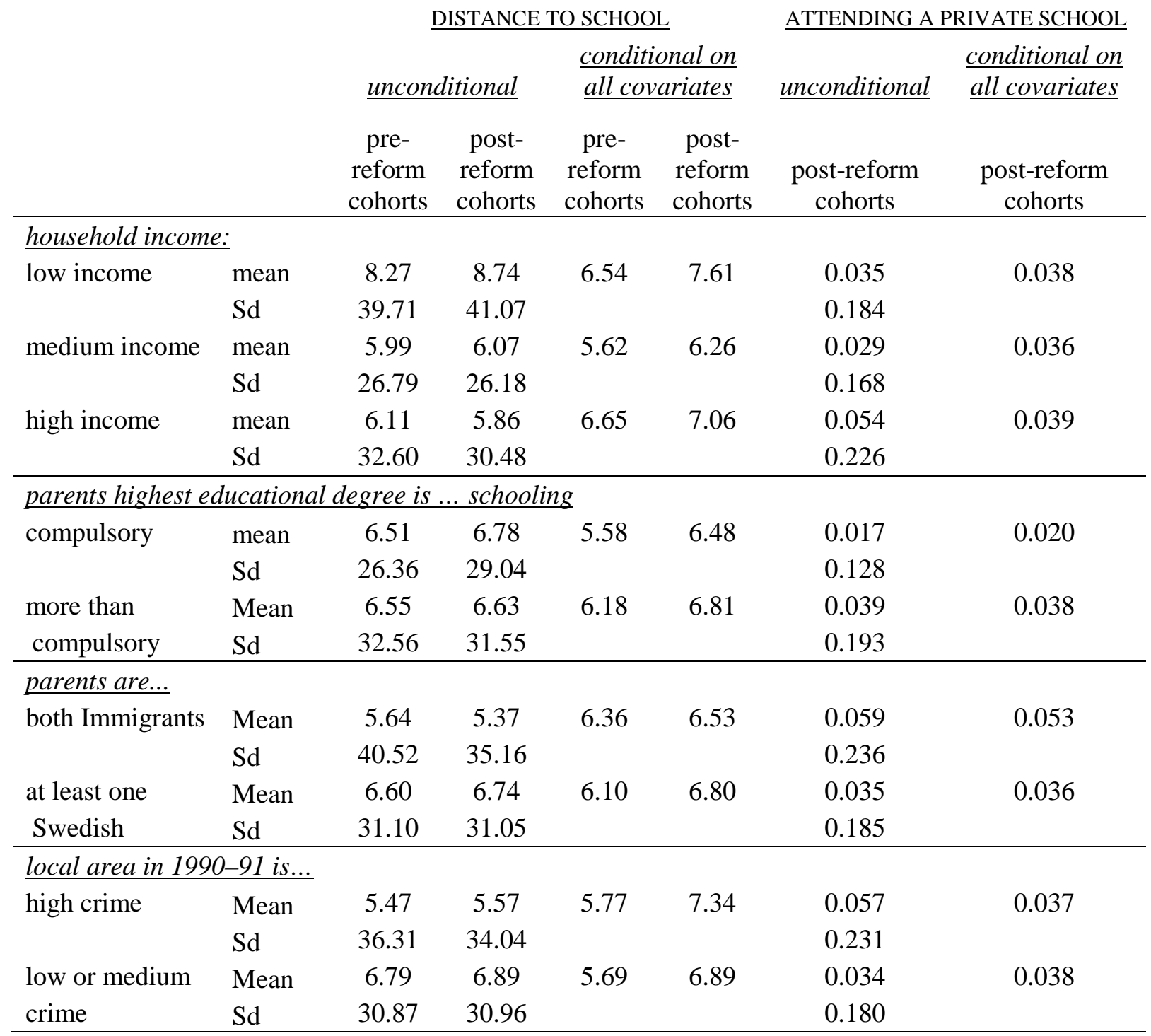

Note: Sample contains only observations with full information on all covariates $X$ given below Table 5 and for whom we observe at least one outcome.

As outlined in Section 3, there are several channels through which the reform may affect both those students who make active choices and those who do not; however, a reasonable hypothesis is that the former group will be more affected. Different choice patterns between groups of students could therefore lead us to think that the reform effect may differ across groups. Böhlmark and Lindahl (2012), who study the expansion of private school attendance, present evidence that one advantage of competition by private schools is an increase in the outcomes of students attending private schools, 
although they show that most of the benefits affect all students, that is also those attending a public school.

With these patterns in mind, we turn to the main empirical analysis of the study.

\section{Empirical strategy}

\subsection{Identification}

We follow the identification strategy used in the companion paper, where we identify the average effects of the reform (see WEF13). Identifying the effect of more school choice as introduced by the reform in 1992 mainly faces two empirical challenges.

The first is the endogenous choice of residence and location of families and schools following the choice reform. After the reform was introduced, many new private schools opened up, and it is highly plausible that neither the for-profit nor the non-forprofit private schools chose their location of business at random. Both cream-skimming arguments as well as motives to help especially disadvantaged children might have influenced the decision where to open a new school. At the same time, if more choice and competition leads to an improved quality of education, parents that are very concerned about their children's education will try to move close to such competitive areas in order to have a higher likelihood to get into one of these schools and in order to face short travel distances.

Not taking these arguments into account in the estimation might lead to either a positive or a negative bias of the effect of having more schools nearby, depending on which of the mechanisms is more important empirically. We solve this issue by using the location of families' residences and the location of schools in 1991, that is, right before the reform, to calculate our choice measure for those students who choose a school after 1992, i.e. those who are affected by the reform. Since the reform came as a surprise, in the sense that it was introduced by the new governing coalition that won the tight 1991 parliamentary election ${ }^{31}$, we can take the pre-reform locations to be

\footnotetext{
${ }^{31}$ The right wing coalition (Moderaterna; Folkpartiet; Centerpartiet; and Kristdemokraterna) obtained 46.6\% of votes, and the socialist block (The Social Democrats and the Left Party (Vänsterpartiet)) 42.2\%. New Democracy, which
} 
exogenous to the reform. To illustrate this approach, take a student born in the year 1983 who, correspondingly, chose a school to start seventh grade in 1996. As this was after the reform, the number of schools around the students' home could be related to her underlying ability, due to the endogenous location of both schools and students after the choice reform. As discussed above, in order to avoid this, we count the number of schools close to the students' residential location in the year 1991. For a student born in 1973, who started seventh grade a decade earlier and left compulsory schooling in 1989, the number of schools close-by cannot have been related to her underlying ability via free school choice as this did not yet exist ${ }^{32}$. Hence, without risking an endogeneity bias caused by reactions to the reform, we count the number of schools around the students' home in 1986, the year in which the student actually chooses a school.

An additional advantage of using measures that were predetermined is that we have a natural starting point from where dynamic competition effects started to evolve. To illuminate this, suppose a child lives close to very many schools right before the introduction of the reform. Once the new rules are in place, the schools start competing for students, new schools may open up and old, bad schools may close down. If the competitive process is strong enough, we might see more and more schools closing down and the best ones attracting more and more students. Some years later, we would then see a rather monopolistic situation, with few schools, but possibly very good outcomes, if only the best schools have sustained in the competition. Relating the number of schools to student outcomes at that later time would then show no, weak, or even a negative relationship between choice opportunities and student performance. It is thus difficult to compare contemporaneous choice measures to student outcomes when it is not clear at which stage of a dynamic process this is observed. Using predetermined measures of school choice as they are observed at the start of the competitive process, in contrast, will incorporate the dynamic changes, like opening or closing of schools, that are a direct result of the initial choice setting.

\footnotetext{
has since then disappeared from politics, obtained $6.7 \%$ of the votes, and The greens, Miljöpartiet, received 3.7\% of the votes and were hence only $0.3 \%$ from parliamentary representation.

${ }^{32}$ It may have been related to ability because of other factors, like Tiebout migration or the correlation between average educational level and density of schools in an area. This is what we refer to as the second challenge to identification and will be described later on in this section.
} 
Needless to say, the pre-reform situation will not remain a relevant measure forever eventually other changes will take place so that the pre-reform situation does no longer measure the relevant conditions forming choice and competition. However, we believe that the 12-year period that we study constitutes a reasonable time frame for this type of analysis. Moreover, we observe in the data that there is a fairly close correlation between the choice index as measured just before the reform and the one measured at the time the individuals make their decision among all subgroups (see Section 8.1.2 in the appendix).

The second challenge to identification is that having more schools nearby to choose from will be correlated with several other factors that might be related to student outcomes, such as living in a more urban neighbourhood, populated, for example, by people with different education backgrounds than people living in rural areas. Even though we observe a broad set of individual, municipality level and parish level characteristics, it is hard to argue that every possible confounding factor is captured by these variables. Therefore, in addition to controlling for these variables in our estimation, we will also control for the effect that having many schools close-by has had before the reform. We achieve this by including cohorts that are not affected by the reform in our analysis and estimating only the differential effect of choice for affected as compared to non-affected cohorts. We will thus net out any potential effect, or spurious correlation, that is related to having many schools in the neighbourhood in a situation where parents cannot choose the school they send their child to. Consequently, our analysis will capture the additional effect of being able to choose more freely among schools, as it was introduced by the Swedish school choice reform.

Our identifying assumption is thus that, if the reform had not been implemented, the relationship between our choice measure and students' outcomes would have been the same as it was in the years before the reform. Even though this assumption cannot be tested empirically, we can test its credibility by performing placebo estimates. To this end, we artificially change the date of the reform to having been enacted two years earlier and test whether we find any treatment effect of this non-existent reform. If that is the case, it shows us that the relation between our choice measure and student 
outcomes, given our covariates, has already changed before the reform, making an identification of the reform effect difficult.

\subsection{Measuring the degree of choice}

This paper will use the same measure for school choice as was used in WEF13. The following section is thus based on the corresponding section in that companion paper.

In order to be able to benefit from the introduction of school choice, it is essential for students to have access to schools close to their home. We thus measure school choice by counting the number of schools that students can potentially choose from ${ }^{33}$ within the proximity of their homes, using the median commuting distance of the home municipality in $1991^{34}$ as radius and, alternatively, a radius of $2 \mathrm{~km}^{35}$. The median value of the municipality-specific median commuting distances is about $5 \mathrm{~km}$. Using the commuting distance of the home municipality in 1991 as radius around students' homes has the advantage of flexibly taking into account the large geographical diversity of Sweden. Nevertheless, we also use a radius of $2 \mathrm{~km}$ around a student's home to examine the robustness of the results. ${ }^{36}$ It shall be noted that these two measures will have a different bite in measuring the number of available schools in different regions: while there are often no schools within $2 \mathrm{~km}$ in rural areas, and this measure therefore does not capture much of the variation in the number of accessible schools there, there will be very many schools in this radius in the big cities such as Stockholm.

In line with previous studies on the Swedish choice reform and WEF13, we focus on analysing choice opportunities for children when they start $7^{\text {th }}$ grade. This is an important stage of compulsory education as grades at the end of $9^{\text {th }}$ grade are important for admission into upper secondary school. Thus, this is a point in time when parents are likely to be interested in choosing a good school. It is also a time when making a school choice is likely to be relevant, since it marks the start of lower secondary school, which is often organised in a separate school from lower education. When calculating our

\footnotetext{
${ }^{33}$ See Section 2 for more detailed information on which schools a student could choose from.

${ }^{34}$ We are grateful to John Östh for providing information on municipality commuting distances, which are measured "as the crow flies", and do not take into account the directions of roads and the like."

${ }^{35}$ See also Gibbons, Machin and Silva (2008), Himmler (2009) and Noailly, Vujic and Aouragh (2009) for other studies using the distance between a student's home and schools.

${ }^{36}$ We also estimated the regressions using the radii 3, 4, 5, and $10 \mathrm{~km}$, see Section 6.3.
} 
choice measure, we thus use the location of residence of students when they are 13 years old and count the number of schools that offer grades 7-9 close to their home ${ }^{37}$. As explained in the last section, for students born in cohorts 1979-1990, that is those who chose a school for grades 7-9 after the 1992 reform, we use the place of residence in 1991 and the schools that were present at that time in order to calculate the prereform choice measures. Moreover, as we only have geographical information on schools starting from year 1988, we use the 1988 location of schools also for students who started grade 7 before that.

Table 4 shows the mean and standard deviation for the pre-reform choice measures which count the number of schools within the median commuting distance, and within $2 \mathrm{~km}$, separately for the different subgroups and for pre- and post-reform cohorts. The number of schools within the median commuting and $2 \mathrm{~km}$ radius is similar for students in the lowest and highest income quartile, but is smaller for those living in households with an income between the $25^{\text {th }}$ and $75^{\text {th }}$ percentile of the distribution. For the postreform cohorts, the choice measures are somewhat larger for the highest income households, also when compared to those with the lowest income. Note though, that this does not show an increase in the number of schools, since the value is measured in 1991, but rather a possible change in residence patterns already before 1991, or the consequences of the law change in 1994 that opened up for choice to public schools in other municipalities ${ }^{38}$. Dividing the sample along the educational background of the parents, we see that low educated households have slightly less schools within the municipalities' median commuting distance around their home, but very similar numbers when counting schools within $2 \mathrm{~km}$ around the home. Furthermore, children with parents that were both born outside of Sweden have more schools nearby on average than children with at least one Swedish-born parent. Lastly, when dividing the sample according to the municipal crime rate in 1991, we can see that students in pre- as well as post-reform cohorts living in high crime areas in 1991 had more schools nearby on average.

\footnotetext{
${ }^{37}$ Measures calculated for the choice options at first and fourth grade are highly correlated with the choice measure for grades 7-9.

${ }^{38}$ See Law 1985:100, Chapter 4 §8a.
} 
Table 4: Descriptive statistics on choice measures for different subgroups

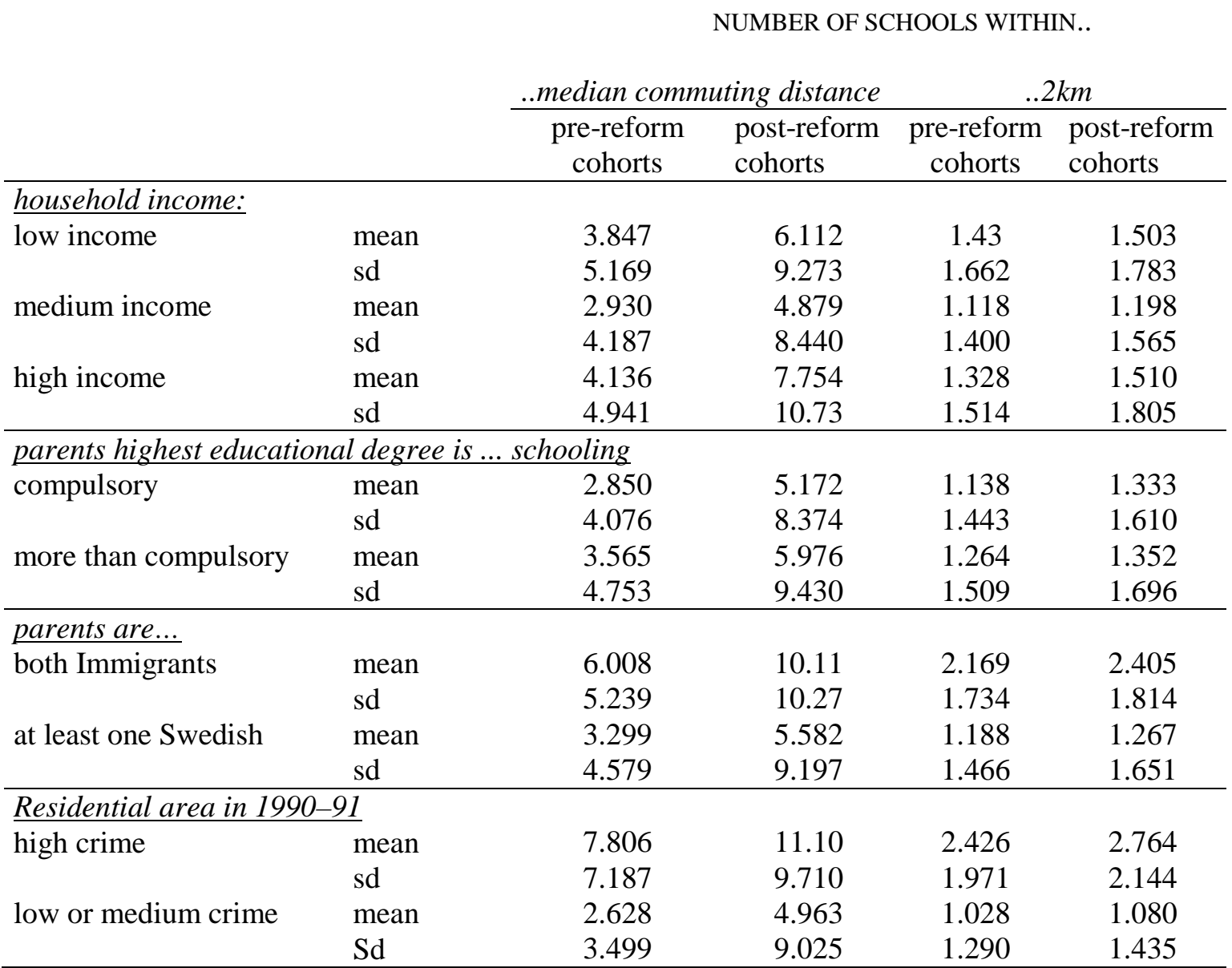

Note: Sample contains only observations with full information on all covariates $X$ given below Table 5 and for whom we observe at least one outcome.

\subsection{Estimation}

The estimation strategy used in this study follows the one applied in the companion paper (WEF13). In order to investigate whether students of different background were differently affected by the 1991 choice reform, we run regressions separately for the different subpopulations. Moreover, to estimate the differential effect of school choice and how it evolves over time for cohorts affected by the reform, as compared to the effect of having many schools nearby for unaffected cohorts, we pool all cohorts and define the following treatment window dummy variables: 


$$
\left(\begin{array}{l}
D_{i}^{1}=1 \text { if born in } 1977 \text { or } 1978 ; \text { zero otherwise } \\
D_{i}^{2}=1 \text { if born in } 1979 \text { or } 1980 \text { or } 1981 ; \text { zero otherwise } \\
D_{i}^{3}=1 \text { if born in } 1982 \text { or } 1983 \text { or } 1984 ; \text { zero otherwise } \\
D_{i}^{4}=1 \text { if born in } 1985 \text { or } 1986 \text { or } 1987 ; \text { zero otherwise } \\
D_{i}^{5}=1 \text { if born in } 1988 \text { or } 1989 \text { or } 1990 ; \text { zero otherwise }
\end{array}\right)
$$

For the pre-reform cohorts, all these treatment dummies are zero. The choice of these windows follows the degree to which students born in the different cohorts were potentially affected by the reform (see also Figure 1): Those born in 1977 started $9^{\text {th }}$ grade in 1992 and could in theory be affected by the choice-reform either through increased competitive pressure on schools, or through the option of switching school, during their last year of compulsory schooling. Although we would not expect any large effects after such a short time period, we allocate them into a separate group as they are not a clear control group. Cohorts 1979-1981 started $7^{\text {th }}$ grade in or after 1992, when the choice reform was in place, and could hence in principle choose the school they wanted to attend for the final stage in compulsory education. The next treatment window dummy, $D_{i}^{3}$, captures all cohorts that were affected by the reform, and could hence in principle make a school choice already for classes 4-6 and 7-9. Finally, for cohorts included in treatment windows $D_{i}^{4}$ and $D_{i}^{5}$, the choice reform was in place throughout their educational career, meaning that they could benefit from more choice in general, but also that the reform had already been in place some years when they entered grade 7, and thus, that competition had already had time to evolve.

\section{Figure 1: Treated cohorts}

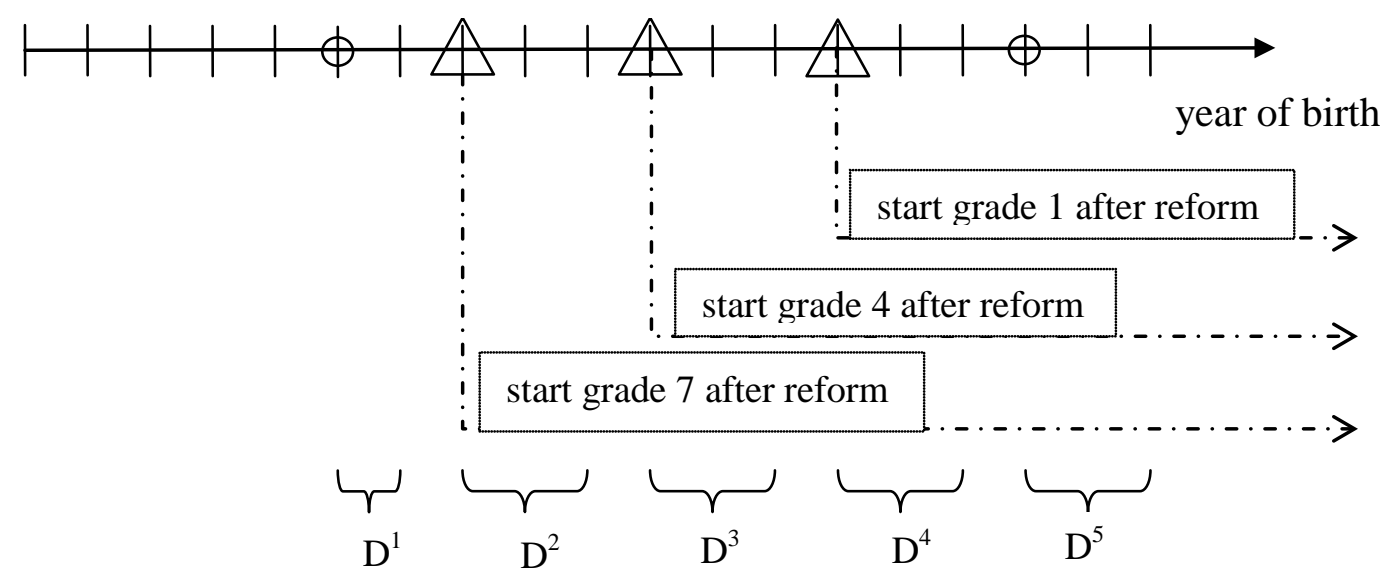


By interacting these dummies with our choice measure, the coefficient corresponding to each "treatment window · choice" interaction term will measure the differential effect of having many schools nearby after the reform, for students in the respective windows. We thus estimate the following equation, separately for each subpopulation of interest:

(2) $Y_{i}=\beta_{1} D_{i}^{1} c_{i}+\beta_{2} D_{i}^{2} c_{i}+\beta_{3} D_{i}^{3} c_{i}+\beta_{4} D_{i}^{4} c_{i}+\beta_{5} D_{i}^{5} c_{i}+\alpha \cdot c_{i}+\gamma_{\text {cohort }}+\lambda_{\text {municipality }}+\delta \cdot X_{i}+u_{i}$ where $\gamma_{\text {cohort }}$ and $\lambda_{\text {municipality }}$ are cohort and municipality fixed-effects and $X$ is a vector of covariates including a wide range of individual, municipal and parish level characteristics (a full list is given below Table 5). ${ }^{39}$ We use OLS for continuous outcomes and Probit for binary outcomes, and cluster standard errors at the schoolcohort level. ${ }^{40}$

The $\beta$-coefficients measure the differential impact of having many schools nearby for cohorts in the respective treatment windows, compared to cohorts that were unaffected by the reform. Thus, they measure the effect of school choice as introduced by the reform. The coefficient $\alpha$ captures any relation between living near many schools and the outcome variable that existed already before the reform. By including $c_{i}$, we control for the correlation between our choice-measure and the outcomes of the pre-reform cohorts. ${ }^{41}$

As we use students' and schools' locations from 1991 for cohorts 1979-1990, we will also measure all municipal and parish- level covariates in 1991. For cohorts 1972-1978, we use the information from the year in which they start $7^{\text {th }}$ grade or, if this is not available due to data limitations, from the closest available date.

\footnotetext{
${ }^{39}$ In a robustness section, in Section 6.3, we will also report the results from the estimation when we allow for the effect of the covariates $\mathrm{X}$ to vary between the treatment windows.

${ }^{40}$ We cannot link schools over time in our dataset; therefore, we cluster standard errors on the school level within each cohort.

${ }^{41}$ The estimate of $\alpha$ potentially includes effects of Tiebout school choice, or yardstick-type effects, due to it being easier to make comparisons of school performance, and hence put pressure on the own school to improve, if there are many schools around. Note, however, that we do not assume a causal interpretation of $\alpha$.
} 


\section{Results}

As mentioned in the introduction, in the companion paper to this study (WEF13), we found only small effects of more school choice as introduced by the 1992 choice reform on the average percentile rank in marks. In this section, we will test whether the small average effects mask heterogeneous effects; first with respect to the distribution of marks, and then with respect to student background.

\subsection{Effects on the distribution of marks}

We start by analysing if the school choice reform affected the distribution of marks, more specifically, whether the effects differed at the important thresholds "receiving a passing grade" and "receiving a high grade”, ${ }^{42}$ For this analysis, we will focus on marks in mathematics at the end of $9^{\text {th }}$ grade, as we think that this subject is more suited for a comparison over time and between immigrants and Swedes than English and Swedish would be.

Table 5 displays the marginal effects of an additional school nearby in 1991 on the probability of receiving a passing or high grade. The first two columns show results using the radius median commuting distance while the third and fourth display those using a $2 \mathrm{~km}$ radius around a students' home to count the number of schools. We can see that there is no effect on the probability of receiving a passing grade when using the median commuting distance. However, this result is not robust to using a radius of $2 \mathrm{~km}$.

\footnotetext{
${ }^{42}$ The other outcomes that we have analysed in the companion paper refer to binary variables and, as such, are not interesting for a distributional analysis. The only exception to this is the cognitive score in the military test, which, however, only takes 9 values, making it less suitable for a distributional analysis. Moreover, it does not have such clear thresholds of interest as do grades.
} 


\section{Table 5: Effect on distribution of marks in 9th grade math}

CHOICE MEASURE:
NUMBER OF SCHOOLS WITHIN RADIUS...

Independent Variable
.. MEDIAN COMMUTING DISTANCE
. $.2 \mathrm{KM}$

\begin{tabular}{cccc}
\hline $\begin{array}{c}\text { receiving a } \\
\text { passing } \\
\text { grade }\end{array}$ & $\begin{array}{c}\text { receiving a } \\
\text { high grade }^{+}\end{array}$ & $\begin{array}{c}\text { receiving a } \\
\text { passing } \\
\text { grade }\end{array}$ & $\begin{array}{c}\text { receiving a } \\
\text { high grade }^{\dagger}\end{array}$
\end{tabular}

\begin{tabular}{|c|c|c|c|c|}
\hline \multicolumn{5}{|c|}{ Marginal effect of choice, relative to untreated cohorts for: } \\
\hline Cohorts 1988--1990 & $\begin{array}{c}0.000342 \\
(0.000278)\end{array}$ & $\begin{array}{c}0.00312 * * * \\
(0.000350)\end{array}$ & $\begin{array}{l}-0.00118^{*} \\
(0.000695)\end{array}$ & $\begin{array}{c}0.00778 * * * \\
(0.00106)\end{array}$ \\
\hline Cohorts 1985--1987 & $\begin{array}{c}0.000117 \\
(0.000280)\end{array}$ & $\begin{array}{c}0.00248 * * * \\
(0.000347)\end{array}$ & $\begin{array}{c}-0.0023 * * * \\
(0.000692)\end{array}$ & $\begin{array}{c}0.00486 * * * \\
(0.00107)\end{array}$ \\
\hline Cohorts 1982--1984 & $\begin{array}{c}-4.84 \mathrm{e}-05 \\
(0.000280)\end{array}$ & $\begin{array}{c}0.00163 * * * \\
(0.000352)\end{array}$ & $\begin{array}{c}-0.00184 * * * \\
(0.000689)\end{array}$ & $\begin{array}{c}0.00120 \\
(0.00113)\end{array}$ \\
\hline Cohorts 1979--1981 & $\begin{array}{l}0.000503^{*} \\
(0.000300)\end{array}$ & $\begin{array}{l}0.000618^{*} \\
(0.000366)\end{array}$ & $\begin{array}{l}0.00198 * * \\
(0.000951)\end{array}$ & $\begin{array}{c}-0.00254^{* *} \\
(0.00113)\end{array}$ \\
\hline Cohorts 1977--1978 & $\begin{array}{l}-0.000268 \\
(0.000388)\end{array}$ & $\begin{array}{l}-0.000195 \\
(0.000440)\end{array}$ & $\begin{array}{l}-0.000726 \\
(0.00113)\end{array}$ & $\begin{array}{l}-0.00221^{*} \\
(0.00132)\end{array}$ \\
\hline Untreated Cohorts (1972--1976) & $\begin{array}{l}-0.000156 \\
(0.000282)\end{array}$ & $\begin{array}{c}-0.00132^{* * *} \\
(0.000338)\end{array}$ & $\begin{array}{l}0.00140 * * \\
(0.000651)\end{array}$ & $\begin{array}{c}0.000363 \\
(0.000798)\end{array}$ \\
\hline Placebo test & pass & pass & pass & fail \\
\hline Observations & $1,712,116$ & $1,712,116$ & $1,712,116$ & $1,712,116$ \\
\hline R-squared ${ }^{\ddagger}$ & 0.134 & 0.0602 & 0.134 & 0.0601 \\
\hline
\end{tabular}

Notes: Robust standard errors in parentheses. Statistical significance at 1, 5 and $10 \%$ level is denoted by ***, **, *. The definition of the placebo tests is explained in Section 5.1.

$\ddagger$ Pseudo R-squared for binary outcomes.

† For the outcome "receiving a high grade", we left out household income and its squared term to achieve convergence.

The following control variables are included in the estimation:

On the municipality level: population density, taxable income and taxable income squared

On the parish level: share of Swedish citizens among the 16-64-year-olds, mean earnings of the 20-64-year-olds, share of university graduates among the 20-64-year-olds, share of employed persons among the 20-64-year-olds, indicator variables for whether the population density of 7-15-year-olds is in the lowest or highest quartile across Sweden

On the individual level: household income and household income squared, whether the household received welfare, age of the mother at birth, indicator for living in a single parent household, number of children in the household, indicator for only child, whether child was born in Sweden, indicator variables on mothers and fathers country of birth separately (Swedish, Nordic (=Norwegian, Finnish, Danish), from other western country(=Western Europe, North America, Australia), rest of the world is base category), indicator variables on whether mother and/or father graduated from university or secondary education.

At the same time, we see an increase in the probability of achieving a high grade in math, for the later cohorts, by around 0.3 percentage points per additional school within the median commuting distance around a students’ home. A qualitatively similar pattern is found using the $2 \mathrm{~km}$ radius. However, when performing a placebo test pretending the reform had happened two years earlier, we find a negative effect of the placebo-reform 
that is statistically significant at the 90 per cent confidence level, indicating that this result should not be over-interpreted as the identification is weak.

Overall, we thus find some suggestive, though somewhat unstable, evidence that the distribution of marks spread out a little in response to the reform. We will further investigate these distributional effects in the next section, where we analyse whether students from a different social background were differently affected by the choice reform.

\subsection{Are students from a socio-economically disadvantaged or migration background harmed by the reform?}

\subsubsection{Heterogeneity with respect to parental household income}

For the reasons explained in Section 3, theoretically it might be that children from low-income families benefit more - or less - than children from high-income families from the school choice reform.

The first three columns of Table 6 display the effect on the percentile rank in $9^{\text {th }}$ grade marks, estimated separately for low-, medium- and high-income households. In all household groups, the general pattern is that effects are negative for the early cohorts, even though mostly not statistically significantly different from zero, whereas for the later cohorts the effects are positive, larger and more often significant. This is in accordance with the results for the average effects in WEF13, as well as with the hypothesis that competitive pressure and realising choice options took some time to fully come into effect. The point estimates for the youngest cohorts are slightly larger for students from families with a lower household income. One additional school in the median commuting distance raises the percentile rank in $9^{\text {th }}$ grade marks by 0.2 points for students from the lowest income households, while the corresponding figure for medium and high income households is 0.13 and 0.1 respectively. The differences between the lowest and the two other income groups are mostly statistically significant ${ }^{43}$. As the standard deviation of the percentile rank is around 28 , these effects are rather small, as are the differences between the groups in absolute terms. When 
multiplying the effect by one standard deviation in the choice measure, which is 9.2 for the affected cohorts in the lowest income group, this implies an increase in the percentile rank by roughly 1.8 points. This is similar to the effect of an increase in the municipal private school share by 10 percentage points, found by Böhlmark and Lindahl (2012). However, the average number of schools within median commuting distance around the home for students affected by the reform and in the lowest income group is 6.1, an increase by 9 schools would thus be very large.

Table 6: Effect of choice on percentile rank in marks and cognitive skills for different household income subgroups; choice radius "median commuting distance"

\begin{tabular}{|c|c|c|c|c|c|c|}
\hline \multirow{2}{*}{$\begin{array}{l}\text { INDEPENDENT } \\
\text { VARIABLE } \\
\text { Household income: }\end{array}$} & \multicolumn{3}{|c|}{ PERCENTILE RANK MARKS } & \multicolumn{3}{|c|}{ COGNITIVE SCORE } \\
\hline & $\begin{array}{c}\text { low } \\
\text { income }\end{array}$ & $\begin{array}{l}\text { medium } \\
\text { income }\end{array}$ & $\begin{array}{c}\text { high } \\
\text { income }\end{array}$ & $\begin{array}{c}\text { low } \\
\text { income }\end{array}$ & $\begin{array}{l}\text { medium } \\
\text { income }\end{array}$ & high income \\
\hline \multicolumn{7}{|c|}{ Marginal effect of choice, relative to untreated cohorts for: } \\
\hline Cohorts 1988-1990 & $\begin{array}{c}0.197 * * * \\
(0.0294)\end{array}$ & $\begin{array}{c}0.127 * * * \\
(0.0236)\end{array}$ & $\begin{array}{c}0.102 * * * \\
(0.0265)\end{array}$ & & & \\
\hline Cohorts 1985-1987 & $\begin{array}{c}0.154^{* * *} \\
(0.0297)\end{array}$ & $\begin{array}{c}0.0553 * * \\
(0.0245)\end{array}$ & $\begin{array}{c}0.0568 * * \\
(0.0266)\end{array}$ & $\begin{array}{l}0.00480 * \\
(0.00275)\end{array}$ & $\begin{array}{c}0.00539 * * * \\
(0.00206)\end{array}$ & $\begin{array}{l}-0.00420 * \\
(0.00249)\end{array}$ \\
\hline Cohorts 1982-1984 & $\begin{array}{c}0.0765^{* *} \\
(0.0298)\end{array}$ & $\begin{array}{c}0.000588 \\
(0.0243)\end{array}$ & $\begin{array}{l}-0.0205 \\
(0.0269)\end{array}$ & $\begin{array}{c}0.00271 \\
(0.00286)\end{array}$ & $\begin{array}{c}0.00419 * * \\
(0.00209)\end{array}$ & $\begin{array}{c}-0.00544^{* *} \\
(0.00247)\end{array}$ \\
\hline Cohorts 1979-1981 & $\begin{array}{c}0.0908 * * * \\
(0.0322)\end{array}$ & $\begin{array}{c}0.0262 \\
(0.0248)\end{array}$ & $\begin{array}{l}-0.0202 \\
(0.0288)\end{array}$ & $\begin{array}{l}0.00484 * \\
(0.00294)\end{array}$ & $\begin{array}{c}0.00172 \\
(0.00218)\end{array}$ & $\begin{array}{c}-0.00708 * * * \\
(0.00261)\end{array}$ \\
\hline Cohorts 1977-1978 & $\begin{array}{l}-0.0115 \\
(0.0363) \\
\end{array}$ & $\begin{array}{l}0.00376 \\
(0.0316)\end{array}$ & $\begin{array}{l}-0.0337 \\
(0.0358)\end{array}$ & $\begin{array}{l}0.00636 * \\
(0.00354)\end{array}$ & $\begin{array}{c}0.00100 \\
(0.00302) \\
\end{array}$ & $\begin{array}{r}0.000935 \\
(0.00326)\end{array}$ \\
\hline $\begin{array}{l}\text { Untreated cohorts } \\
(1972-1976)\end{array}$ & $\begin{array}{c}-0.106^{* * *} \\
(0.0286)\end{array}$ & $\begin{array}{l}-0.0301 \\
(0.0231)\end{array}$ & $\begin{array}{l}-0.00249 \\
(0.0259)\end{array}$ & $\begin{array}{l}-0.00318 \\
(0.00275)\end{array}$ & $\begin{array}{l}-0.00184 \\
(0.00207)\end{array}$ & $\begin{array}{l}0.00537 * * \\
(0.00250)\end{array}$ \\
\hline Placebo Test & pass & pass & pass & pass & pass & pass \\
\hline Observations & 396,923 & 873,180 & 445,318 & 135,210 & 312,206 & 162,766 \\
\hline R-squared ${ }^{\ddagger}$ & 0.138 & 0.131 & 0.182 & 0.113 & 0.113 & 0.154 \\
\hline
\end{tabular}

The effect of more school choice on cognitive skills (see Columns 4-6 in Table 6) is similar for the low and medium income households, but with an increase of around 0.005 points for each additional school, and the cognitive score varying between 0 and 9, it is very small. Children from high income households display an equally small, but

\footnotetext{
${ }^{43}$ We test statistical significance between point estimates from separate regressions by running a fully interacted estimation of the model; results are available from the others upon request.
} 
negative effect. Looking at the distribution of $9^{\text {th }}$ grade math marks, we find no effect for any income group on the probability of receiving a passing grade ${ }^{44}$, and effects of an around 0.3 percentage points increase in the likelihood of achieving a high grade per additional school in the commuting distance for all three groups (see Table 7). However, the identification of the result is weak for the high income group as the placebo test fails. Concerning the probability of having committed a crime until age 22, we almost only find significant effects in the lowest income group, where an increase in choice leads to a small reduction of about 0.1 percentage points in the probability (see Table 8$)^{45}$.

Table 7: Effect of choice on probability of receiving a high or passing grade in math for different household income subgroups; choice radius "median commuting distance"

\begin{tabular}{|c|c|c|c|c|c|c|}
\hline \multirow{3}{*}{$\begin{array}{l}\text { INDEPENDENT } \\
\text { VARIABLE } \\
\text { Household income: }\end{array}$} & \multirow{2}{*}{\multicolumn{3}{|c|}{$\underline{\text { RECEIVING A HIGH GRADE IN MATH }}$}} & \multirow{2}{*}{\multicolumn{3}{|c|}{$\frac{\text { RECEIVING A PASSING GRADE IN }}{\underline{\text { MATH }}}$}} \\
\hline & & & & & & \\
\hline & low income & $\begin{array}{l}\text { medium } \\
\text { income }\end{array}$ & $\begin{array}{c}\text { high } \\
\text { income }\end{array}$ & $\begin{array}{c}\text { low } \\
\text { income }\end{array}$ & $\begin{array}{l}\text { medium } \\
\text { income }\end{array}$ & $\begin{array}{c}\text { high } \\
\text { income }\end{array}$ \\
\hline \multicolumn{7}{|c|}{ Marginal effect of choice, relative to untreated cohorts for: } \\
\hline Cohorts 1988-1990 & $\begin{array}{l}0.0037 * * * \\
(0.00049)\end{array}$ & $\begin{array}{l}0.0031^{* * *} \\
(0.00044)\end{array}$ & $\begin{array}{c}0.0021 * * * \\
(0.00057)\end{array}$ & $\begin{array}{c}0.0007 \\
(0.00048)\end{array}$ & $\begin{array}{c}0.0006^{*} \\
(0.00037)\end{array}$ & $\begin{array}{c}0.0002 \\
(0.00038)\end{array}$ \\
\hline Cohorts 1985-1987 & $\begin{array}{l}0.0032 * * * \\
(0.00049)\end{array}$ & $\begin{array}{c}0.0024 * * * \\
(0.00044)\end{array}$ & $\begin{array}{l}0.0014^{* *} \\
(0.00056)\end{array}$ & $\begin{array}{c}0.0004 \\
(0.00049)\end{array}$ & $\begin{array}{c}0.0003 \\
(0.00037)\end{array}$ & $\begin{array}{c}0.0001 \\
(0.00038)\end{array}$ \\
\hline Cohorts 1982-1984 & $\begin{array}{c}0.0024 * * * \\
(0.00050)\end{array}$ & $\begin{array}{c}0.0016^{* * *} \\
(0.00045)\end{array}$ & $\begin{array}{c}0.0004 \\
(0.00057)\end{array}$ & $\begin{array}{c}-0.0000 \\
(0.00049)\end{array}$ & $\begin{array}{c}0.0001 \\
(0.00037)\end{array}$ & $\begin{array}{c}0.0002 \\
(0.00039)\end{array}$ \\
\hline Cohorts 1979-1981 & $\begin{array}{l}0.0013^{* *} \\
(0.00054)\end{array}$ & $\begin{array}{c}0.0009 * \\
(0.00047)\end{array}$ & $\begin{array}{c}-0.0000 \\
(0.00059)\end{array}$ & $\begin{array}{c}0.0007 \\
(0.00054)\end{array}$ & $\begin{array}{l}0.0010 * * \\
(0.00040)\end{array}$ & $\begin{array}{c}0.0001 \\
(0.00041)\end{array}$ \\
\hline Cohorts 1977-1978 & $\begin{array}{c}-0.0000 \\
(0.00064) \\
\end{array}$ & $\begin{array}{c}0.0004 \\
(0.00058) \\
\end{array}$ & $\begin{array}{c}-0.0006 \\
(0.00073) \\
\end{array}$ & $\begin{array}{c}-0.0005 \\
(0.00066) \\
\end{array}$ & $\begin{array}{c}0.0001 \\
(0.00052) \\
\end{array}$ & $\begin{array}{c}-0.0003 \\
(0.00049) \\
\end{array}$ \\
\hline $\begin{array}{l}\text { Untreated cohorts } \\
(1972-1976)\end{array}$ & $\begin{array}{c}-0.0021 * * * \\
(0.00049)\end{array}$ & $\begin{array}{l}-0.0016 * \star \star \\
(0.00043)\end{array}$ & $\begin{array}{c}-0.0006 \\
(0.00056)\end{array}$ & $\begin{array}{c}-0.0004 \\
(0.00050)\end{array}$ & $\begin{array}{c}-0.0004 \\
(0.00037)\end{array}$ & $\begin{array}{c}-0.0002 \\
(0.00039)\end{array}$ \\
\hline Placebo Test & pass & pass & fail & pass & pass & pass \\
\hline Observations & 395,334 & 871,845 & 444,937 & 395,334 & 871,845 & 444,937 \\
\hline R-squared ${ }^{\ddagger}$ & 0.0425 & 0.0411 & 0.0661 & 0.105 & 0.124 & 0.163 \\
\hline
\end{tabular}

\footnotetext{
${ }^{44}$ There are a couple of very small but statistically significant effects for the medium income group, but qualitatively the result for this outcome suggests no effect.

${ }^{45}$ Note that the average probability of ever having been committed for a crime at age 22, as reported in Table 1 , was around 20 per cent for the low-income group.
} 
Table 8: Effect of choice on probability of committing a crime until age 22 for different household income subgroups; choice radius "median commuting distance"

\begin{tabular}{|c|c|c|c|}
\hline \multirow{2}{*}{$\begin{array}{l}\text { INDEPENDENT VARIABLE } \\
\text { Household income: }\end{array}$} & \multicolumn{3}{|c|}{ CRIME UNTIL AGE 22} \\
\hline & low income & medium income & high income \\
\hline \multicolumn{4}{|c|}{ Marginal effect of choice, relative to untreated cohorts for: } \\
\hline \multirow[t]{2}{*}{ Cohorts 1985-1987 } & $-0.00143^{* * *}$ & -0.000447 & -0.000331 \\
\hline & $(0.000381)$ & $(0.000284)$ & $(0.000287)$ \\
\hline \multirow[t]{2}{*}{ Cohorts 1982-1984 } & $-0.00169 * * *$ & $-0.000606^{* *}$ & -0.000283 \\
\hline & $(0.000390)$ & $(0.000288)$ & $(0.000291)$ \\
\hline \multirow[t]{2}{*}{ Cohorts 1979-1981 } & $-0.00165^{* * *}$ & -0.000364 & -0.000211 \\
\hline & $(0.000422)$ & $(0.000303)$ & $(0.000310)$ \\
\hline \multirow[t]{2}{*}{ Cohorts 1977-1978 } & -0.000609 & 0.000157 & 8.49e-05 \\
\hline & $(0.000545)$ & $(0.000379)$ & $(0.000387)$ \\
\hline Untreated cohorts & $0.00156 * * *$ & $0.000679 * *$ & 0.000453 \\
\hline$(1972-1976)$ & $(0.000380)$ & $(0.000290)$ & $(0.000296)$ \\
\hline Placebo Test & pass & pass & pass \\
\hline Observations & 326,904 & 717,262 & 364,926 \\
\hline R-squared ${ }^{\ddagger}$ & 0.0315 & 0.0304 & 0.0269 \\
\hline
\end{tabular}

Overall, the effects are small as well as the differences between the subgroups. We thus find no evidence that would support the claim that disadvantaged children had been harmed by the reform. On the contrary, we find slightly higher point estimates for lowincome households, suggesting that low income households benefited more from the potential choice options, although this difference is very small.

\subsubsection{Heterogeneity with respect to educational background of parents}

Next, we explore whether children whose parents have a lower education were differently affected by the choice reform compared to children with higher educated parents. Table 9 and Table 10 show that there is no indication that children with low educated parents, defined as both parents having no more than compulsory education, have benefited less from school choice in terms of grades at the end of $9^{\text {th }}$ grade. On the contrary, most of the point estimates for children from households with a lower education are either similar, or even slightly larger, compared to those of higher education background. Concerning the cognitive score in the military draft, one school 
more increases the score by 0.015 for the youngest cohorts of students with low educated parents (see Column 4 in Table 9). The corresponding coefficient for children from higher educated parents is statistically insignificant and significantly smaller. This result is robust to using the alternative radius of $2 \mathrm{~km}$, where the point estimates differ even more ${ }^{46}$.

Table 9: Effect of choice on percentile rank in marks and cognitive skills for different parental education levels; choice radius "median commuting distance"

\begin{tabular}{|c|c|c|c|c|}
\hline \multirow{2}{*}{$\begin{array}{l}\text { INDEPENDENT VARIABLE } \\
\text { Parental education is... }\end{array}$} & \multicolumn{2}{|c|}{ PERCENTILE RANK MARKS } & \multicolumn{2}{|c|}{ COGNITIVE SCORE } \\
\hline & $\begin{array}{l}\text { more than } \\
\text { compulsory }\end{array}$ & compulsory & $\begin{array}{l}\text { more than } \\
\text { compulsory }\end{array}$ & compulsory \\
\hline \multicolumn{5}{|c|}{ Marginal effect of choice, relative to untreated cohorts for: } \\
\hline Cohorts 1988-1990 & $\begin{array}{c}0.133^{* * *} \\
(0.0191)\end{array}$ & $\begin{array}{c}0.148^{* * *} \\
(0.0436)\end{array}$ & & \\
\hline Cohorts 1985-1987 & $\begin{array}{c}0.0806^{* * *} \\
(0.0194)\end{array}$ & $\begin{array}{l}0.0911^{* *} \\
(0.0430)\end{array}$ & $\begin{array}{c}0.00110 \\
(0.00159)\end{array}$ & $\begin{array}{c}0.0144 * * * \\
(0.00448)\end{array}$ \\
\hline Cohorts 1982-1984 & $\begin{array}{c}0.0118 \\
(0.0189)\end{array}$ & $\begin{array}{c}0.0358 \\
(0.0429)\end{array}$ & $\begin{array}{l}-0.000499 \\
(0.00159)\end{array}$ & $\begin{array}{l}0.0141 * * * \\
(0.00438)\end{array}$ \\
\hline Cohorts 1979-1981 & $\begin{array}{c}0.0167 \\
(0.0204)\end{array}$ & $\begin{array}{l}0.129 * * * \\
(0.0441)\end{array}$ & $\begin{array}{l}-0.00157 \\
(0.00167)\end{array}$ & $\begin{array}{l}0.0154 * * * \\
(0.00461)\end{array}$ \\
\hline Cohorts 1977-1978 & $\begin{array}{l}-0.0165 \\
(0.0236)\end{array}$ & $\begin{array}{c}0.0382 \\
(0.0559)\end{array}$ & $\begin{array}{c}0.00239 \\
(0.00218)\end{array}$ & $\begin{array}{c}0.00557 \\
(0.00594)\end{array}$ \\
\hline $\begin{array}{l}\text { Untreated cohorts } \\
(1972-1976)\end{array}$ & $\begin{array}{l}-0.0351 * \\
(0.0181)\end{array}$ & $\begin{array}{l}-0.0686 * \\
(0.0406)\end{array}$ & $\begin{array}{c}0.00130 \\
(0.00160)\end{array}$ & $\begin{array}{c}-0.0131^{* * *} \\
(0.00431)\end{array}$ \\
\hline Placebo Test & pass & pass & pass & pass \\
\hline Observations & $1,550,081$ & 165,340 & 544,573 & 65,609 \\
\hline R-squared ${ }^{\ddagger}$ & 0.175 & 0.060 & 0.129 & 0.050 \\
\hline
\end{tabular}

Notes: Robust standard errors in parentheses. Statistical significance at 1, 5 and $10 \%$ level is denoted by ***, **, *. For a complete list of included covariates see Table 5. The definition of the placebo tests is explained in Section 5.1. $\ddagger$ Pseudo R-squared for binary outcomes.

${ }^{46}$ See Table 36 and Table 37. 
Table 10: Effect of choice on probability of receiving a high or passing grade in math for different parental education levels; choice radius "median commuting distance"

\begin{tabular}{|c|c|c|c|c|}
\hline INDEPENDENT VARIABLE & $\underline{\text { HIGH G }}$ & MATH & PASSING & E MATH \\
\hline Parental education is... & $\begin{array}{l}\text { more than } \\
\text { compulsory }\end{array}$ & compulsory & $\begin{array}{l}\text { more than } \\
\text { compulsory }\end{array}$ & compulsory \\
\hline Marginal effect of choice & ve to untreate & orts for: & & \\
\hline Cohorts 1988-1990 & $0.00311 * * *$ & $0.00242 * * *$ & 0.000435 & 0.000221 \\
\hline & $(0.000365)$ & $(0.000706)$ & $(0.000284)$ & $(0.000771)$ \\
\hline Cohorts 1985-1987 & $0.00244 * * *$ & $0.00232 * * *$ & 0.000260 & -0.000871 \\
\hline & $(0.000361)$ & $(0.000670)$ & $(0.000286)$ & $(0.000747)$ \\
\hline Cohorts 1982-1984 & $0.00155^{* * *}$ & $0.00123 *$ & 0.000107 & -0.00124 \\
\hline & $(0.000366)$ & $(0.000683)$ & $(0.000286)$ & $(0.000754)$ \\
\hline Cohorts 1979-1981 & 0.000499 & $0.00138 *$ & 0.000448 & $0.00141 *$ \\
\hline & $(0.000379)$ & $(0.000749)$ & $(0.000306)$ & $(0.000832)$ \\
\hline Cohorts 1977-1978 & -0.000319 & 0.000983 & -0.000307 & 0.000361 \\
\hline & $(0.000458)$ & $(0.000934)$ & $(0.000390)$ & $(0.00110)$ \\
\hline Untreated cohorts & $-0.00132 * * *$ & -0.00101 & -0.000267 & 0.000439 \\
\hline$(1972-1976)$ & $(0.000351)$ & $(0.000657)$ & $(0.000289)$ & $(0.000759)$ \\
\hline Placebo Test & pass & pass & pass & pass \\
\hline Observations & $1,547,652$ & 164,464 & $1,547,652$ & 164,464 \\
\hline R-squared ${ }^{\ddagger}$ & 0.0575 & 0.0206 & 0.133 & 0.0609 \\
\hline
\end{tabular}

\subsubsection{Heterogeneity with respect to migrant background}

Now we turn to analysing whether children whose parents were both born outside of Sweden were differently affected by the choice reform. Again, we find that the point estimates for the effect of school choice on marks and the cognitive score are very similar in size for children with at least one Swedish parent and those whose parents were both born outside of Sweden (see Table 11). The same holds when we study the effect on the probability to receive a high or a pass final math grade (see Table 12). However, when we instead use the choice measure counting the number of schools within $2 \mathrm{~km}$ around a student's home, the results are more mixed ${ }^{47}$ and indicate larger effects for children of Swedish parents on $9^{\text {th }}$ grade marks but smaller effects on cognitive scores in the youngest cohort group. Most of these differences are however

\footnotetext{
${ }^{47}$ See Table 39.
} 
not, or only at the $90 \%$ confidence level, statistically significantly different. Moreover, we find that, for children whose parents were both born outside of Sweden in the youngest cohorts, having one more school within $2 \mathrm{~km}$ increases the likelihood of having a university degree by 1.15 percentage points, while this number is smaller and only weakly identified, as indicated by significant Placebo tests, for children with Swedish parents ${ }^{48}$. Overall, the results for the subpopulations of children with or without at least one native Swedish parent are less robust than the results for the other subpopulations. One conclusion that can be drawn is, however, that there is no clear pattern indicating that children from immigrants have been harmed by more choice at the outset of the reform compared to children with at least one Swedish-born parent.

Table 11: Effect of choice on percentile rank in marks and cognitive skills for different parental migration backgrounds; choice radius "median commuting distance"

\begin{tabular}{|c|c|c|c|c|}
\hline \multirow{2}{*}{$\begin{array}{l}\text { INDEPENDENT VARIABLE } \\
\text { Parental migration background }\end{array}$} & \multicolumn{2}{|c|}{ PERCENTILE RANK MARKS } & \multicolumn{2}{|c|}{ COGNITIVE SCORE } \\
\hline & $\begin{array}{l}\text { at least one } \\
\text { Swedish }\end{array}$ & $\begin{array}{c}\text { both } \\
\text { immigrants }\end{array}$ & $\begin{array}{l}\text { at least one } \\
\text { Swedish }\end{array}$ & $\begin{array}{c}\text { both } \\
\text { immigrants }\end{array}$ \\
\hline \multicolumn{5}{|c|}{ Marginal effect of choice, relative to untreated cohorts for: } \\
\hline Cohorts 1988-1990 & $\begin{array}{c}0.142^{* * *} \\
(0.0186)\end{array}$ & $\begin{array}{c}0.161 * * * \\
(0.0547)\end{array}$ & & \\
\hline Cohorts 1985-1987 & $\begin{array}{c}0.0892 * * * \\
(0.0190)\end{array}$ & $\begin{array}{c}0.0810 \\
(0.0537)\end{array}$ & $\begin{array}{c}0.00118 \\
(0.00156)\end{array}$ & $\begin{array}{l}0.00972 * \\
(0.00542)\end{array}$ \\
\hline Cohorts 1982-1984 & $\begin{array}{c}0.0172 \\
(0.0186)\end{array}$ & $\begin{array}{l}-0.00374 \\
(0.0542)\end{array}$ & $\begin{array}{l}-0.000621 \\
(0.00157)\end{array}$ & $\begin{array}{c}0.00739 \\
(0.00539)\end{array}$ \\
\hline Cohorts 1979-1981 & $\begin{array}{c}0.0180 \\
(0.0200)\end{array}$ & $\begin{array}{c}0.0767 \\
(0.0561)\end{array}$ & $\begin{array}{l}-0.00212 \\
(0.00167)\end{array}$ & $\begin{array}{c}0.00790 \\
(0.00562)\end{array}$ \\
\hline Cohorts 1977-1978 & $\begin{array}{l}-0.0185 \\
(0.0237)\end{array}$ & $\begin{array}{l}0.00110 \\
(0.0664)\end{array}$ & $\begin{array}{c}0.00270 \\
(0.00216)\end{array}$ & $\begin{array}{c}0.00242 \\
(0.00712)\end{array}$ \\
\hline $\begin{array}{l}\text { Untreated cohorts } \\
(1972-1976)\end{array}$ & $\begin{array}{c}-0.0361^{* *} \\
(0.0177)\end{array}$ & $\begin{array}{l}-0.0871 \\
(0.0534)\end{array}$ & $\begin{array}{c}0.00160 \\
(0.00158)\end{array}$ & $\begin{array}{l}-0.00990^{*} \\
(0.00545)\end{array}$ \\
\hline Placebo Test & pass & pass & pass & pass \\
\hline Observations & $1,599,471$ & 115,950 & 575,487 & 34,695 \\
\hline R-squared ${ }^{\ddagger}$ & 0.191 & 0.139 & 0.139 & 0.150 \\
\hline
\end{tabular}

${ }^{48}$ See Table 41. 
Table 12: Effect of choice on probability of receiving a high or passing grade in math for different parental migration backgrounds; choice radius "median commuting distance"

\begin{tabular}{|c|c|c|c|c|}
\hline \multirow{2}{*}{$\begin{array}{l}\text { INDEPENDENT VARIABLE } \\
\text { Parental education is... }\end{array}$} & \multicolumn{2}{|c|}{ HIGH GRADE MATH } & \multicolumn{2}{|c|}{ PASSING GRADE MATH } \\
\hline & $\begin{array}{l}\text { at least one } \\
\text { Swedish }\end{array}$ & $\begin{array}{c}\text { both } \\
\text { immigrants }\end{array}$ & $\begin{array}{l}\text { at least one } \\
\text { Swedish }\end{array}$ & $\begin{array}{c}\text { both } \\
\text { immigrants }\end{array}$ \\
\hline \multicolumn{5}{|c|}{ Marginal effect of choice, relative to untreated cohorts for: } \\
\hline Cohorts 1988-1990 & $\begin{array}{c}0.00330 * * * \\
(0.000362)\end{array}$ & $\begin{array}{c}0.00282 * * * \\
(0.000859)\end{array}$ & $\begin{array}{l}0.000471^{*} \\
(0.000281)\end{array}$ & $\begin{array}{c}0.000697 \\
(0.000978)\end{array}$ \\
\hline Cohorts 1985-1987 & $\begin{array}{c}0.00261^{* * *} \\
(0.000359)\end{array}$ & $\begin{array}{c}0.00249 * * * \\
(0.000849)\end{array}$ & $\begin{array}{c}0.000270 \\
(0.000283)\end{array}$ & $\begin{array}{l}-1.15 e-05 \\
(0.000969)\end{array}$ \\
\hline Cohorts 1982-1984 & $\begin{array}{c}0.00171 * * * \\
(0.000363)\end{array}$ & $\begin{array}{c}0.00161 * \\
(0.000868)\end{array}$ & $\begin{array}{c}8.60 \mathrm{e}-05 \\
(0.000283)\end{array}$ & $\begin{array}{l}-0.000396 \\
(0.000977)\end{array}$ \\
\hline Cohorts 1979-1981 & $\begin{array}{c}0.000554 \\
(0.000379)\end{array}$ & $\begin{array}{c}0.000581 \\
(0.000908)\end{array}$ & $\begin{array}{c}0.000347 \\
(0.000309)\end{array}$ & $\begin{array}{c}0.00141 \\
(0.00101)\end{array}$ \\
\hline Cohorts 1977-1978 & $\begin{array}{l}-0.000141 \\
(0.000456)\end{array}$ & $\begin{array}{l}-0.00134 \\
(0.00104)\end{array}$ & $\begin{array}{l}-0.000330 \\
(0.000399) \\
\end{array}$ & $\begin{array}{l}-0.000129 \\
(0.00124) \\
\end{array}$ \\
\hline $\begin{array}{l}\text { Untreated cohorts } \\
(1972-1976)\end{array}$ & $\begin{array}{c}-0.00141^{* * *} \\
(0.000348)\end{array}$ & $\begin{array}{l}-0.000966 \\
(0.000846)\end{array}$ & $\begin{array}{l}-0.000230 \\
(0.000287)\end{array}$ & $\begin{array}{l}-0.000292 \\
(0.000988)\end{array}$ \\
\hline Placebo Test & pass & pass & pass & pass \\
\hline Observations & $1,596,671$ & 115,445 & $1,596,671$ & 115,414 \\
\hline R-squared ${ }^{\ddagger}$ & 0.0606 & 0.0527 & 0.135 & 0.121 \\
\hline
\end{tabular}

\subsubsection{Heterogeneity with respect to high crime vs. low crime area}

Lastly, we investigate whether children living in high crime areas benefit more or less from school choice than children living in low or medium crime areas. In this section, we hence explore if the effects differ with respect to the area characteristics of the student instead of with respect to the parental background.

When we stratify the sample according to living in a high or low crime area in 1991, we find that students in high crime areas have often benefitted more from school choice, in terms of short-run outcomes, than those in low or medium level crime areas (see Section 8.1.4 in the appendix). An important fact to point out, however, is that the high crime municipalities are mostly urban municipalities, and we found in our companion paper (see WEF13) that the effects on marks are mostly driven by individuals living in urban areas. In order to not confuse heterogeneous effects between areas with different crime rates with heterogeneity arising from living in an urban or rural municipality, we 
run four separate regressions for all combinations of living in high crime vs. medium level crime and urban vs. non-urban municipalities.

Table 13 shows the results for the percentile rank in $9^{\text {th }}$ grade marks and the cognitive score, and Table 14 shows results on the distribution of $9^{\text {th }}$ grade math marks.

Table 13: Effect of choice on the percentile rank in marks and cognitive skills for local areas with high or low/medium youth crime levels; choice radius "median commuting distance"

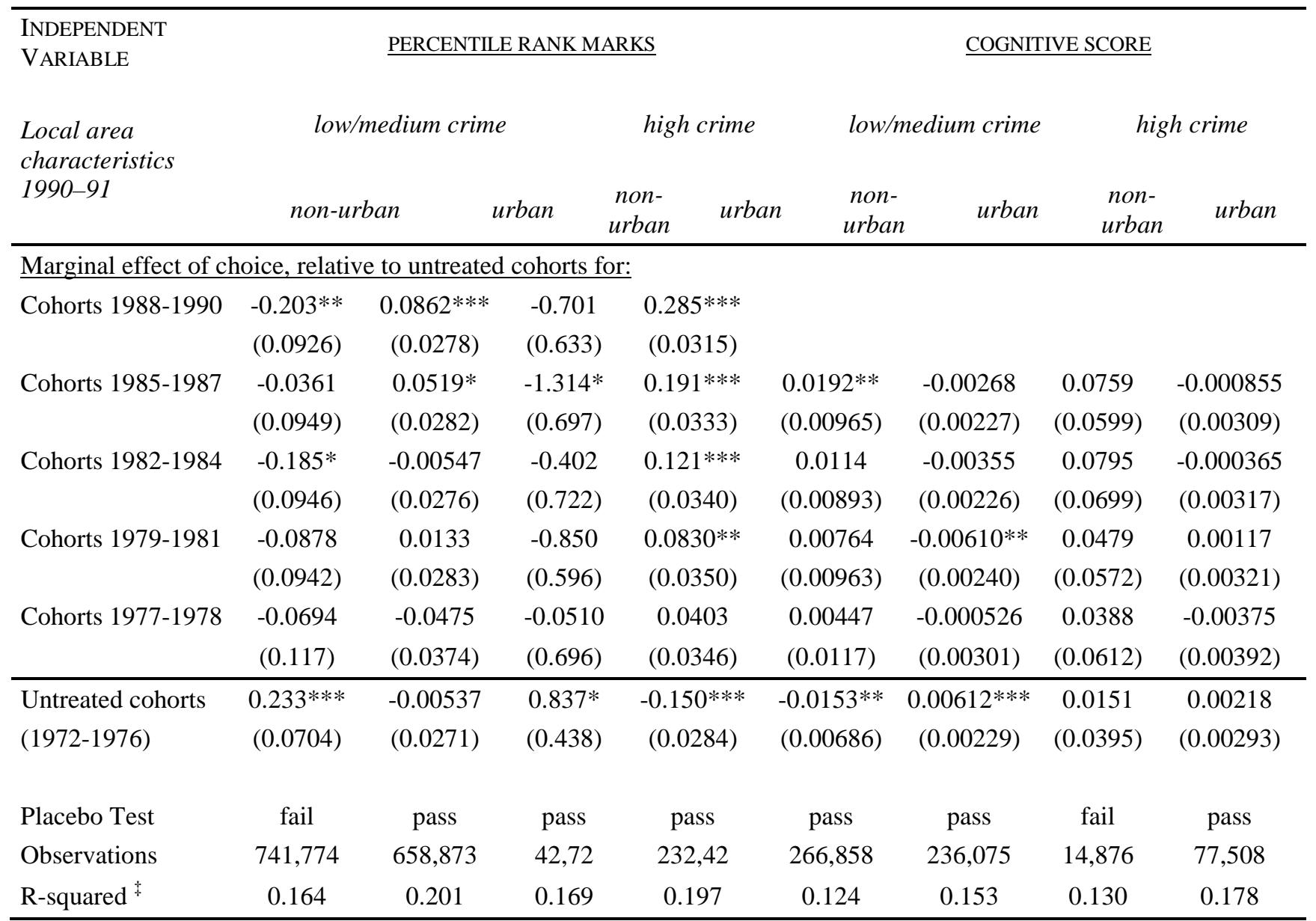

Notes: Robust standard errors in parentheses. Statistical significance at 1,5 and $10 \%$ level is denoted by $* * *, * *$, For a complete list of included covariates see Table 5. The definition of the placebo tests is explained in Section 5.1.

$\ddagger$ Pseudo R-squared for binary outcomes. 
Table 14 : Effect of choice on probability of receiving a high or passing grade in math for local areas with high or low/medium youth crime levels; choice radius "median commuting distance"

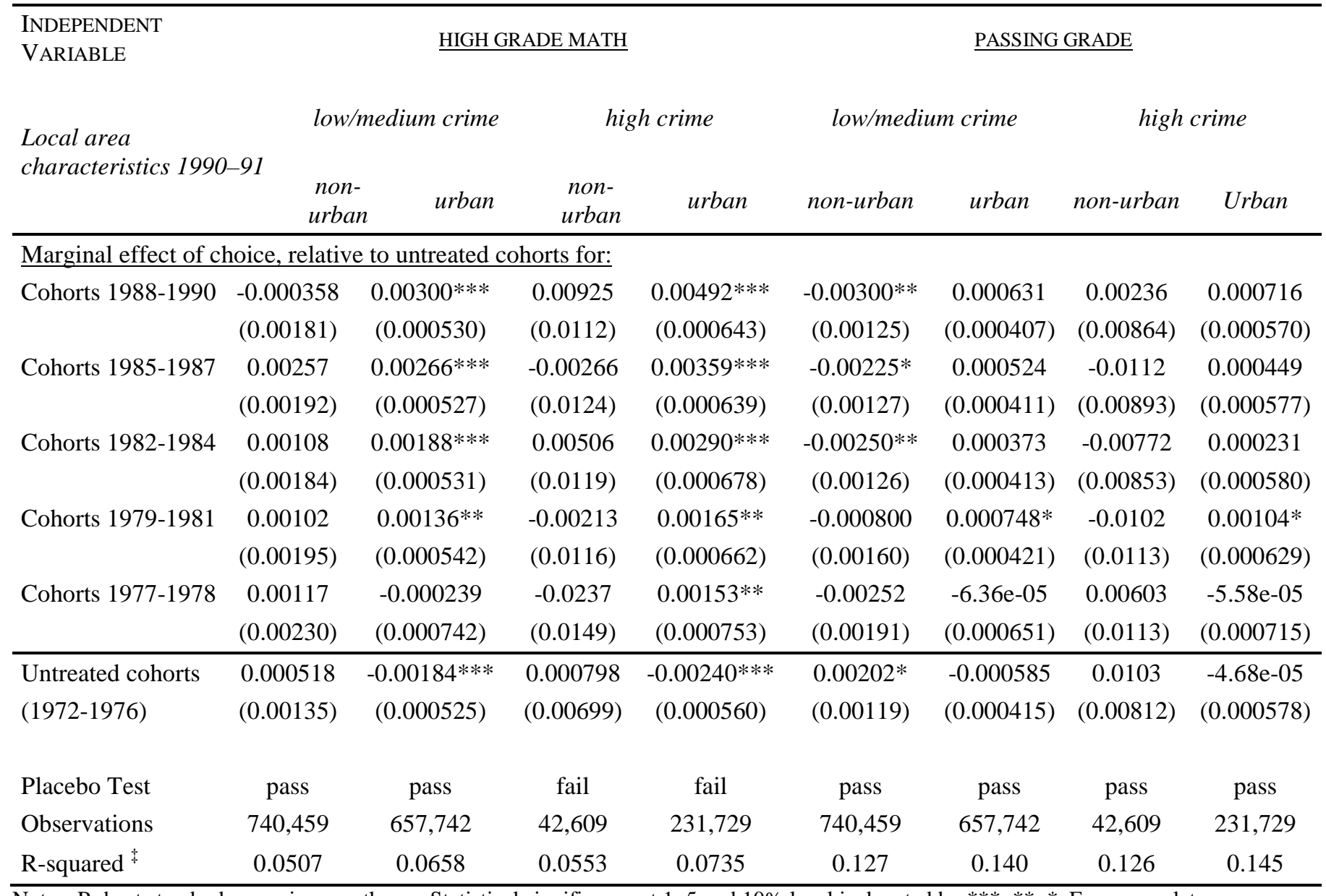

Notes: Robust standard errors in parentheses. Statistical significance at 1, 5 and $10 \%$ level is denoted by ***, **, *. For a complete list of included covariates see Table 5. The definition of the placebo tests is explained in Section 5.1.

$\ddagger$ Pseudo R-squared for binary outcomes.

To begin with, it should be noted that most of the estimated effects are very small, and often not significantly different from zero. Table 13 shows that the small positive results on the average percentile rank in marks are mostly driven by individuals living in high crime urban areas, while results in other areas are even sometimes statistically significantly negative. However, the identification for the results for the non-urban low and medium level crime areas is rather weak, indicated by the failing placebo test. A 
similar pattern arises also when using the $2 \mathrm{~km}$ radius to construct the choice measure ${ }^{49}$. For the cognitive score at the age of around 18, we find almost no statistically significant effect (see Table 13). The probability of achieving a high grade in math is positively affected in high crime urban areas, while effects are mostly insignificant for the other subgroups (see Table 14). Correspondingly, the probability of receiving a passing grade is negatively affected by more choice for some cohorts in all but the high crime municipal regions, where the point estimates are positive and sometimes significant (see Table 14). Taken together, there is no indication that children living in high crime areas were harmed by the school choice as introduced by the reform. Though the evidence is sometimes weak, it rather seems to be the case that those living in urban high crime areas benefited relatively more than others from increased choice options.

For all of the above subgroups, we also ran further estimations for the probability of committing a crime until age 22, receiving a university degree until age 25, and being employed at age $25^{50}$. Especially for the latter two, we often ran into identification problems in the sense that the placebo test failed. Estimated effects were small but the placebo estimates were often of the same size, which is why results on these later outcomes should not be overinterpreted. However, as for the above presented results, there was almost never an indication for students from more disadvantaged backgrounds benefiting less from having more schools nearby before the choice reform. Qualitatively, the same is true when estimating the effect of choice using the number of schools within a $2 \mathrm{~km}$ radius instead of the median commuting distance ${ }^{51}$.

\subsection{Robustness analysis}

In order to test the robustness of our results, we also estimated alternative regression specifications. Moreover, we present results using the pre-reform choice measures as instrumental variables for actual choice opportunities at the time of decision making.

\footnotetext{
${ }^{49}$ See Table 44 and Table 45.

${ }^{50}$ See tables in Section 8.2.3.2.

${ }^{51}$ See tables in Section 8.2.3.2.
} 


\subsubsection{Alternative regression specifications}

First, as we study student outcomes over a long time period, it is possible that the influence of the included covariates has changed over time. To account for this, we allow the coefficients of the covariates to differ between treatment windows by adding the interaction of the individual, parish and municipality level covariates and the treatment windows to the regression specification. The results, which are available upon request from the authors, show that although the pattern of effects in general remains the same across treatment windows and groups of students, the sizes of the estimates are much smaller than the baseline, often about half the size. They are also often not significantly different from zero.

Second, several other education-related reforms were implemented during the $1990 s^{52}$. In particular, the 1991 decentralization reform increased the municipalities' role in the provision of compulsory education, which means that municipality level factors might have had a changing role for the outcomes of students over time. Whereas our baseline specification controls for the influence of both a set of observed municipality level variables, and, through the inclusion of municipality fixed effects, for time constant unobserved municipality factors, it may thus be that the influence of such unobserved factors differs over time. We allow for this by adding interactions between the municipality fixed effects and the treatment window dummies to the regression (in addition to the interaction between covariates and treatment window dummies). As this specification exhibited convergence problems for the probit estimations, we only run regressions using OLS/LPM. The results for the binary outcomes should thus be interpreted with caution. The point estimates from this specification (available upon request from the authors) are further reduced and often not statistically different from zero.

Third, even though the baseline specification includes a number of local area level covariates, it could still be that our school choice option index captures effects of other unobserved local factors. To the extent that such effects remain stable over time, we can control for this by including fixed effects at the same level as was used to construct the

\footnotetext{
${ }^{52}$ See a discussion in the appendix of the companion paper, Wondratschek et al. (2013b).
} 
choice-option index, that is, the $100 * 100 \mathrm{~m}$ geographical coordinate boxes. We do this by adding fixed effects for the geographical coordinate boxes to the estimation. However, similarly to the regression including interactions between municipality and treatment window dummies, these specifications were estimated as linear functions for all outcomes, and the cautionary remark for the binary outcome variables thus also applies here. The results from this set of regressions follow a similar pattern as when the coordinate box fixed effects are excluded, although the coefficients are in general larger and more often statistically different from zero. To a large degree, this is explained by the fact that we lose observations in coordinate boxes without repeated observations, which is more often the case in non-urban than urban areas. As effects are larger in urban areas (see Wondratschek et al. 2013b), and those observations have an increased weight in the smaller sample, we observe larger point estimates for the average effect. ${ }^{53}$

Taken together, we interpret the results from these additional analyses as supportive of our main conclusion, namely that we find no evidence that students - neither from a less nor from a more socio-economically advantaged background - were harmed by the introduction of the school choice reform in 1992. The baseline analysis furthermore suggests somewhat larger effects for some of the more disadvantaged groups of students. Although this pattern remains the same in the robustness analysis, the fact that the estimated effects are often smaller and often not statistically significantly different from zero suggests that this finding should be interpreted with caution. In particular, and this holds both for the baseline and the robustness analysis, the estimated effects are small for all groups of students and should qualitatively be viewed as very small or close to zero effects.

\subsubsection{Instrumental variable estimations}

Furthermore, as an alternative to our main estimations, we also estimated an IVregression, where we use the pre-reform choice measure as an instrument for the

\footnotetext{
${ }^{53}$ We ran this specification for all the above specified regressions: that is, for the baseline specification as well as when we included covariates interacted with the treatment windows, and, additionally, municipality specific effects interacted with the treatment windows. The pattern of larger effects when the coordinate fixed effects are included holds for all these specifications. It shall be noted that, in contrast to the previous specifications were standard errors were clustered at the school by year level, we now estimated standard errors clustered at the level of the geographical coordinate boxes.
} 
amount of choice available at the time when the student enters $7^{\text {th }}$ grade. This specification was estimated for the outcome percentile rank in $9^{\text {th }}$ grade marks, the result is given in Table 24 in the Appendix. Since the pre- and post-reform choice measures are closely related (as reported in Section 8.1.2 in the Appendix), these results are bound to be relatively similar. This is also what we find: For the younger birth cohorts, the effects of choice on the percentile rank in marks are positive across all groups of students, and (with a few exceptions) statistically significant, although the sizes of the effects are smaller than the estimates of the baseline specification. For the early cohorts, the estimates are often statistically insignificant, although in some cases statistically significant and negative. Overall, the differences between groups of students are small. The qualitative result of positive, but very small effects for all groups of younger cohorts, and of even smaller differences across groups, thus holds also in the IV-analysis. Note however that the IV- specification has a slightly different interpretation than the baseline regression: whereas the latter measures the reduced form effects of the reform, including the formation of schools after the reform, the IVestimates measure the effect of the actual choice options available when the decision for a school is made.

Finally, we also ran the baseline specification using different measures for the number of schools near a student's residence. That is, in addition to measuring school choice as the number of schools within a radius equalling the median commuting distance in the municipality, which was our baseline specification, or within $2 \mathrm{~km}$, which we also presented above, we also ran specifications where we counted the number of schools within a radius of $3,4,5$, and $10 \mathrm{~km}$, respectively. The results, which are available from the authors upon request, do not differ qualitatively from the overall results of the above presented analysis.

\section{Conclusion}

We can conclude that our analyses show no evidence indicating that children from a socio-economically disadvantaged or immigration background have been harmed by school choice as it evolved after the introduction of the 1992 reform. The effects are 
small or zero and similar for different subgroups. If anything, they rather indicate slightly more positive effects on some outcomes for socio-economically disadvantaged children than for socio-economically more advantaged children, although the positive effects often disappear in alternative specifications.

In order to avoid endogenous sorting of schools and parents into different areas after the reform, we measure school choice right before the introduction of the reform, which is, as we show, still closely related to the school choice at the time of decision making. Our estimates thus capture the effect of more school choice as is present right at the outset of the reform, including the dynamic processes that are a direct result of it, like the opening or closing of public and private schools and moves by parents in response to the changed system. Moreover, as we can test for, and sometimes find, placebo effects, especially concerning adult outcomes, we focus our interpretation on the most reliable results.

Previous studies analysing the Swedish 1992 choice reforms find that children from a lower-educated or migrant background are not hurt by an increased private school share, but that they benefit relatively less (Sandström and Bergström (2005), Björklund et al. (2004), Ahlin (2003)). These results are, however, no contradiction to the ones found in this study, as they focus on a different phenomenon of the choice reform. While previous studies have focused on studying the effects of competition by private schools, this study evaluates the overall dynamic effects that work through having more choice at the outset of the reform, that is also among public schools. 


\section{References}

Ahlin, Å (2003), ”Does school competition matter? Effects of a large-scale school choice reform on student performance”, Department of Economics, Uppsala University, Working Paper 2003:2.

Björklund, A, Edin, P, Fredriksson, P and A Krueger (2004), "Education, equality and efficiency - An analysis of Swedish school reforms during the 1990s”, IFAU Report 2004:1.

Björklund, A, Clark, M A, Edin, P-A, Fredriksson, P and A Krueger (2005), “The education market comes to Sweden. An evaluation of Sweden's surprising school reforms”, (Ed. Björklund, A), Russel Sage Foundation, New York.

Burgess, S, Greaves, E, Vignoles, A and D Wilson (2009), "What parents want: School preferences and school choice”, CMPO Working Paper 09/222.

Böhlmark, A and M Lindahl (2007), "The impact of school choice on pupil achievement, segregation and costs: Swedish evidence”, IZA DP No. 2786.

Böhlmark, A and M Lindahl (2012), “Independent schools and long-run educational outcomes: Evidence from Sweden's large scale voucher reform”, IZA DP No. 6683.

De Giorgi, G, Pellizzari, M and W G Woolston (2009), “Class Size and Class Heterogeneity.” Journal of the European Economic Association, vol 10, pp. 795-830.

De Giorgi, G and M Pellizzari (2011), “Understanding Social Interactions: Evidence from the Classroom.” IZA Discussion Paper No. 5624.

Deming, D (2011), “Better schools, less crime?”, The Quarterly Journal of Economics, vol 126, pp. 2063-2115.

Epple, D and R E Romano (1998), “Competition between private and public schools, vouchers and peer effects”, The American Economic Review, vol 88, pp. 33-62.

Gibbons, S, Machin, S and O Silva (2008), "Choice, competition and pupil achievement”, Journal of the European Economic Association, vol 6, pp. 912-947.

Hastings, J S, Kane, T K and D O Staiger (2006), "Heterogeneous preferences and the efficacy of public school choice”, NBER Working Paper No. 12145. 
Hastings, J and J Weinstein (2008), "Information, school choice and academic achievement: Evidence from two experiments”, The Quarterly Journal of Economics, vol 123: 1373-1414.

Himmler, O (2009), "The effects of school competition on academic achievement and grading standards”, CESifo Working Paper Series No. 2676.

Hoxby, C M (2000), “Does competition among public schools benefit students and taxpayers?”, American Economic Review, vol 90, pp. 1209-1238.

Hoxby, C M (2003), "School choice and school productivity. Could school choice be a tide that lifts all boats?”, in: The Economics of School Choice (Ed. Hoxby, C), pp. 287-342, National Bureau of Economic Research, Inc.

Lindqvist, E and R Vestman (2011), “The labour market returns to cognitive and noncognitive ability: Evidence from the Swedish enlistment”, American Economic Journal: Applied Economics, vol 3, pp. 101-28.

Nechyba, T (2006), “Income and peer quality sorting in public and private schools”, in: Handbook of the Economics of Education (Ed. Hanushek E, and F Welch), vol 2, chapter 22, Elsevier.

Noailly, J, Vujić, S and A Aouragh (2009), “The effects of competition on the quality of primary schools in the Netherlands”, CPB Discussion Paper No 120.

Sacerdote, B (2011), "Peer effects in education: How might they work, how big are they and how much do we know thus far?”, in: Handbook of the Economics of Education (Ed. Hanushek, E, Machin, S and L Woessmann), vol 3, chapter 4, Elsevier.

Sandström, M and F Bergström (2005), "School vouchers in practise: competition will not hurt you”, Journal of Public Economics, vol 89, pp. 351-380.

The National Board of Education (Skolverket) (1996), “Att välja skola - effekter av valmöjlighet i grundskolan”, Report Nr 109.

The National Board of Education (Skolverket) (2003), "Valfrihet och dess effekter inom skolområdet”, Report 230.

Vlachos, J (2010), ”Betygets värde. En analys av hur konkurrens påverkar betygssättningen vid svenska skolor.”, Uppdragsforskningsrapport 2010:6, Konkurrensverket. 
Von Greiff, C (2009), ”En skola med lika resurser? En ESO-rapport om likvärdighet och resursfördelning”, ESO-rapport 2009:5.

Waslander, S, Pater, C and M van der Weide (2010), "Markets in education: An analytical review of empirical research on market mechanisms in education”, OECD Education Working Paper, No. 52.

Wondratschek, V, Edmark K and M Frölich (2013a), "The short- and long-term effects of school choice on student outcomes - evidence from a school choice reform in Sweden”, Annals of Economics and Statistics, vol 111/112, pp 71-101.

Wondratschek, V, Edmark K and M Frölich (2013b), “The short- and long-term effects of school choice on student outcomes - evidence from a school choice reform in Sweden”, IFAU Working Paper, 2013: 20.

Östh, J, Andersson, E and B Malmberg (2010), "School choice and increasing performance difference: A counterfactual approach”, Stockholm Research Reports in Demography 2010:11, Department of Sociology, Stockholm University. 


\section{Appendix}

\subsection{Additional analysis}

This section presents additional analyses that are not included in the main body of the paper.

\subsubsection{Segregation between schools}

As the school choice reform has allowed all students to choose the school that they would like to attend, it may be that the composition of students at individual schools across Sweden has changed after as compared to before the reform. In particular, one argument against free school choice often mentioned in the political debate was the concern that segregation between schools along the socio-economic or migration background of the parents may increase with free school choice (see National Board of Education (2003), p.45). At the same time, one could argue that school choice mitigates existing residential segregation as the composition of schools is no longer necessarily identical to that of the residential area. Böhlmark and Lindahl (2007) have found that segregation between public and private schools along parental education and migration background increases with an increasing share of students attending private schools in a municipality. As this result focuses on the growth of private schools, it does not take into account the effects of choice among public schools, which is of high relevance for the present study.

In order to explore whether segregation among students in grades 7-9 has changed after the reform, we compute the standard deviation in the share of students of a specific socio-economic background across schools in Sweden for each cohort of students born between 1972 and 1990. We then compare the average of this value for cohorts that were affected by the reform to the average for those that were not, that is we compare the standard deviation in student characteristics across schools between cohorts 19721976 and 1977-1990. Note that this exercise does not show effects of school choice on student segregation in schools as residential segregation might have changed over time as well, impacting also the composition of students at different schools. It is merely a 
way to describe whether Sweden has seen an increase in student segregation across schools after the 1992 school choice reform.

Table 15 presents the results of this exercise for the socio-economic characteristics considered in this study, being parental education, income and immigration background. We can see from this table that there is no change in the degree of overall student segregation between Swedish schools offering grades 7-9 after the choice reform ${ }^{54}$.

Table 15: Average between-school standard deviation of parental characteristics

\begin{tabular}{lcc}
\hline & \multicolumn{2}{c}{$\begin{array}{c}\text { Mean value of the between school standard } \\
\text { deviation }\end{array}$} \\
\hline Share in the school with: & $\begin{array}{c}\text { pre-reform } \\
\text { (cohorts 72-76) }\end{array}$ & $\begin{array}{c}\text { post-reform } \\
\text { (cohorts 77-90) }\end{array}$ \\
\hline Both parents non-Swedish & 0.040 & 0.041 \\
Both parents only pre-secondary education & 0.028 & 0.029 \\
Low household income & 0.031 & 0.031 \\
Medium household income & 0.037 & 0.037 \\
High household income & 0.043 & 0.044 \\
\hline Number of observations & 5040 & 18851 \\
\hline
\end{tabular}

\subsubsection{Relation between degree of choice measured before and after the reform}

In this section, we explore the relation between the degree of school choice as measured before the introduction of the reform, in 1991, and as measured at the actual time the child chooses a school for grades 7-9, at age 13 . We conduct this analysis for cohorts that started grade 7 in or after 1992, i.e. for students born in or after 1979, as these are the cohorts for which we use the pre-reform measure instead of the actual measure of school choice in the main estimations that are presented in Section 6. In order for these main analyses to be meaningful, it is important that pre-reform and actual choice measures are related for all subgroups.

Similar to the corresponding analysis in WEF13, we regress the actual choice measure, that is the number of schools within the median commuting distance of the municipality measured at age 13, on the number of schools within the child's median 
commuting distance around her 1991 place of residence, i.e. the pre-reform choice measure that we use in the main analysis. In order to capture changes in the development of the number of schools over time, we interact the choice measure with a linear time trend. Since the variation that we use in the main estimations in Section 6 is conditional on covariates and cohort and municipality dummies, we include these covariates here as well and cluster on the municipality level ${ }^{55}$.

Table 16 and Table 17 present the marginal effects of an additional school within the median commuting distance as measured before the reform on the number of schools nearby when the child is 13 years old for the different subgroups. The correlation between the pre-reform and the post-reform measure is increasing over time, suggesting an increase in the number of schools, and is mostly close to or larger than one. Moreover, the relation is similar for the different subgroups and only slightly smaller for children from a disadvantaged or migration background.

The results thus suggest that the choice measures taken in 1991 are closely related to the post-reform measures taken at the time when children start grade 7 for all subgroups.

\footnotetext{
${ }^{54}$ This result also holds when distinguishing further between individual cohorts instead of just comparing pre- and post-reform cohorts.

${ }^{55}$ In accordance with main analyses, the covariates and municipality dummies are measured in 1991, that is at the pre-reform location of residence.
} 
Table 16: Relation between pre-reform and post-reform choice measure, separately for subgroups according to household income and parental education

\begin{tabular}{|c|c|c|c|c|c|}
\hline \multicolumn{4}{|l|}{ INDEPENDENT } & & DISTANCE \\
\hline Household background & $\begin{array}{c}\text { low } \\
\text { income }\end{array}$ & $\begin{array}{l}\text { medium } \\
\text { income }\end{array}$ & $\begin{array}{c}\text { high } \\
\text { income }\end{array}$ & $\begin{array}{c}\text { higher } \\
\text { educated }\end{array}$ & $\begin{array}{c}\text { low } \\
\text { educated }\end{array}$ \\
\hline \multicolumn{6}{|c|}{ Marginal effect of number of schools within median commuting distance in 1991 for: } \\
\hline Cohorts 1988-1990 & $\begin{array}{c}1.195^{* * *} \\
(0.0217)\end{array}$ & $\begin{array}{c}1.324^{* * *} \\
(0.0217)\end{array}$ & $\begin{array}{c}1.381 * * * \\
(0.0210)\end{array}$ & $\begin{array}{c}1.323^{* * *} \\
(0.0200)\end{array}$ & $\begin{array}{c}1.292 * * * \\
(0.0291)\end{array}$ \\
\hline Cohorts $1985-1987$ & $\begin{array}{c}1.037 * * * \\
(0.0150)\end{array}$ & $\begin{array}{c}1.153^{* * *} \\
(0.0166)\end{array}$ & $\begin{array}{c}1.210^{* * *} \\
(0.0151)\end{array}$ & $\begin{array}{c}1.155^{* * *} \\
(0.0153)\end{array}$ & $\begin{array}{c}1.120^{* * *} \\
(0.0211)\end{array}$ \\
\hline Cohorts 1982-1984 & $\begin{array}{c}0.880^{* * *} \\
(0.0109)\end{array}$ & $\begin{array}{c}0.981^{* * *} \\
(0.0155)\end{array}$ & $\begin{array}{c}1.039 * * * \\
(0.0124)\end{array}$ & $\begin{array}{c}0.986 * * * \\
(0.0138)\end{array}$ & $\begin{array}{c}0.948 * * * \\
(0.0173)\end{array}$ \\
\hline Cohorts 1979-1981 & $\begin{array}{c}0.722 * * * \\
(0.0123)\end{array}$ & $\begin{array}{c}0.810 * * * \\
(0.0189)\end{array}$ & $\begin{array}{c}0.868 * * * \\
(0.0145)\end{array}$ & $\begin{array}{c}0.817 * * * \\
(0.0163)\end{array}$ & $\begin{array}{c}0.776^{* * *} \\
(0.0203)\end{array}$ \\
\hline Observations & 253,127 & 567,675 & 296,972 & $1,035,610$ & 82,164 \\
\hline R-squared ${ }^{\ddagger}$ & 0.731 & 0.784 & 0.805 & 0.782 & 0.784 \\
\hline
\end{tabular}

Table 17: Relation between pre-reform and post-reform choice measure, separately for subgroups according to parental migration background and crime rate of local area

\begin{tabular}{|c|c|c|c|c|}
\hline \multicolumn{5}{|l|}{ INDEPENDENT } \\
\hline VARIABLE & \multicolumn{4}{|c|}{ ACTUAL NUMBER OF SCHOOLS WITHIN MEDIAN COMMUTING DISTANCE } \\
\hline $\begin{array}{l}\text { Migration background } \\
\text { and area backgrounds }\end{array}$ & $\begin{array}{l}\text { at least one } \\
\text { parent born in } \\
\text { Sweden }\end{array}$ & $\begin{array}{l}\text { both parents } \\
\text { born abroad }\end{array}$ & $\begin{array}{c}\text { low/medium } \\
\text { crime local area }\end{array}$ & $\begin{array}{c}\text { high crime local } \\
\text { area }\end{array}$ \\
\hline \multicolumn{5}{|c|}{ Marginal effect of number of schools within median commuting distance in 1991 for: } \\
\hline \multirow[t]{2}{*}{ Cohorts $1988-1990$} & $1.328 * * *$ & $1.221 * * *$ & $1.358 * * *$ & $1.211^{* * *}$ \\
\hline & $(0.0201)$ & $(0.0278)$ & $(0.0165)$ & $(0.0517)$ \\
\hline \multirow[t]{2}{*}{ Cohorts 1985-1987 } & $1.162 * * *$ & $1.060 * * *$ & $1.188^{* * *}$ & $1.053 * * *$ \\
\hline & $(0.0152)$ & $(0.0222)$ & $(0.0129)$ & $(0.0335)$ \\
\hline \multirow[t]{2}{*}{ Cohorts 1982-1984 } & $0.996 * * *$ & $0.899 * * *$ & $1.017 * * *$ & $0.894 * * *$ \\
\hline & $(0.0136)$ & $(0.0208)$ & $(0.0111)$ & $(0.0186)$ \\
\hline \multirow[t]{2}{*}{ Cohorts 1979-1981 } & $0.830 * * *$ & $0.738 * * *$ & $0.847 * * *$ & $0.736 * * *$ \\
\hline & $(0.0165)$ & $(0.0242)$ & $(0.0117)$ & $(0.0185)$ \\
\hline Observations & $1,035,577$ & 82,197 & 842,062 & 187,315 \\
\hline R-squared ${ }^{\ddagger}$ & 0.786 & 0.709 & 0.802 & 0.701 \\
\hline
\end{tabular}




\subsubsection{Linking the probability of attending a private school, and distance to school of attendance, to choice measures}

In this section, we study whether the degree of school choice as present at the outset of the reform is related to the probability of having made an active school choice. As we lack information on who has actually made an active choice, we use two indicators that we can construct from our data: whether a student attended a private school and the distance to the school of attendance in $9^{\text {th }}$ grade. Attending a private school is clear evidence for an active school choice, as opting out of the public school system requires parents to act. The travel distance to school, however, can only be seen as an approximate indicator of school choice in general - to public as well as private schools since students that opt out of the school of their catchment area are likely to increase their travel distance, as the catchment area school is in general the nearest one. However, with new schools opening up and old ones possibly closing down, an increased travel distance is not a perfect measure of choosing another than the default school. Moreover, any changes in travel distance over time may of course be related to other factors and general trends too, like for example a trend to move into less or more densely populated areas. In addition, the average size of a change in the travel distance may vary for different groups of the population without indicating a different propensity to make an active choice: if there are more schools close-by, making an active choice still does not imply a large increase in travel distance.

Since attending a private school was extremely rare before the 1992 reform, when estimating the effect of having more schools to choose from, we cannot follow a beforeafter comparison strategy as we did in Section 6. Nevertheless, since the private school share increased only gradually as it took some time for private schools to open up, it is also informative to analyse the development of the likelihood to attend a private school for the different subgroups over time.

Regarding private school attendance, our results show that the effect of an additional school nearby on the probability of attending a private school is larger for the later cohorts, but is small and very similar across all groups (see Table 18 and Table 19). ${ }^{56}$

\footnotetext{
${ }^{56}$ As could be seen in Table 3 the share of students attending a private school was, on average for the post-reform cohorts, between 2 and 6 percent depending on student subgroup. For the groups with the largest estimates in Table
} 
The point estimates for children from migrants is slightly larger, but when using the choice measure counting the number of schools within a $2 \mathrm{~km}$ radius instead of within the commuting distance, this result reverses.

Over time, also the distance to the school of attendance is increasingly correlated with having more schools near the home (see Table 20 and Table 21). For students born in 1988-90, having one more school nearby is correlated with an increase in the travel distance to school of $0.07 \mathrm{~km}-0.4 \mathrm{~km}$ compared to the pre-reform situation, depending on the student group studied. The increase, in absolute terms, is larger for students living in areas with low/medium youth crime rates and students with low-educated parents. The estimated increases in travel distance do not vary much depending on household income or whether the parents were born in Sweden or not.

The overall pattern in these tables is compatible with the hypothesis that students in areas with more schools around have changed their school choice behaviour more than students in areas with fewer schools nearby after the introduction of the choice reform.

Table 18: Effect of choice on probability of attending a private school, separately for subgroups according to household income and parental education

\begin{tabular}{|c|c|c|c|c|c|}
\hline \multirow{2}{*}{$\begin{array}{l}\text { INDEPENDENT } \\
\text { VARIABLE } \\
\text { Household } \\
\text { background: }\end{array}$} & \multicolumn{5}{|c|}{ ATTENDING A PRIVATE SCHOOL } \\
\hline & $\begin{array}{c}\text { low } \\
\text { income } t\end{array}$ & $\begin{array}{l}\text { medium } \\
\text { income } t\end{array}$ & $\begin{array}{c}\text { high } \\
\text { income } t\end{array}$ & $\begin{array}{c}\text { parental } \\
\text { education } \\
\text { high } t\end{array}$ & $\begin{array}{c}\text { parental } \\
\text { education } \\
\text { low } t\end{array}$ \\
\hline \multicolumn{6}{|c|}{ Marginal effect of choice for: } \\
\hline Cohorts 1988-1990 & $\begin{array}{c}0.000493 * * \\
(0.000219)\end{array}$ & $\begin{array}{c}0.000363 * * \\
(0.000179)\end{array}$ & $\begin{array}{c}0.000502 \\
(0.000316)\end{array}$ & $\begin{array}{l}0.000425 * * \\
(0.000216)\end{array}$ & $\begin{array}{l}0.000633^{* * *} \\
(0.000182)\end{array}$ \\
\hline Cohorts 1985-1987 & $\begin{array}{c}0.000417 * * * \\
(0.000135)\end{array}$ & $\begin{array}{c}0.000326 * * * \\
(0.000111)\end{array}$ & $\begin{array}{c}0.000331 \\
(0.000226)\end{array}$ & $\begin{array}{c}0.000324 * * \\
(0.000139)\end{array}$ & $\begin{array}{c}0.000516^{* * *} \\
(0.000135)\end{array}$ \\
\hline Cohorts 1982-1984 & $\begin{array}{c}0.000170^{*} \\
(0.0001)\end{array}$ & $\begin{array}{c}0.0001 \\
(0.0001)\end{array}$ & $\begin{array}{c}(0.0000) \\
(0.000171)\end{array}$ & $\begin{array}{l}(0.0001) \\
(0.0001)\end{array}$ & $\begin{array}{c}0.000142^{* *} \\
(0.0001)\end{array}$ \\
\hline Cohorts 1979-1981 & $\begin{array}{c}0.000146^{*} \\
(0.0001)\end{array}$ & $\begin{array}{c}0.000111^{*} \\
(0.0001)\end{array}$ & $\begin{array}{c}0.000271 \\
(0.000180)\end{array}$ & $\begin{array}{c}0.000172 * \\
(0.0001)\end{array}$ & $\begin{array}{c}0.0000 \\
(0.0001)\end{array}$ \\
\hline Observations & 253,076 & 545,596 & 280,816 & $1,003,352$ & 76,136 \\
\hline R-squared ${ }^{\ddagger}$ & 0.122 & 0.137 & 0.116 & 0.128 & 0.140 \\
\hline
\end{tabular}

18 and Table 19, students with both parents born abroad and students in high crime areas, the average private school attendance, post-reform, was close to 6 percent. The results in Table 18 and Table 19 are thus small in relation to these average attendance rates. 
Table 19: Effect of choice on probability of attending a private school, separately for subgroups according to parental migration background and crime level in local area

\begin{tabular}{|c|c|c|c|c|}
\hline \multirow{2}{*}{$\begin{array}{l}\text { INDEPENDENT VARIABLE } \\
\text { migration background and local } \\
\text { area background }\end{array}$} & \multicolumn{4}{|c|}{ ATTENDING A PRIVATE SCHOOL } \\
\hline & $\begin{array}{l}\text { at least } \\
\text { one parent } \\
\text { born in } \\
\text { Sweden } t\end{array}$ & $\begin{array}{c}\text { both parents } \\
\text { born } \\
\text { abroad } t\end{array}$ & $\begin{array}{c}\text { low/medium } \\
\text { crime local } \\
\text { area } t\end{array}$ & $\begin{array}{l}\text { high crime } \\
\text { local area } t\end{array}$ \\
\hline \multicolumn{5}{|l|}{ Marginal effect of choice for: } \\
\hline Cohorts 1988-1990 & $\begin{array}{c}0.000325 \\
(0.000207)\end{array}$ & $\begin{array}{c}0.00187 * * * \\
(0.000421)\end{array}$ & $\begin{array}{c}0.000223 \\
(0.000206)\end{array}$ & $\begin{array}{c}0.00205^{* * *} \\
(0.000556)\end{array}$ \\
\hline Cohorts 1985-1987 & $\begin{array}{l}0.000238^{*} \\
(0.000131)\end{array}$ & $\begin{array}{c}0.00154 * * * \\
(0.000318)\end{array}$ & $\begin{array}{c}0.000179 \\
(0.000129)\end{array}$ & $\begin{array}{c}0.00165 * * * \\
(0.000395)\end{array}$ \\
\hline Cohorts 1982-1984 & $\begin{array}{c}0.0001 \\
(0.0001)\end{array}$ & $\begin{array}{c}0.000533 * * \\
(0.000215)\end{array}$ & $\begin{array}{l}-2.36 e-05 \\
(9.02 e-05)\end{array}$ & $\begin{array}{c}0.00108 * * * \\
(0.000234)\end{array}$ \\
\hline Cohorts 1979-1981 & $\begin{array}{c}0.000122 \\
(0.0001)\end{array}$ & $\begin{array}{c}0.000724^{* * *} \\
(0.000185)\end{array}$ & $\begin{array}{c}4.35 \mathrm{e}-05 \\
(9.09 \mathrm{e}-05)\end{array}$ & $\begin{array}{c}0.000949 * * * \\
(0.000175)\end{array}$ \\
\hline Observations & $1,000,823$ & 78,665 & 876,775 & 180,901 \\
\hline R-squared ${ }^{\ddagger}$ & 0.133 & 0.123 & 0.135 & 0.106 \\
\hline
\end{tabular}

Table 20: Effect of choice on distance to school, separately for subgroups according to household income and parental education

\begin{tabular}{|c|c|c|c|c|c|}
\hline \multirow{2}{*}{$\begin{array}{l}\text { INDEPENDENT } \\
\text { VARIABLE } \\
\text { Household } \\
\text { background: } \\
\end{array}$} & \multicolumn{5}{|c|}{ DISTANCE TO SCHOOL } \\
\hline & low income & $\begin{array}{l}\text { medium } \\
\text { income }\end{array}$ & high income & $\begin{array}{c}\text { parental } \\
\text { education } \\
\text { high }\end{array}$ & $\begin{array}{c}\text { parental } \\
\text { education } \\
\text { low }\end{array}$ \\
\hline \multicolumn{6}{|c|}{ Marginal effect of choice for: } \\
\hline Cohorts 1988-1990 & $\begin{array}{c}0.174 * * * \\
(0.0368)\end{array}$ & $\begin{array}{c}0.240 * * * \\
(0.0208)\end{array}$ & $\begin{array}{c}0.170 * * * \\
(0.0236)\end{array}$ & $\begin{array}{c}0.193^{* * *} \\
(0.0172)\end{array}$ & $\begin{array}{c}0.403^{* * *} \\
(0.0467)\end{array}$ \\
\hline Cohorts 1985-1987 & $\begin{array}{c}0.168 * * * \\
(0.0384)\end{array}$ & $\begin{array}{c}0.245^{* * *} \\
(0.0215)\end{array}$ & $\begin{array}{c}0.151^{* * *} \\
(0.0239)\end{array}$ & $\begin{array}{c}0.188 * * * \\
(0.0175)\end{array}$ & $\begin{array}{c}0.367 * * * \\
(0.0419)\end{array}$ \\
\hline Cohorts 1982-1984 & $\begin{array}{c}0.106 * * * \\
(0.0377)\end{array}$ & $\begin{array}{c}0.227 * * * \\
(0.0215)\end{array}$ & $\begin{array}{c}0.119 * * * \\
(0.0244)\end{array}$ & $\begin{array}{c}0.158 * * * \\
(0.0175)\end{array}$ & $\begin{array}{c}0.334 * * * \\
(0.0452)\end{array}$ \\
\hline Cohorts 1979-1981 & $\begin{array}{c}0.0647 \\
(0.0393)\end{array}$ & $\begin{array}{c}0.185^{* * *} \\
(0.0243)\end{array}$ & $\begin{array}{c}0.129 * * * \\
(0.0254)\end{array}$ & $\begin{array}{c}0.136 * * * \\
(0.0188)\end{array}$ & $\begin{array}{c}0.221^{* * *} \\
(0.0457)\end{array}$ \\
\hline Cohorts 1977-1978 & $\begin{array}{l}-0.00428 \\
(0.0445)\end{array}$ & $\begin{array}{c}0.0621^{* *} \\
(0.0278)\end{array}$ & $\begin{array}{c}0.0284 \\
(0.0299)\end{array}$ & $\begin{array}{c}0.0223 \\
(0.0207)\end{array}$ & $\begin{array}{c}0.162 * * * \\
(0.0503)\end{array}$ \\
\hline Observations & 383,753 & 835,536 & 429,053 & $1,491,491$ & 156,851 \\
\hline R-squared & 0.015 & 0.019 & 0.013 & 0.014 & 0.024 \\
\hline
\end{tabular}


Table 21: Effect of choice on distance to school, separately for subgroups according to parental migration background and crime level in local area

\begin{tabular}{|c|c|c|c|c|}
\hline \multirow{2}{*}{$\begin{array}{l}\text { INDEPENDENT VARIABLE } \\
\text { migration background and local } \\
\text { area background }\end{array}$} & \multicolumn{4}{|c|}{ DISTANCE TO SCHOOL } \\
\hline & $\begin{array}{l}\text { at least } \\
\text { one parent } \\
\text { born in } \\
\text { Sweden }\end{array}$ & $\begin{array}{l}\text { both parents } \\
\text { born abroad }\end{array}$ & $\begin{array}{c}\text { low/medium } \\
\text { crime local } \\
\text { area }\end{array}$ & $\begin{array}{l}\text { high crime } \\
\text { local area }\end{array}$ \\
\hline \multicolumn{5}{|l|}{ Marginal effect of choice for: } \\
\hline Cohorts 1988-1990 & $\begin{array}{c}0.216^{* * *} \\
(0.0172)\end{array}$ & $\begin{array}{c}0.219 * * * \\
(0.0578)\end{array}$ & $\begin{array}{c}0.308 * * * \\
(0.0227)\end{array}$ & $\begin{array}{c}0.0679 * * \\
(0.0297)\end{array}$ \\
\hline Cohorts 1985-1987 & $\begin{array}{c}0.212 * * * \\
(0.0176)\end{array}$ & $\begin{array}{c}0.214 * * * \\
(0.0578)\end{array}$ & $\begin{array}{c}0.302 * * * \\
(0.0230)\end{array}$ & $\begin{array}{c}0.0483 \\
(0.0320)\end{array}$ \\
\hline Cohorts 1982-1984 & $\begin{array}{c}0.182 * * * \\
(0.0175)\end{array}$ & $\begin{array}{c}0.157 * * * \\
(0.0586)\end{array}$ & $\begin{array}{c}0.279 * * * \\
(0.0230)\end{array}$ & $\begin{array}{c}-0.000377 \\
(0.0318)\end{array}$ \\
\hline Cohorts 1979-1981 & $\begin{array}{c}0.152^{* * *} \\
(0.0189)\end{array}$ & $\begin{array}{c}0.118^{*} \\
(0.0639)\end{array}$ & $\begin{array}{c}0.238 * * * \\
(0.0247)\end{array}$ & $\begin{array}{c}0.0386 \\
(0.0328)\end{array}$ \\
\hline Cohorts 1977-1978 & $\begin{array}{c}0.0419 * * \\
(0.0211)\end{array}$ & $\begin{array}{c}0.0226 \\
(0.0743)\end{array}$ & $\begin{array}{l}0.00658 \\
(0.0297)\end{array}$ & $\begin{array}{c}0.0467 \\
(0.0350)\end{array}$ \\
\hline Observations & $1,535,782$ & 112,560 & $1,345,010$ & 267,259 \\
\hline R-squared & 0.015 & 0.019 & 0.016 & 0.011 \\
\hline
\end{tabular}

\subsubsection{Exploring heterogeneity with respect to whether individuals live in a high versus low or medium crime municipality, not splitting the sample into urban and non-urban areas}

As we present the results for different subgroups of students living in high versus low or medium crime areas in Section 6.2 separately for urban and non-urban municipalities, this section shows the results when not making the latter distinction. Looking first at the outcome percentile rank in $9^{\text {th }}$ grade marks in Table 22, we find that the point estimates are always positive and mostly significant in the high crime areas, and always negative and mostly significant in the low and medium crime areas ${ }^{57}$. Though the magnitude of the estimates is still very small, it thus seems that effects in the higher crime areas drive the positive pooled results. As outlined in Section 6.2, this

\footnotetext{
${ }^{57}$ One interesting pattern to note is that these differential results between the high- and low/medium crime municipalities are due to differences in the estimates for the pre-reform (control group) cohorts, rather than differences in the post-reform choice estimates. That is, the estimates for the untreated cohorts 1972-76 suggest that having more schools nearby is negatively correlated with students' outcomes in the high-crime areas, but significantly positively correlated with students' outcomes in the low crime areas. For the post-reform cohorts, effects for both subgroups are almost always positive, but since we estimate the differential impact of choice over time,
} 
is also related to the fact that municipalities with a higher crime rate are more often urban areas.

With respect to the cognitive score (see columns 3 and 4 in Table 22) and the probability of receiving a high grade in math (see Table 23), we find no sizable differences in the size of the effects. Even though we find very small negative effects on the probability of receiving a passing grade (of around 0.1 to 0.2 percentage points) for those living in low crime areas, there is also a negative Placebo-effect, which makes the identification for this outcome difficult. Qualitatively, the results are similar when using the $2 \mathrm{~km}$ radius (see Table 44 and Table 45 ). We can thus conclude again that we do not find any evidence for children in high crime areas having benefited less or having been harmed by the reform; if anything, they seem to have benefited a bit more.

Table 22: Effect of choice on the percentile rank in marks and cognitive skills for local areas with high or low/medium youth crime levels; choice radius "median commuting distance"

\begin{tabular}{|c|c|c|c|c|}
\hline \multirow{2}{*}{$\begin{array}{l}\text { INDEPENDENT } \\
\text { VARIABLE } \\
\text { Local area } \\
\text { characteristics 1990-91 }\end{array}$} & \multicolumn{2}{|c|}{$\underline{\text { PERCENTILE RANK MARKS }}$} & \multicolumn{2}{|c|}{$\underline{\text { COGNITIVE SCORE }}$} \\
\hline & $\begin{array}{c}\text { low/medium } \\
\text { crime }\end{array}$ & high crime & $\begin{array}{l}\text { low/medium } \\
\text { crime }\end{array}$ & high crime \\
\hline \multicolumn{5}{|c|}{ Marginal effect of choice, relative to untreated cohorts for: } \\
\hline Cohorts 1988-1990 & $\begin{array}{c}0.0742^{* * *} \\
(0.0251)\end{array}$ & $\begin{array}{r}0.221 * * * \\
(0.0297)\end{array}$ & & \\
\hline Cohorts 1985-1987 & $\begin{array}{c}0.0328 \\
(0.0253)\end{array}$ & $\begin{array}{l}0.136 * * * \\
(0.0313)\end{array}$ & $\begin{array}{l}-0.00212 \\
(0.00198)\end{array}$ & $\begin{array}{l}0.000694 \\
(0.00286)\end{array}$ \\
\hline Cohorts 1982-1984 & $\begin{array}{l}-0.0358 \\
(0.0249)\end{array}$ & $\begin{array}{l}0.0734 * * \\
(0.0312)\end{array}$ & $\begin{array}{c}-0.00387 * * \\
(0.00196)\end{array}$ & $\begin{array}{l}0.000675 \\
(0.00299)\end{array}$ \\
\hline Cohorts 1979-1981 & $\begin{array}{l}-0.0129 \\
(0.0255)\end{array}$ & $\begin{array}{l}0.0547 * \\
(0.0325)\end{array}$ & $\begin{array}{c}-0.00519 * * \\
(0.00206)\end{array}$ & $\begin{array}{l}0.000626 \\
(0.00299)\end{array}$ \\
\hline Cohorts 1977-1978 & $\begin{array}{c}-0.0793 * * \\
(0.0334)\end{array}$ & $\begin{array}{l}0.0546 * \\
(0.0326)\end{array}$ & $\begin{array}{l}0.000681 \\
(0.00262)\end{array}$ & $\begin{array}{l}0.000944 \\
(0.00361)\end{array}$ \\
\hline $\begin{array}{l}\text { Untreated cohorts } \\
(1972-1976)\end{array}$ & $\begin{array}{c}0.0240 \\
(0.0244)\end{array}$ & $\begin{array}{c}-0.119 * * * \\
(0.0272)\end{array}$ & $\begin{array}{l}0.00512 * * \\
(0.00203)\end{array}$ & $\begin{array}{l}0.000716 \\
(0.00276)\end{array}$ \\
\hline Placebo Test & $\begin{array}{c}\text { pass } \\
1,400,647\end{array}$ & $\begin{array}{c}\text { pass } \\
275,140\end{array}$ & $\begin{array}{c}\text { pass } \\
502,933\end{array}$ & $\begin{array}{c}\text { pass } \\
92,384\end{array}$ \\
\hline Observations & & & & \\
\hline R-squared ${ }^{\ddagger}$ & 0.185 & 0.194 & 0.142 & 0.170 \\
\hline
\end{tabular}

taking the pre-reform cohorts $1972-76$ as the baseline, we find negative coefficients for the low/medium crime areas, and positive coefficients for the high-crime areas. 
Table 23: Effect of choice on the probability of receiving a high or passing grade in math for local areas with high or low/medium youth crime levels; choice radius "median commuting distance"

\begin{tabular}{|c|c|c|c|c|}
\hline \multirow{2}{*}{$\begin{array}{l}\text { INDEPENDENT VARIABLE } \\
\text { Local area } \\
\text { characteristics 1990-91 }\end{array}$} & \multicolumn{2}{|c|}{ HIGH GRADE MATH } & \multicolumn{2}{|c|}{ PASSING GRADE } \\
\hline & low/medium crime & high crime & $\begin{array}{c}\text { low/medium } \\
\text { crime }\end{array}$ & high crime \\
\hline \multicolumn{5}{|c|}{ Marginal effect of choice, relative to untreated cohorts for: } \\
\hline Cohorts 1988-1990 & $\begin{array}{c}0.00341^{* * *} \\
(0.000464)\end{array}$ & $\begin{array}{c}0.00466^{* * * *} \\
(0.000558)\end{array}$ & $\begin{array}{c}0.000114 \\
(0.000376)\end{array}$ & $\begin{array}{c}0.00180 * * * \\
(0.000449)\end{array}$ \\
\hline Cohorts 1985-1987 & $\begin{array}{c}0.00289 * * * \\
(0.000459)\end{array}$ & $\begin{array}{c}0.00339 * * * \\
(0.000555)\end{array}$ & $\begin{array}{c}-4.84 \mathrm{e}-05 \\
(0.000380)\end{array}$ & $\begin{array}{c}0.00139 * * * \\
(0.000451)\end{array}$ \\
\hline Cohorts 1982-1984 & $\begin{array}{c}0.00205^{* * *} \\
(0.000464)\end{array}$ & $\begin{array}{c}0.00254 * * * \\
(0.000592)\end{array}$ & $\begin{array}{l}-0.000223 \\
(0.000380)\end{array}$ & $\begin{array}{l}0.00112^{* *} \\
(0.000451)\end{array}$ \\
\hline Cohorts 1979-1981 & $\begin{array}{l}0.00118^{* *} \\
(0.000475)\end{array}$ & $\begin{array}{l}0.00130 * * \\
(0.000584)\end{array}$ & $\begin{array}{c}0.000208 \\
(0.000385)\end{array}$ & $\begin{array}{c}0.00146 * * * \\
(0.000521)\end{array}$ \\
\hline Cohorts 1977-1978 & $\begin{array}{c}-0.000773 \\
(0.000634)\end{array}$ & $\begin{array}{l}0.00153 * * \\
(0.000668)\end{array}$ & $\begin{array}{l}-0.000903 \\
(0.000573)\end{array}$ & $\begin{array}{c}0.000781 \\
(0.000636)\end{array}$ \\
\hline $\begin{array}{l}\text { Untreated cohorts } \\
(1972-1976)\end{array}$ & $\begin{array}{c}-0.00183 * * * \\
(0.000460)\end{array}$ & $\begin{array}{c}-0.00239 * * * \\
(0.000491)\end{array}$ & $\begin{array}{c}3.75 \mathrm{e}-05 \\
(0.000385)\end{array}$ & $\begin{array}{c}-0.00129 * * * \\
(0.000444)\end{array}$ \\
\hline Placebo Test & pass & fail & fail & pass \\
\hline Observations & $1,398,201$ & 274,338 & $1,398,201$ & 274,338 \\
\hline R-squared ${ }^{\ddagger}$ & 0.0589 & 0.0697 & 0.133 & 0.141 \\
\hline
\end{tabular}

\subsubsection{Further robustness analysis}

In cases where the placebo test fails, that is where we find that the effect of the number of schools nearby has changed already for unaffected cohorts born in 1975 and 1976 compared to cohorts born in 1972 to 1974, we modelled and estimated a prereform trend to control for these changes. To this end, we included both linear and quadratic time trends in the effect of the number of schools in the estimation and allowed the corresponding coefficients to differ between treatment windows. Then, we repeated the placebo test, that is we tested whether this trend captured all time-variation in the effect among cohorts before the reform. However, as this was mostly not the case, meaning that the identification problem could almost never be mitigated by controlling for a pre-reform trend, we do not show corresponding estimates. 


\subsubsection{Instrumental variable estimation of effects of actual school choice}

In this section, we conduct instrumental variable (IV) regressions to estimate the effect of actual choice options on student outcomes. Basically, the results of Section 8.1.2 represent the first-stage component, where the pre-reform measures (which are exogenous with respect to the reform) are used to predict later choice options. The following table now provides the "second-stage", i.e. the effect of actual choice on student outcomes (using the pre-reform measure as the excluded instrumental variable).

In Table 24 we show the instrumental variable regression of actual school choice options, using the pre-reform choice measure as instrument. We note that the overall pattern of results from the IV analysis resembles the results of the baseline analysis: For the younger birth cohorts, the effects of choice on the percentile rank marks are positive across all groups of students. The sizes of the effects are however smaller. This is roughly in line with the results of Section 8.1.2, where we found for the younger cohorts that the actual number of schools increases with the pre-reform measure by a factor of about 1.2. Thus the effects of actual choice must be smaller in magnitude than those of the baseline regression. For cohorts who were already attending compulsory school when the reform was introduced, i.e. those born in 1984 or earlier, the coefficients in Table 24 are often negative, and sometimes statistically significant.

In any case, the differences between groups of students are small, although the point estimates tend to be somewhat larger among students with at least one Swedish-born parent, compared to students with two foreign-born students, and among students in high-crime, compared to low-crime, areas. This pattern somewhat contrasts to the results from the baseline estimation, where the larger coefficients were found for the students with two foreign-born students. However, we would like to emphasize that the qualitative result, of positive, but very small, effects for all groups of younger cohorts, and of even smaller differences across groups, holds also in the IV-analysis. 
Table 24: Instrumental variable regression: Effect of choice on percentile rank in marks for different parental or local area backgrounds; choice radius "median commuting distance"

OUTCOME VARIABLE

PERCENTILE RANK MARKS

\begin{tabular}{|c|c|c|c|c|c|}
\hline Household background & $\begin{array}{l}\text { high } \\
\text { income }\end{array}$ & $\begin{array}{l}\text { medium } \\
\text { income }\end{array}$ & $\begin{array}{c}\text { low } \\
\text { income }\end{array}$ & $\begin{array}{l}\text { more than } \\
\text { compulsory } \\
\text { education }\end{array}$ & $\begin{array}{c}\text { only } \\
\text { compulsory } \\
\text { education }\end{array}$ \\
\hline \multicolumn{6}{|c|}{ Marginal effect of choice, relative to untreated cohorts, for: } \\
\hline Cohorts 1988-1990 & $\begin{array}{c}0.0666 * * * \\
(0.00888)\end{array}$ & $\begin{array}{c}0.0684^{* * *} \\
(0.00870)\end{array}$ & $\begin{array}{c}0.0696 * * * \\
(0.0118)\end{array}$ & $\begin{array}{c}0.0670^{* * *} \\
(0.00699)\end{array}$ & $\begin{array}{c}0.0663 * * * \\
(0.0207)\end{array}$ \\
\hline Cohorts 1985-1987 & $\begin{array}{c}0.0377 * * * \\
(0.00902)\end{array}$ & $\begin{array}{l}0.0203 * * \\
(0.00961)\end{array}$ & $\begin{array}{c}0.0402 * * * \\
(0.0128)\end{array}$ & $\begin{array}{c}0.0326 * * * \\
(0.00732)\end{array}$ & $\begin{array}{c}0.0260 \\
(0.0213)\end{array}$ \\
\hline Cohorts 1982-1984 & $\begin{array}{c}-0.0209 * \\
(0.0125)\end{array}$ & $\begin{array}{c}-0.0249 * * \\
(0.0121)\end{array}$ & $\begin{array}{l}-0.0238 \\
(0.0158)\end{array}$ & $\begin{array}{l}-0.0213^{* *} \\
(0.00902)\end{array}$ & $\begin{array}{l}-0.0201 \\
(0.0239)\end{array}$ \\
\hline Cohorts 1979-1981 & $\begin{array}{l}-0.0247 \\
(0.0193)\end{array}$ & $\begin{array}{c}-0.00435 \\
(0.0158)\end{array}$ & $\begin{array}{l}-0.0115 \\
(0.0233)\end{array}$ & $\begin{array}{l}-0.0200 \\
(0.0139)\end{array}$ & $\begin{array}{c}0.0671 * * \\
(0.0321)\end{array}$ \\
\hline Cohorts 1977-1978 & $\begin{array}{l}-0.0485 \\
(0.0331)\end{array}$ & $\begin{array}{l}-0.0117 \\
(0.0295)\end{array}$ & $\begin{array}{c}-0.121^{* * *} \\
(0.0333)\end{array}$ & $\begin{array}{c}-0.0505^{* *} \\
(0.0207)\end{array}$ & $\begin{array}{c}-0.0252 \\
(0.0542)\end{array}$ \\
\hline First stage F-statistic & $\geq 3470$ & $\geq 3641$ & $\geq 2555$ & $\geq 4004$ & $\geq 1593$ \\
\hline Observations & 331,311 & 648,312 & 296,586 & $1,177,647$ & 98,562 \\
\hline R-squared & 0.858 & 0.783 & 0.722 & 0.804 & 0.658 \\
\hline $\begin{array}{l}\text { Migration background } \\
\text { and local area } \\
\text { background }\end{array}$ & $\begin{array}{l}\text { at least one } \\
\text { Swedish }\end{array}$ & $\begin{array}{c}\text { both } \\
\text { immigrants }\end{array}$ & $\begin{array}{l}\text { low/medium } \\
\text { crime area }\end{array}$ & $\begin{array}{c}\text { high crime } \\
\text { area }\end{array}$ & \\
\hline \multicolumn{6}{|c|}{ Marginal effect of choice, relative to untreated cohorts, for: } \\
\hline Cohorts 1988-1990 & $\begin{array}{c}0.0723^{* * *} \\
(0.00698)\end{array}$ & $\begin{array}{c}0.0625^{* * *} \\
(0.0218)\end{array}$ & $\begin{array}{c}0.0648 * * * \\
(0.00489)\end{array}$ & $\begin{array}{c}0.0804^{* * *} \\
(0.0131)\end{array}$ & \\
\hline Cohorts 1985-1987 & $\begin{array}{c}0.0375 * * * \\
(0.00736)\end{array}$ & $\begin{array}{l}0.00675 \\
(0.0224)\end{array}$ & $\begin{array}{c}0.0384^{* * * *} \\
(0.00539)\end{array}$ & $\begin{array}{c}0.0220 \\
(0.0134)\end{array}$ & \\
\hline Cohorts 1982-1984 & $\begin{array}{l}-0.0181^{* *} \\
(0.00919)\end{array}$ & $\begin{array}{c}-0.0747 * * * \\
(0.0264)\end{array}$ & $\begin{array}{c}-0.0149 * * \\
(0.00681)\end{array}$ & $\begin{array}{l}-0.0288 \\
(0.0177)\end{array}$ & \\
\hline Cohorts 1979-1981 & $\begin{array}{l}-0.0207 \\
(0.0139)\end{array}$ & $\begin{array}{l}-0.00291 \\
(0.0340)\end{array}$ & $\begin{array}{l}0.00314 \\
(0.0105)\end{array}$ & $\begin{array}{c}-0.0527 * * \\
(0.0215)\end{array}$ & \\
\hline Cohorts 1977-1978 & $\begin{array}{c}-0.0597 * * * \\
(0.0212)\end{array}$ & $\begin{array}{l}-0.0621 \\
(0.0589)\end{array}$ & $\begin{array}{c}-0.0623 * * * \\
(0.0225)\end{array}$ & $\begin{array}{l}-0.0539 * \\
(0.0291)\end{array}$ & \\
\hline First stage F-statistic & $\geq 3686$ & $\geq 1859$ & $\geq 3532$ & $\geq 1767$ & \\
\hline Observations & $1,184,916$ & 91,293 & $1,040,647$ & 209,129 & \\
\hline R-squared & 0.802 & 0.746 & 0.799 & 0.792 & \\
\hline
\end{tabular}




\subsubsection{Tables reporting additional descriptive statistics and analyses}

This subsection presents, for reporting purposes, tables including more detailed descriptive statistics (in Section 8.1.7.1) and additional estimation results relating to the analyses in the main body of the text (in Section 8.1.7.2). 


\subsubsection{Descriptive Statistics}

Table 25: Descriptive statistics on covariates included in the estimation

\begin{tabular}{|c|c|c|c|}
\hline & Mean & Std. Dev. & Median \\
\hline \multicolumn{4}{|l|}{ Municipality level variables } \\
\hline Population density & 392.35 & 876.36 & 64.00 \\
\hline $\begin{array}{l}\text { Average taxable income in year t-2 in } 100 \text { SEK, deflated } \\
\text { to } 2006\end{array}$ & 1079.05 & 153.39 & 1067.89 \\
\hline Urban municipality & 0.54 & 0.50 & \\
\hline \multicolumn{4}{|l|}{ Parish level variables } \\
\hline Share of 16--64 year olds born in Sweden & 0.89 & 0.08 & 0.92 \\
\hline Average yearly earnings of 20--64 year olds in 100 SEK & 1140.46 & 224.25 & 1150.94 \\
\hline Share of 20-64 year olds with university degree & 0.20 & 0.09 & 0.18 \\
\hline Share of 20-64 year olds that are employed & 0.83 & 0.04 & 0.84 \\
\hline $\begin{array}{l}\text { Population density of } 7--15 \text { year olds in lower quartile of } \\
\text { distribution }\end{array}$ & 0.09 & 0.28 & \\
\hline $\begin{array}{l}\text { Population density of 7--15 year olds in highest quartile of } \\
\text { distribution }\end{array}$ & 0.64 & 0.48 & \\
\hline \multicolumn{4}{|l|}{ Individual level variables } \\
\hline Household income in 1000 SEK, deflated to 2006 & 373.77 & 382.38 & 350.00 \\
\hline Household received welfare & 0.06 & 0.24 & \\
\hline Age of mother at birth & 27.78 & 5.05 & 27.00 \\
\hline Single parent household & 0.22 & 0.42 & \\
\hline Number of children & 2.23 & 1.01 & 2.00 \\
\hline Only child & 0.23 & 0.42 & \\
\hline Child born in Sweden & 0.96 & 0.19 & \\
\hline Mother born in Sweden & 0.89 & 0.32 & \\
\hline Mother born in Scandinavia, outside of Sweden & 0.05 & 0.21 & \\
\hline $\begin{array}{l}\text { Mother born in western Europe, North America or } \\
\text { Australia }\end{array}$ & 0.01 & 0.10 & \\
\hline Father born in Sweden & 0.88 & 0.32 & \\
\hline Father born in Scandinavia, outside of Sweden & 0.04 & 0.19 & \\
\hline $\begin{array}{l}\text { Father born in western Europe, North America or } \\
\text { Australia }\end{array}$ & 0.02 & 0.13 & \\
\hline Mother has university degree & 0.31 & 0.46 & \\
\hline Mother's highest degree is from secondary education & 0.49 & 0.50 & \\
\hline Father has university degree & 0.27 & 0.44 & \\
\hline Father's highest degree is from secondary education & 0.46 & 0.50 & \\
\hline Number of observations: 1756681 & & & \\
\hline
\end{tabular}


The following tables repeat the information discussed in Section 4.2, but additionally contain the standard deviation and number of observations in the different subgroups.

Table 26: Descriptive statistics on outcome variables, separately for different household income groups

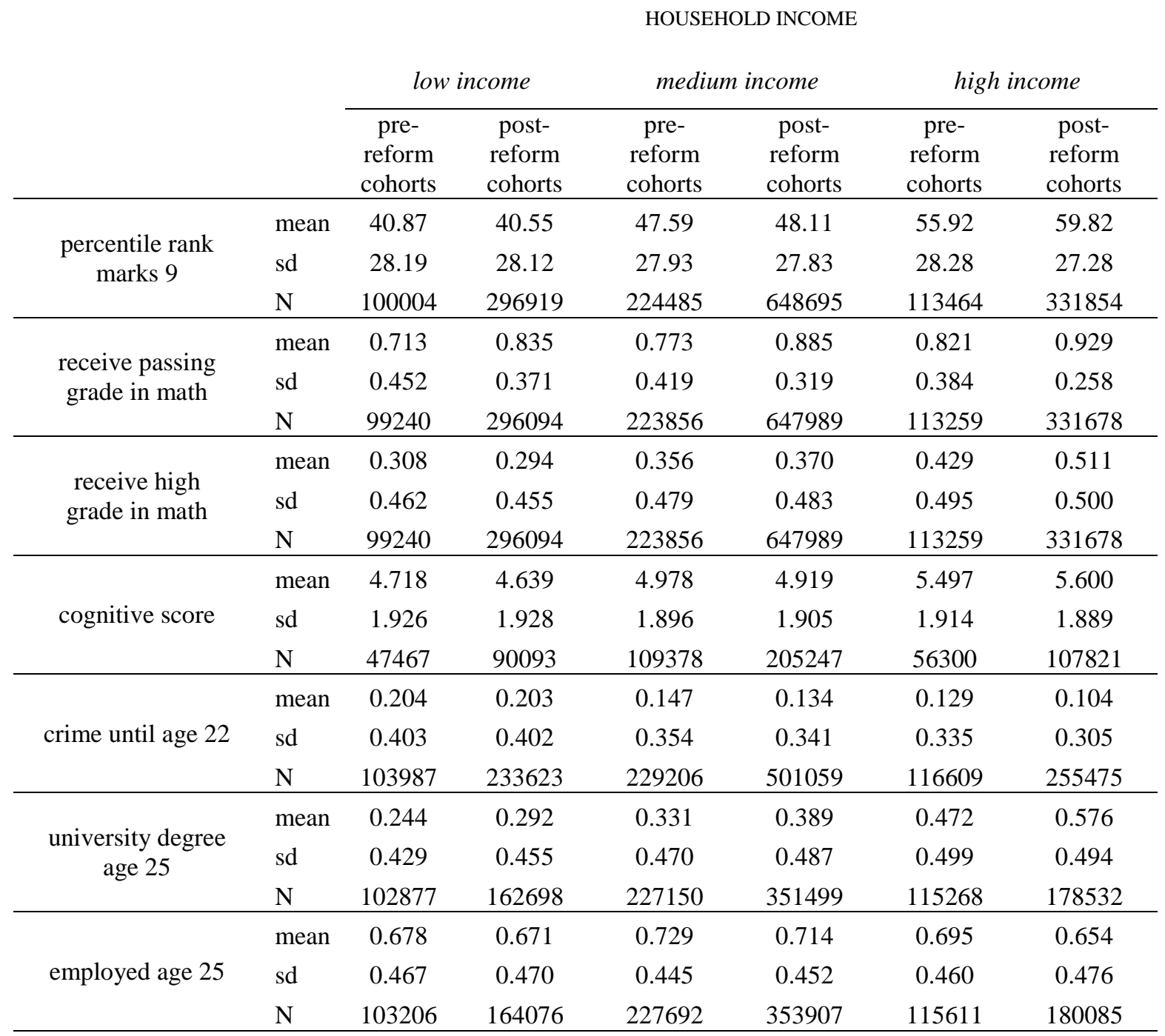

Note: Sample contains only observations with full information on all covariates $X$ given below Table 5 . 
Table 27: Descriptive statistics on outcome variables, separately for different levels of parental education

EDUCATIONAL BACKGROUND OF PARENTS

\begin{tabular}{|c|c|c|c|c|c|}
\hline & & \multicolumn{2}{|c|}{ compulsory schooling } & \multicolumn{2}{|c|}{$\begin{array}{c}\text { more than compulsory } \\
\text { schooling }\end{array}$} \\
\hline & & $\begin{array}{l}\text { pre-reform } \\
\text { cohorts }\end{array}$ & $\begin{array}{c}\text { post-reform } \\
\text { cohorts }\end{array}$ & $\begin{array}{c}\text { pre-reform } \\
\text { cohorts }\end{array}$ & $\begin{array}{c}\text { post-reform } \\
\text { cohorts }\end{array}$ \\
\hline \multirow{3}{*}{$\begin{array}{l}\text { percentile rank marks } \\
\qquad 9\end{array}$} & mean & 36.37 & 34.01 & 50.34 & 50.68 \\
\hline & sd & 26.55 & 25.80 & 28.41 & 28.44 \\
\hline & $\mathrm{N}$ & 66721 & 98619 & 371232 & $1.179 \mathrm{e}+06$ \\
\hline \multirow{3}{*}{$\begin{array}{l}\text { receive passing grade } \\
\text { in math }\end{array}$} & mean & 0.684 & 0.763 & 0.788 & 0.895 \\
\hline & sd & 0.465 & 0.426 & 0.409 & 0.307 \\
\hline & $\mathrm{N}$ & 66284 & 98180 & 370071 & $1.178 \mathrm{e}+06$ \\
\hline \multirow{3}{*}{$\begin{array}{l}\text { receive high grade in } \\
\text { math }\end{array}$} & mean & 0.275 & 0.220 & 0.380 & 0.403 \\
\hline & sd & 0.447 & 0.414 & 0.485 & 0.491 \\
\hline & $\mathrm{N}$ & 66284 & 98180 & 370071 & $1.178 \mathrm{e}+06$ \\
\hline \multirow{3}{*}{ cognitive score } & mean & 4.142 & 3.997 & 5.218 & 5.137 \\
\hline & sd & 1.818 & 1.801 & 1.902 & 1.922 \\
\hline & $\mathrm{N}$ & 31801 & 34827 & 181344 & 368334 \\
\hline \multirow{3}{*}{ crime until age 22} & mean & 0.186 & 0.201 & 0.150 & 0.137 \\
\hline & sd & 0.389 & 0.401 & 0.357 & 0.344 \\
\hline & $\mathrm{N}$ & 69070 & 89864 & 380732 & 900293 \\
\hline \multirow{3}{*}{$\begin{array}{l}\text { university degree age } \\
25\end{array}$} & mean & 0.159 & 0.191 & 0.381 & 0.440 \\
\hline & sd & 0.366 & 0.393 & 0.486 & 0.496 \\
\hline & $\mathrm{N}$ & 68456 & 71130 & 376839 & 621599 \\
\hline \multirow{3}{*}{ employed age 25} & mean & 0.740 & 0.728 & 0.702 & 0.684 \\
\hline & sd & 0.439 & 0.445 & 0.457 & 0.465 \\
\hline & $\mathrm{N}$ & 68738 & 72153 & 377771 & 625915 \\
\hline
\end{tabular}

Note: Sample contains only observations with full information on all covariates $X$ given below Table 5 . 
Table 28: Descriptive statistics on outcome variables, separately for different parental migration backgrounds

PARENTAL MIGRATION BACKGROUND

\begin{tabular}{|c|c|c|c|c|c|}
\hline & & \multicolumn{2}{|c|}{ both immigrants } & \multicolumn{2}{|c|}{ at least one is Swedish } \\
\hline & & $\begin{array}{l}\text { pre-reform } \\
\text { cohorts }\end{array}$ & $\begin{array}{l}\text { post-reform } \\
\text { cohorts }\end{array}$ & $\begin{array}{c}\text { pre-reform } \\
\text { cohorts }\end{array}$ & $\begin{array}{l}\text { post-reform } \\
\text { cohorts }\end{array}$ \\
\hline \multirow{3}{*}{$\begin{array}{l}\text { percentile rank } \\
\text { marks } 9\end{array}$} & mean & 43.00 & 44.42 & 48.52 & 49.78 \\
\hline & sd & 28.63 & 28.94 & 28.54 & 28.53 \\
\hline & $\mathrm{N}$ & 24390 & 91560 & 413563 & $1.186 \mathrm{e}+06$ \\
\hline \multirow{3}{*}{$\begin{array}{l}\text { receive passing grade } \\
\text { in math }\end{array}$} & mean & 0.686 & 0.824 & 0.777 & 0.889 \\
\hline & sd & 0.464 & 0.381 & 0.416 & 0.314 \\
\hline & $\mathrm{N}$ & 24152 & 91293 & 412203 & $1.184 \mathrm{e}+06$ \\
\hline \multirow{3}{*}{$\begin{array}{l}\text { receive high grade in } \\
\text { math }\end{array}$} & mean & 0.276 & 0.304 & 0.369 & 0.396 \\
\hline & sd & 0.447 & 0.460 & 0.483 & 0.489 \\
\hline & $\mathrm{N}$ & 24152 & 91293 & 412203 & $1.184 \mathrm{e}+06$ \\
\hline \multirow{3}{*}{ cognitive score } & mean & 4.197 & 4.201 & 5.100 & 5.095 \\
\hline & sd & 1.966 & 1.924 & 1.917 & 1.927 \\
\hline & $\mathrm{N}$ & 10017 & 25427 & 203128 & 377734 \\
\hline \multirow{3}{*}{ crime until age 22} & mean & 0.242 & 0.226 & 0.150 & 0.136 \\
\hline & sd & 0.428 & 0.418 & 0.357 & 0.343 \\
\hline & $\mathrm{N}$ & 25883 & 74372 & 423919 & 915785 \\
\hline \multirow{3}{*}{$\begin{array}{l}\text { university degree age } \\
\qquad 25\end{array}$} & mean & 0.249 & 0.346 & 0.353 & 0.420 \\
\hline & sd & 0.432 & 0.476 & 0.478 & 0.494 \\
\hline & $\mathrm{N}$ & 25444 & 51737 & 419851 & 640992 \\
\hline \multirow{3}{*}{ employed age 25} & mean & 0.631 & 0.607 & 0.713 & 0.695 \\
\hline & sd & 0.482 & 0.488 & 0.452 & 0.460 \\
\hline & $\mathrm{N}$ & 25577 & 52375 & 420932 & 645693 \\
\hline
\end{tabular}

Note: Sample contains only observations with full information on all covariates $X$ given below Table 5. 
Table 29: Descriptive statistics on outcome variables, separately for different levels of youth crime in the local area in 1990-91

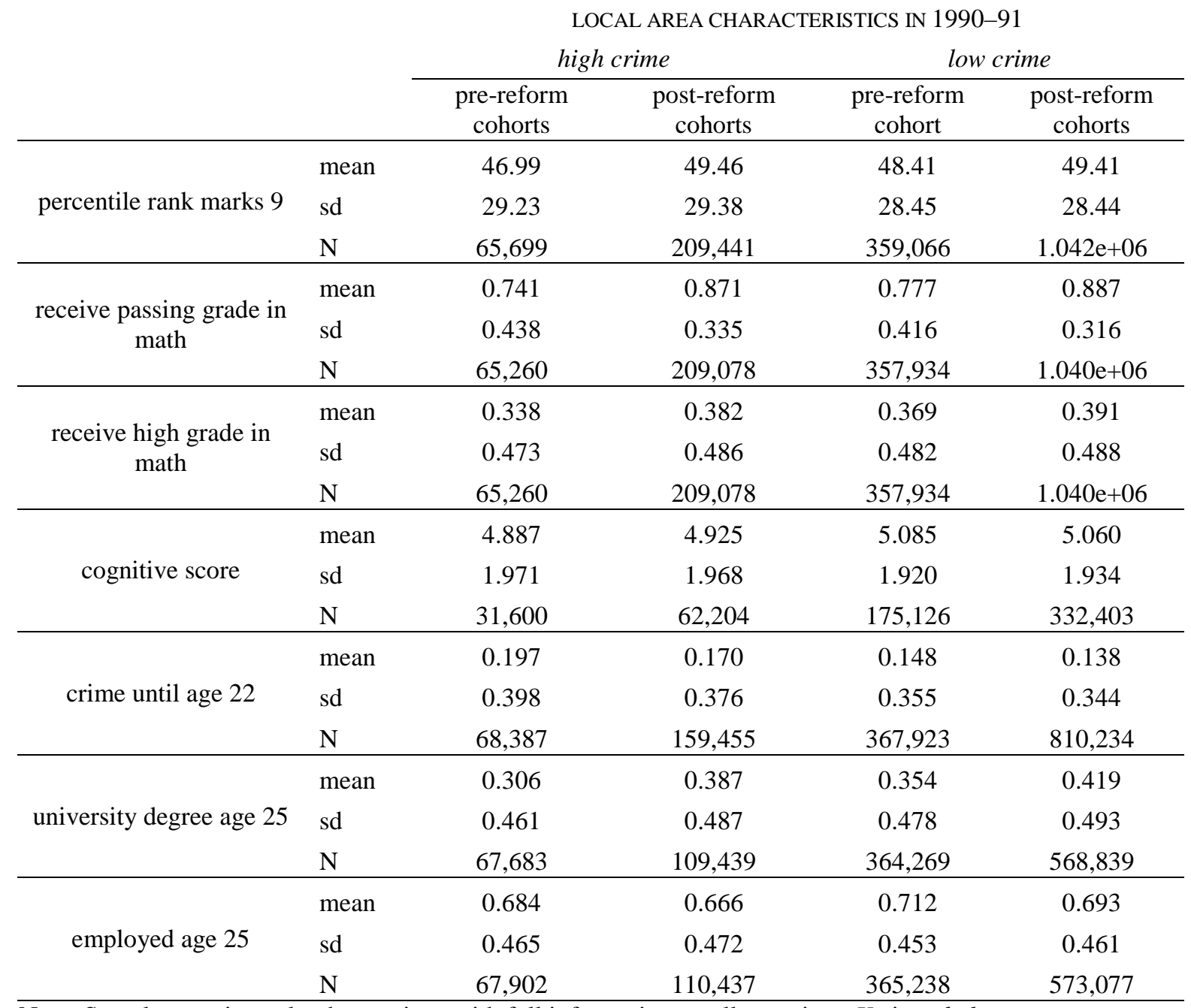

Note: Sample contains only observations with full information on all covariates $X$ given below Table 5 .

\subsubsection{Tables on subgroup analyses for later outcomes}

The following section presents additional tables on the results of the effects of more school choice through having many schools nearby just before the reform. Thus, as regards the structure, the tables are similar to those discussed in Section 6.2. The next subsection includes results from using the choice measure that counts the number of schools within the median commuting distance of the home municipality around a student's home in 1991, the subsequent one presents those using a radius of $2 \mathrm{~km}$ instead. 


\section{Using the choice measure "number of schools within median commuting distance"}

Table 30: Effect of choice on education and employment at age $\mathbf{2 5}$ for different household income subgroups; choice radius "median commuting distance"

\begin{tabular}{|c|c|c|c|c|c|c|}
\hline $\begin{array}{l}\text { INDEPENDENT } \\
\text { VARIABLE }\end{array}$ & \multicolumn{3}{|c|}{$\underline{\text { UNIVERSITY DEGREE AT AGE } 25}$} & \multicolumn{3}{|c|}{$\underline{\text { EMPLOYED AT AGE } 25}$} \\
\hline Household income: & low income & $\begin{array}{l}\text { medium } \\
\text { income }\end{array}$ & $\begin{array}{c}\text { high } \\
\text { income }\end{array}$ & low income & $\begin{array}{l}\text { medium } \\
\text { income }\end{array}$ & $\begin{array}{c}\text { high } \\
\text { income }\end{array}$ \\
\hline \multicolumn{7}{|c|}{ Marginal effect of choice, relative to untreated cohorts for: } \\
\hline Cohorts 1982-1984 & $\begin{array}{c}0.00174 * * * \\
(0.000454)\end{array}$ & $\begin{array}{c}0.00186 * * * \\
(0.000404)\end{array}$ & $\begin{array}{c}0.000604 \\
(0.000507)\end{array}$ & $\begin{array}{c}0.00149 * * * \\
(0.000476)\end{array}$ & $\begin{array}{l}0.000671 * \\
(0.000375)\end{array}$ & $\begin{array}{c}0.000237 \\
(0.000465)\end{array}$ \\
\hline Cohorts 1979-1981 & $\begin{array}{l}0.000840 * \\
(0.000497)\end{array}$ & $\begin{array}{c}0.000531 \\
(0.000425)\end{array}$ & $\begin{array}{l}-0.000740 \\
(0.000528)\end{array}$ & $\begin{array}{l}0.00114^{* *} \\
(0.000490)\end{array}$ & $\begin{array}{l}0.000716 * \\
(0.000398)\end{array}$ & $\begin{array}{c}0.000138 \\
(0.000485)\end{array}$ \\
\hline Cohorts 1977-1978 & $\begin{array}{l}-0.000917 \\
(0.000607)\end{array}$ & $\begin{array}{c}0.000145 \\
(0.000545)\end{array}$ & $\begin{array}{l}-0.00119 * \\
(0.000658)\end{array}$ & $\begin{array}{c}0.000922 \\
(0.000598)\end{array}$ & $\begin{array}{l}-0.000128 \\
(0.000483)\end{array}$ & $\begin{array}{l}-0.000569 \\
(0.000605)\end{array}$ \\
\hline $\begin{array}{l}\text { Untreated cohorts } \\
(1972-1976)\end{array}$ & $\begin{array}{c}-0.000758 * \\
(0.000451)\end{array}$ & $\begin{array}{l}-0.000301 \\
(0.000405)\end{array}$ & $\begin{array}{c}0.000219 \\
(0.000517)\end{array}$ & $\begin{array}{l}-0.0024 * * * \\
(0.000487)\end{array}$ & $\begin{array}{l}-0.0012 * * * \\
(0.000387)\end{array}$ & $\begin{array}{l}-0.000467 \\
(0.000473)\end{array}$ \\
\hline Placebo Test & pass & fail & fail & fail & fail & pass \\
\hline Observations & 259,062 & 571,525 & 289,872 & 259,226 & 571,687 & 289,932 \\
\hline R-squared ${ }^{\ddagger}$ & 0.0936 & 0.0917 & 0.134 & 0.0254 & 0.0271 & 0.0405 \\
\hline
\end{tabular}


Table 31: Effect of choice on probability of committing a crime until age 22 and education and employment at age $\mathbf{2 5}$ for different parental education levels; choice radius "median commuting distance"

\begin{tabular}{|c|c|c|c|c|c|c|}
\hline $\begin{array}{l}\text { INDEPENDENT } \\
\text { VARIABLE }\end{array}$ & \multicolumn{2}{|c|}{ CRIME AGE 22} & \multicolumn{2}{|c|}{$\underline{\text { UNIVERSITY DEGREE AGE } 25}$} & \multicolumn{2}{|c|}{$\underline{\text { EMPLOYED AGE } 25}$} \\
\hline $\begin{array}{l}\text { Parental education } \\
\text { is... }\end{array}$ & $\begin{array}{l}\text { more than } \\
\text { compulsory }\end{array}$ & compulsory & $\begin{array}{c}\text { more than } \\
\text { compulsory } t\end{array}$ & compulsory & $\begin{array}{l}\text { more than } \\
\text { compulsory }\end{array}$ & compulsory \\
\hline \multicolumn{7}{|c|}{ Marginal effect of choice, relative to untreated cohorts for: } \\
\hline Cohorts 1985-1987 & $\begin{array}{c}-0.00054 * * * \\
(0.000197)\end{array}$ & $\begin{array}{l}-0.000811 \\
(0.000600)\end{array}$ & & & & \\
\hline Cohorts 1982-1984 & $\begin{array}{c}-0.00063 * * * \\
(0.000201)\end{array}$ & $\begin{array}{l}-0.00122 * * \\
(0.000581)\end{array}$ & $\begin{array}{c}0.00134 * * * \\
(0.000313)\end{array}$ & $\begin{array}{c}0.00229 * * * \\
(0.000612)\end{array}$ & $\begin{array}{c}0.000416 \\
(0.000273)\end{array}$ & $\begin{array}{c}0.00295 * * * \\
(0.000698)\end{array}$ \\
\hline Cohorts 1979-1981 & $\begin{array}{c}-0.000431 * * \\
(0.000216)\end{array}$ & $\begin{array}{l}-0.0022 * * * \\
(0.000623)\end{array}$ & $\begin{array}{c}0.0001 \\
(0.000329)\end{array}$ & $\begin{array}{c}0.00171 * * * \\
(0.000656)\end{array}$ & $\begin{array}{c}0.000348 \\
(0.000296)\end{array}$ & $\begin{array}{c}0.00251^{* * *} \\
(0.000731)\end{array}$ \\
\hline Cohorts 1977-1978 & $\begin{array}{c}0.000129 \\
(0.000287) \\
\end{array}$ & $\begin{array}{c}-0.00159 * * \\
(0.000745)\end{array}$ & $\begin{array}{c}-0.000708 * \\
(0.000414)\end{array}$ & $\begin{array}{c}0.000949 \\
(0.000848)\end{array}$ & $\begin{array}{l}-0.000179 \\
(0.000343)\end{array}$ & $\begin{array}{c}0.00136 \\
(0.000909)\end{array}$ \\
\hline $\begin{array}{l}\text { Untreated cohorts } \\
(1972-1976)\end{array}$ & $\begin{array}{c}0.000728^{* * *} \\
(0.000201)\end{array}$ & $\begin{array}{c}0.000879 \\
(0.000585)\end{array}$ & $\begin{array}{l}-0.000153 \\
(0.000312)\end{array}$ & $\begin{array}{l}-0.000841 \\
(0.000603)\end{array}$ & $\begin{array}{l}-0.0009 * * * \\
(0.000279)\end{array}$ & $\begin{array}{l}-0.0033^{* * *} \\
(0.000712)\end{array}$ \\
\hline Placebo Test & pass & pass & fail & pass & fail & pass \\
\hline Observations & $1,255,800$ & 153,292 & 984,366 & 136,093 & 984,638 & 136,207 \\
\hline R-squared ${ }^{\ddagger}$ & 0.0364 & 0.0366 & 0.114 & 0.0374 & 0.0293 & 0.0339 \\
\hline
\end{tabular}


Table 32: Effect of choice on probability of committing a crime until age 22 and education and employment at age 25 for different parental migration backgrounds; choice radius "median commuting distance"

\begin{tabular}{|c|c|c|c|c|c|c|}
\hline \multirow{2}{*}{$\begin{array}{l}\text { INDEPENDENT } \\
\text { VARIABLE } \\
\text { Parental migration } \\
\text { background }\end{array}$} & \multicolumn{2}{|c|}{ CRIME AGE 22} & \multicolumn{2}{|c|}{ UNIVERSITY DEGREE AGE 25} & \multicolumn{2}{|c|}{ EMPLOYED AGE 25} \\
\hline & $\begin{array}{l}\text { at least one } \\
\text { Swedish }\end{array}$ & $\begin{array}{c}\text { both } \\
\text { immigrants }\end{array}$ & $\begin{array}{l}\text { at least one } \\
\text { Swedish } t\end{array}$ & $\begin{array}{c}\text { both } \\
\text { immigrants }\end{array}$ & $\begin{array}{l}\text { at least one } \\
\text { Swedish }\end{array}$ & $\begin{array}{l}\text { both } \\
\text { immigrants }\end{array}$ \\
\hline \multicolumn{7}{|c|}{ Marginal effect of choice, relative to untreated cohorts for: } \\
\hline Cohorts 1985-1987 & $\begin{array}{c}-0.000475 * * \\
(0.000194)\end{array}$ & $\begin{array}{c}-0.00106 \\
(0.000784)\end{array}$ & & & & \\
\hline Cohorts 1982-1984 & $\begin{array}{c}-0.000508 * * \\
(0.000197)\end{array}$ & $\begin{array}{l}-0.00181^{* *} \\
(0.000790)\end{array}$ & $\begin{array}{c}0.000852 * * * \\
(0.000308)\end{array}$ & $\begin{array}{c}0.00215 * * * \\
(0.000804)\end{array}$ & $\begin{array}{l}0.000520 * \\
(0.000270)\end{array}$ & $\begin{array}{c}0.00124 \\
(0.000887)\end{array}$ \\
\hline Cohorts 1979-1981 & $\begin{array}{l}-0.000372 * \\
(0.000215)\end{array}$ & $\begin{array}{l}-0.00208^{* *} \\
(0.000835)\end{array}$ & $\begin{array}{l}-0.000251 \\
(0.000327)\end{array}$ & $\begin{array}{c}0.00128 \\
(0.000836)\end{array}$ & $\begin{array}{l}0.000496 * \\
(0.000292)\end{array}$ & $\begin{array}{c}0.000833 \\
(0.000930)\end{array}$ \\
\hline Cohorts 1977-1978 & $\begin{array}{c}0.000189 \\
(0.000280)\end{array}$ & $\begin{array}{l}-0.00156 \\
(0.00100)\end{array}$ & $\begin{array}{l}-0.000747 * \\
(0.000419)\end{array}$ & $\begin{array}{l}0.000721 \\
(0.00105)\end{array}$ & $\begin{array}{l}-0.000182 \\
(0.000345)\end{array}$ & $\begin{array}{l}0.000888 \\
(0.00117)\end{array}$ \\
\hline $\begin{array}{l}\text { Untreated cohorts } \\
(1972-1976)\end{array}$ & $\begin{array}{c}0.000607 * * * \\
(0.000199)\end{array}$ & $\begin{array}{c}0.00142 * \\
(0.000787)\end{array}$ & $\begin{array}{c}0.000252 \\
(0.000309)\end{array}$ & $\begin{array}{l}-0.000779 \\
(0.000812)\end{array}$ & $\begin{array}{l}-0.0011^{* * *} \\
(0.000276)\end{array}$ & $\begin{array}{c}-0.00120 \\
(0.000899)\end{array}$ \\
\hline Placebo Test & pass & pass & fail & pass & fail & pass \\
\hline Observations & $1,313,155$ & 95,925 & $1,045,998$ & 74,437 & $1,046,309$ & 74,523 \\
\hline R-squared ${ }^{\ddagger}$ & 0.0355 & 0.0319 & 0.128 & 0.103 & 0.0291 & 0.0300 \\
\hline
\end{tabular}

Notes: Robust standard errors in parentheses. Statistical significance at 1,5 and $10 \%$ level is denoted by $* * *, * *, *$. For a complete list of included covariates see Table 5. The definition of the placebo tests is explained in Section 5.1. $\ddagger$ Pseudo Rsquared for binary outcomes. † For the outcome "receiving a high grade", we left out household income and its squared term to achieve convergence. 
Table 33: Effect of choice on probability of committing a crime until age 22 and education and employment at age 25 for local areas with high or low/medium youth crime levels; choice radius "median commuting distance"

\begin{tabular}{|c|c|c|c|c|c|c|}
\hline $\begin{array}{l}\text { INDEPENDENT } \\
\text { VARIABLE }\end{array}$ & CRIME & AGE 22 & $\frac{\text { UNIVERSITY }}{2}$ & $\frac{\text { DEGREE AGE }}{2}$ & EMPLOYE & AGE 25 \\
\hline $\begin{array}{l}\text { Local area } \\
\text { characteristics } \\
\text { 1990-91 }\end{array}$ & $\begin{array}{c}\text { low/medium } \\
\text { crime }\end{array}$ & high crime & $\begin{array}{c}\text { low/medium } \\
\text { crime }\end{array}$ & high crime & $\begin{array}{c}\text { low/medium } \\
\text { crime }\end{array}$ & high crime \\
\hline \multicolumn{7}{|c|}{ Marginal effect of choice, relative to untreated cohorts for: } \\
\hline Cohorts 1985-1987 & $\begin{array}{l}-0.00049 * * \\
(0.000245)\end{array}$ & $\begin{array}{c}0.000283 \\
(0.000401)\end{array}$ & & & & \\
\hline Cohorts 1982-1984 & $\begin{array}{l}-0.00055 * * \\
(0.000250)\end{array}$ & $\begin{array}{c}0.000031 \\
(0.000392)\end{array}$ & $\begin{array}{c}0.000073 \\
(0.000391)\end{array}$ & $\begin{array}{c}0.00209 * * * \\
(0.000471)\end{array}$ & $\begin{array}{l}0.000653^{*} \\
(0.000352)\end{array}$ & $\begin{array}{c}0.000275 \\
(0.000466)\end{array}$ \\
\hline Cohorts 1979-1981 & $\begin{array}{l}-0.000425 \\
(0.000268)\end{array}$ & $\begin{array}{l}-0.000092 \\
(0.000420)\end{array}$ & $\begin{array}{l}-0.00086 * * \\
(0.000395)\end{array}$ & $\begin{array}{l}0.000971 * \\
(0.000509)\end{array}$ & $\begin{array}{l}0.000687^{*} \\
(0.000369)\end{array}$ & $\begin{array}{l}-0.000063 \\
(0.000503)\end{array}$ \\
\hline Cohorts 1977-1978 & $\begin{array}{c}0.000504 \\
(0.000367)\end{array}$ & $\begin{array}{c}0.000264 \\
(0.000492)\end{array}$ & $\begin{array}{c}-0.00139 * * \\
(0.000595)\end{array}$ & $\begin{array}{c}0.000412 \\
(0.000585)\end{array}$ & $\begin{array}{l}-0.000666 \\
(0.000486)\end{array}$ & $\begin{array}{l}-0.000201 \\
(0.000518) \\
\end{array}$ \\
\hline $\begin{array}{l}\text { Untreated cohorts } \\
(1972-1976)\end{array}$ & $\begin{array}{c}0.000554^{* *} \\
(0.000254)\end{array}$ & $\begin{array}{l}-0.000121 \\
(0.000385)\end{array}$ & $\begin{array}{c}0.00115^{* * *} \\
(0.000404)\end{array}$ & $\begin{array}{c}-0.0026 * * * \\
(0.000414)\end{array}$ & $\begin{array}{c}-0.0011^{* * *} \\
(0.000368)\end{array}$ & $\begin{array}{l}-0.000582 \\
(0.000465)\end{array}$ \\
\hline Placebo Test & pass & pass & fail & pass & pass & pass \\
\hline Observations & $1,154,475$ & 221,285 & 919,955 & 173,060 & 920,240 & 173,157 \\
\hline R-squared ${ }^{\ddagger}$ & 0.0359 & 0.0407 & 0.125 & 0.132 & 0.0302 & 0.0278 \\
\hline
\end{tabular}


Using the choice measure "number of schools within $2 \mathbf{k m}$

Table 34: Effect of choice on percentile rank in marks and cognitive skills for different household income subgroups; choice radius $2 \mathbf{k m}$

\begin{tabular}{|c|c|c|c|c|c|c|}
\hline \multirow{2}{*}{$\begin{array}{l}\text { INDEPENDENT } \\
\text { VARIABLE } \\
\text { Household income: }\end{array}$} & \multicolumn{3}{|c|}{$\underline{\text { PERCENTILE RANK MARKS }}$} & \multicolumn{3}{|c|}{$\underline{\text { COGNITIVE SCORE }}$} \\
\hline & low income & $\begin{array}{c}\text { medium } \\
\text { income }\end{array}$ & $\begin{array}{c}\text { high } \\
\text { income }\end{array}$ & low income & $\begin{array}{l}\text { medium } \\
\text { income }\end{array}$ & $\begin{array}{c}\text { high } \\
\text { income }\end{array}$ \\
\hline \multicolumn{7}{|c|}{ Marginal effect of choice, relative to untreated cohorts for: } \\
\hline Cohorts 1988-1990 & $\begin{array}{c}0.536 * * * \\
(0.0924)\end{array}$ & $\begin{array}{c}0.294 * * * \\
(0.0740)\end{array}$ & $\begin{array}{l}0.199 * * \\
(0.0822)\end{array}$ & & & \\
\hline Cohorts 1985-1987 & $\begin{array}{l}0.403^{* * *} \\
(0.0949)\end{array}$ & $\begin{array}{l}-0.0536 \\
(0.0796)\end{array}$ & $\begin{array}{c}0.0289 \\
(0.0895)\end{array}$ & $\begin{array}{c}0.0397 * * * \\
(0.00945)\end{array}$ & $\begin{array}{c}0.0216 * * * \\
(0.00718)\end{array}$ & $\begin{array}{l}-0.00189 \\
(0.00871)\end{array}$ \\
\hline Cohorts 1982-1984 & $\begin{array}{c}0.0995 \\
(0.0989)\end{array}$ & $\begin{array}{l}-0.157 * \\
(0.0803)\end{array}$ & $\begin{array}{l}-0.201^{* *} \\
(0.0937)\end{array}$ & $\begin{array}{l}0.0210^{* *} \\
(0.00973)\end{array}$ & $\begin{array}{l}0.0208 * * * \\
(0.00719)\end{array}$ & $\begin{array}{c}-0.0144 \\
(0.00895)\end{array}$ \\
\hline Cohorts 1979-1981 & $\begin{array}{c}0.158 \\
(0.0989)\end{array}$ & $\begin{array}{l}-0.0316 \\
(0.0802)\end{array}$ & $\begin{array}{c}-0.336 * * * \\
(0.0998)\end{array}$ & $\begin{array}{l}0.0370 * * * \\
(0.00942)\end{array}$ & $\begin{array}{c}0.0132 * \\
(0.00723)\end{array}$ & $\begin{array}{l}-0.0195 * * \\
(0.00894)\end{array}$ \\
\hline Cohorts 1977-1978 & $\begin{array}{l}-0.0974 \\
(0.105)\end{array}$ & $\begin{array}{l}-0.0213 \\
(0.0891)\end{array}$ & $\begin{array}{c}-0.243^{* *} \\
(0.109)\end{array}$ & $\begin{array}{c}0.0338 * * * \\
(0.0108)\end{array}$ & $\begin{array}{c}0.00823 \\
(0.00839)\end{array}$ & $\begin{array}{l}0.000851 \\
(0.00983)\end{array}$ \\
\hline $\begin{array}{l}\text { Untreated cohorts } \\
(1972-1976)\end{array}$ & $\begin{array}{l}-0.0654 \\
(0.0685)\end{array}$ & $\begin{array}{c}0.104 * \\
(0.0547)\end{array}$ & $\begin{array}{l}0.320 * * * \\
(0.0648)\end{array}$ & $\begin{array}{c}-0.0259 * * * \\
(0.00670)\end{array}$ & $\begin{array}{c}-0.0145^{* * *} \\
(0.00514)\end{array}$ & $\begin{array}{c}0.00520 \\
(0.00639)\end{array}$ \\
\hline Placebo Test & pass & pass & fail & pass & pass & pass \\
\hline Observations & 396,923 & 873,180 & 445,318 & 135,210 & 312,206 & 162,766 \\
\hline R-squared ${ }^{\ddagger}$ & 0.138 & 0.131 & 0.182 & 0.113 & 0.113 & 0.154 \\
\hline
\end{tabular}


Table 35: Effect of choice on probability of receiving a high or passing grade in math for different household income subgroups; choice radius $2 \mathbf{k m}$

\begin{tabular}{|c|c|c|c|c|c|c|}
\hline \multirow{2}{*}{$\begin{array}{l}\text { INDEPENDENT } \\
\text { VARIABLE } \\
\text { Household income: }\end{array}$} & \multicolumn{3}{|c|}{$\underline{\text { RECEIVING A HIGH GRADE IN MATH }}$} & \multicolumn{3}{|c|}{$\underline{\text { RECEIVING A PASSING GRADE IN MATH }}$} \\
\hline & low income & $\begin{array}{l}\text { medium } \\
\text { income }\end{array}$ & $\begin{array}{c}\text { high } \\
\text { income }\end{array}$ & low income & $\begin{array}{l}\text { medium } \\
\text { income }\end{array}$ & $\begin{array}{c}\text { high } \\
\text { income }\end{array}$ \\
\hline \multicolumn{7}{|c|}{ Marginal effect of choice, relative to untreated cohorts for: } \\
\hline Cohorts $1988-1990$ & $\begin{array}{c}0.0105 * * * \\
(0.00153)\end{array}$ & $\begin{array}{c}0.00715^{* * *} \\
(0.00134)\end{array}$ & $\begin{array}{c}0.00693 * * * \\
(0.00167)\end{array}$ & $\begin{array}{l}0.000156 \\
(0.00131)\end{array}$ & $\begin{array}{l}-0.000122 \\
(0.000940)\end{array}$ & $\begin{array}{c}-0.00148 \\
(0.000951)\end{array}$ \\
\hline Cohorts 1985-1987 & $\begin{array}{c}0.00784 * * * \\
(0.00162)\end{array}$ & $\begin{array}{c}0.00370 * * * \\
(0.00136)\end{array}$ & $\begin{array}{c}0.00390 * * \\
(0.00179)\end{array}$ & $\begin{array}{l}-0.000992 \\
(0.00133)\end{array}$ & $\begin{array}{l}-0.00174 * \\
(0.000929)\end{array}$ & $\begin{array}{l}-0.00210^{* *} \\
(0.000946)\end{array}$ \\
\hline Cohorts 1982-1984 & $\begin{array}{c}0.00461 * * * \\
(0.00169)\end{array}$ & $\begin{array}{l}0.000515 \\
(0.00149)\end{array}$ & $\begin{array}{l}-0.000916 \\
(0.00180)\end{array}$ & $\begin{array}{l}-0.00108 \\
(0.00133)\end{array}$ & $\begin{array}{c}-0.00141 \\
(0.000911)\end{array}$ & $\begin{array}{c}-0.00114 \\
(0.000956)\end{array}$ \\
\hline Cohorts 1979-1981 & $\begin{array}{c}0.00159 \\
(0.00169)\end{array}$ & $\begin{array}{l}-0.00223 \\
(0.00143)\end{array}$ & $\begin{array}{c}-0.0056 * * * \\
(0.00191)\end{array}$ & $\begin{array}{c}0.00190 \\
(0.00170)\end{array}$ & $\begin{array}{c}0.00340 * * * \\
(0.00125)\end{array}$ & $\begin{array}{l}0.000278 \\
(0.00132)\end{array}$ \\
\hline Cohorts 1977-1978 & $\begin{array}{c}-0.0000 \\
(0.00194)\end{array}$ & $\begin{array}{l}-0.00137 \\
(0.00176)\end{array}$ & $\begin{array}{l}-0.00377^{*} \\
(0.00210)\end{array}$ & $\begin{array}{l}-0.00122 \\
(0.00196)\end{array}$ & $\begin{array}{c}-0.0001 \\
(0.00147)\end{array}$ & $\begin{array}{l}-0.000703 \\
(0.00152)\end{array}$ \\
\hline $\begin{array}{l}\text { Untreated cohorts } \\
(1972-1976)\end{array}$ & $\begin{array}{c}-0.00250 * * \\
(0.00122)\end{array}$ & $\begin{array}{l}-0.000675 \\
(0.00101)\end{array}$ & $\begin{array}{l}0.00328 * * \\
(0.00134)\end{array}$ & $\begin{array}{l}0.000454 \\
(0.00119)\end{array}$ & $\begin{array}{c}0.000565 \\
(0.000872)\end{array}$ & $\begin{array}{c}0.00166 * \\
(0.000931)\end{array}$ \\
\hline Placebo Test & fail & fail & pass & pass & pass & pass \\
\hline Observations & 395,334 & 871,845 & 444,937 & 395,334 & 871,845 & 444,937 \\
\hline R-squared ${ }^{\ddagger}$ & 0.0423 & 0.0410 & 0.0661 & 0.105 & 0.124 & 0.163 \\
\hline
\end{tabular}


Table 36: Effect of choice on probability of committing a crime until age 22 for different household income subgroups; choice radius $2 \mathbf{k m}$

\begin{tabular}{|c|c|c|c|}
\hline \multirow{2}{*}{$\begin{array}{l}\text { INDEPENDENT VARIABLE } \\
\text { Household income: }\end{array}$} & \multicolumn{3}{|c|}{ CRIME UNTIL AGE 22} \\
\hline & low income & medium income & high income \\
\hline \multicolumn{4}{|c|}{ Marginal effect of choice, relative to untreated cohorts for: } \\
\hline \multirow[t]{2}{*}{ Cohorts 1985-1987 } & $-0.00275^{* *}$ & 0.000760 & 0.00126 \\
\hline & $(0.00123)$ & $(0.000860)$ & $(0.000950)$ \\
\hline \multirow[t]{2}{*}{ Cohorts 1982-1984 } & $-0.00253 *$ & 0.000462 & 0.000729 \\
\hline & $(0.00134)$ & $(0.000899)$ & $(0.000998)$ \\
\hline \multirow[t]{2}{*}{ Cohorts 1979-1981 } & $-0.00287 * *$ & -0.000281 & $0.00178 *$ \\
\hline & $(0.00135)$ & $(0.000920)$ & $(0.00107)$ \\
\hline \multirow[t]{2}{*}{ Cohorts 1977-1978 } & 4.03e-05 & 0.00129 & 0.00159 \\
\hline & $(0.00161)$ & $(0.00105)$ & $(0.00119)$ \\
\hline Untreated cohorts & $0.00311^{* * *}$ & 0.000507 & -0.000851 \\
\hline$(1972-1976)$ & $(0.000958)$ & $(0.000690)$ & $(0.000758)$ \\
\hline Placebo Test & pass & pass & pass \\
\hline Observations & 326,904 & 717,262 & 364,926 \\
\hline R-squared ${ }^{\ddagger}$ & 0.0315 & 0.0304 & 0.0269 \\
\hline
\end{tabular}


Table 37: Effect of choice on education and employment at age $\mathbf{2 5}$ for different household income subgroups; choice radius $\mathbf{2 k m}$

\begin{tabular}{|c|c|c|c|c|c|c|}
\hline \multirow{2}{*}{$\begin{array}{l}\text { INDEPENDENT } \\
\text { VARIABLE } \\
\text { Household income: }\end{array}$} & \multicolumn{3}{|c|}{ UNIVERSITY DEGREE AT AGE 25} & \multicolumn{3}{|c|}{$\underline{\text { EMPLOYED AT AGE } 25}$} \\
\hline & low income & $\begin{array}{l}\text { medium } \\
\text { income }\end{array}$ & high income & low income & $\begin{array}{l}\text { medium } \\
\text { income }\end{array}$ & $\begin{array}{c}\text { high } \\
\text { income }\end{array}$ \\
\hline \multicolumn{7}{|c|}{ Marginal effect of choice, relative to untreated cohorts for: } \\
\hline Cohorts 1982-1984 & $\begin{array}{c}0.00868 * * * \\
(0.00153)\end{array}$ & $\begin{array}{c}0.00728 * * * \\
(0.00134)\end{array}$ & $\begin{array}{c}0.0001 \\
(0.00189)\end{array}$ & $\begin{array}{c}0.00420 * * * \\
(0.00155)\end{array}$ & $\begin{array}{c}0.00151 \\
(0.00116)\end{array}$ & $\begin{array}{c}0.00132 \\
(0.00152)\end{array}$ \\
\hline Cohorts 1979-1981 & $\begin{array}{c}0.00517 * * * \\
(0.00160)\end{array}$ & $\begin{array}{c}0.00444 * * * \\
(0.00137)\end{array}$ & $\begin{array}{c}-0.00376 * * \\
(0.00188)\end{array}$ & $\begin{array}{c}0.00144 \\
(0.00153)\end{array}$ & $\begin{array}{c}0.00161 \\
(0.00121)\end{array}$ & $\begin{array}{c}-0.0000 \\
(0.00165)\end{array}$ \\
\hline Cohorts 1977-1978 & $\begin{array}{c}-0.000698 \\
(0.00178) \\
\end{array}$ & $\begin{array}{c}0.00265^{*} \\
(0.00156) \\
\end{array}$ & $\begin{array}{l}-0.00287 \\
(0.00212) \\
\end{array}$ & $\begin{array}{c}0.00299 \\
(0.00183) \\
\end{array}$ & $\begin{array}{c}0.00182 \\
(0.00139) \\
\end{array}$ & $\begin{array}{l}-0.00224 \\
(0.00192)\end{array}$ \\
\hline $\begin{array}{l}\text { Untreated cohorts } \\
(1972-1976)\end{array}$ & $\begin{array}{c}-0.00251^{* *} \\
(0.00111)\end{array}$ & $\begin{array}{l}-0.000501 \\
(0.000960)\end{array}$ & $\begin{array}{c}0.00392 * * * \\
(0.00132)\end{array}$ & $\begin{array}{l}-0.006 * * * \\
(0.00121)\end{array}$ & $\begin{array}{l}-0.0055^{* * *} \\
(0.000898)\end{array}$ & $\begin{array}{c}-0.0047 * * * \\
(0.00125)\end{array}$ \\
\hline Placebo Test & pass & fail & pass & pass & fail & pass \\
\hline Observations & 259,062 & 571,525 & 289,872 & 259,226 & 571,687 & 289,932 \\
\hline R-squared ${ }^{\ddagger}$ & 0.0936 & 0.0917 & 0.134 & 0.0254 & 0.0271 & 0.0406 \\
\hline
\end{tabular}


Table 38: Effect of choice on percentile rank in marks and cognitive skills for different parental education levels; choice radius $2 \mathbf{k m}$

\begin{tabular}{lcccc}
\hline INDEPENDENT VARIABLE & \multicolumn{2}{c}{ PERCENTILE RANK MARKS } & \multicolumn{2}{c}{ COGNITIVE SCORE } \\
Parental education is... & $\begin{array}{c}\text { more than } \\
\text { compulsory }\end{array}$ & compulsory & $\begin{array}{c}\text { more than } \\
\text { compulsory }\end{array}$ & Compulsory \\
\hline \multicolumn{2}{l}{ Marginal effect of choice, relative to untreated cohorts for: } & & \\
Cohorts 1988-1990 & $0.282^{* * *}$ & $0.453^{* * *}$ & & \\
Cohorts 1985-1987 & $(0.0591)$ & $(0.166)$ & & $0.0525^{* * *}$ \\
Cohorts 1982-1984 & 0.0565 & 0.230 & $0.0157^{* * *}$ & $(0.0184)$ \\
Cohorts 1979-1981 & $(0.0634)$ & $(0.156)$ & $(0.00517)$ & $0.0511^{* * *}$ \\
Cohorts 1977-1978 & $-0.155^{* *}$ & 0.237 & 0.00629 & $(0.0158)$ \\
& $(0.0627)$ & $(0.151)$ & $(0.00539)$ & $0.0385^{* * *}$ \\
\hline Untreated cohorts & $-0.131^{*}$ & $0.349 * *$ & 0.00745 & $(0.0147)$ \\
(1972-1976) & $(0.0675)$ & $(0.140)$ & $(0.00555)$ & $0.0291^{*}$ \\
Placebo Test & $-0.156^{* *}$ & 0.232 & $0.0112^{*}$ & $(0.0161)$ \\
\hline Observations & $(0.0682)$ & $(0.152)$ & $(0.00642)$ & $-0.0424^{* * *}$ \\
\hline
\end{tabular}

Notes: Robust standard errors in parentheses. Statistical significance at 1, 5 and 10\% level is denoted by ***, **, *. For a complete list of included covariates see Table 5. The definition of the placebo tests is explained in Section 5.1. $\ddagger$ Pseudo R-squared for binary outcomes. 
Table 39: Effect of choice on probability of receiving a high or passing grade in math for different parental education levels; choice radius $2 \mathbf{k m}$

\begin{tabular}{|c|c|c|c|c|}
\hline \multirow{2}{*}{$\begin{array}{l}\text { INDEPENDENT VARIABLE } \\
\text { Parental education is... }\end{array}$} & \multicolumn{2}{|c|}{$\underline{\text { HIGH GRADE MATH }}$} & \multicolumn{2}{|c|}{ PASSING GRADE MATH } \\
\hline & $\begin{array}{l}\text { more than } \\
\text { compulsory }\end{array}$ & compulsory & $\begin{array}{l}\text { more than } \\
\text { compulsory }\end{array}$ & Compulsory \\
\hline \multicolumn{5}{|c|}{ Marginal effect of choice, relative to untreated cohorts for: } \\
\hline Cohorts 1988-1990 & $\begin{array}{c}0.00748 * * * \\
(0.00110)\end{array}$ & $\begin{array}{c}0.00949 * * * \\
(0.00258)\end{array}$ & $\begin{array}{c}-0.000894 \\
(0.000702)\end{array}$ & $\begin{array}{l}-0.000081 \\
(0.00245)\end{array}$ \\
\hline Cohorts 1985-1987 & $\begin{array}{c}0.00450 * * * \\
(0.00111)\end{array}$ & $\begin{array}{c}0.00623 * * \\
(0.00246)\end{array}$ & $\begin{array}{c}-0.00187 * * * \\
(0.000696)\end{array}$ & $\begin{array}{l}-0.00436 * \\
(0.00229)\end{array}$ \\
\hline Cohorts 1982-1984 & $\begin{array}{l}0.000417 \\
(0.00119)\end{array}$ & $\begin{array}{l}0.00487 * * \\
(0.00243)\end{array}$ & $\begin{array}{l}-0.00153^{* *} \\
(0.000697)\end{array}$ & $\begin{array}{l}-0.00309 \\
(0.00208)\end{array}$ \\
\hline Cohorts 1979-1981 & $\begin{array}{c}-0.00347^{* * * *} \\
(0.00118)\end{array}$ & $\begin{array}{c}0.00312 \\
(0.00240)\end{array}$ & $\begin{array}{c}0.00137 \\
(0.000973)\end{array}$ & $\begin{array}{l}0.00623 * * \\
(0.00266)\end{array}$ \\
\hline Cohorts 1977-1978 & $\begin{array}{c}-0.00307 * * \\
(0.00138)\end{array}$ & $\begin{array}{c}0.00308 \\
(0.00258)\end{array}$ & $\begin{array}{l}-0.00113 \\
(0.00117)\end{array}$ & $\begin{array}{c}0.00179 \\
(0.00284)\end{array}$ \\
\hline $\begin{array}{l}\text { Untreated cohorts } \\
(1972-1976)\end{array}$ & $\begin{array}{c}0.000709 \\
(0.000838)\end{array}$ & $\begin{array}{l}-0.00284 * \\
(0.00158)\end{array}$ & $\begin{array}{c}0.00108 \\
(0.000665)\end{array}$ & $\begin{array}{c}0.00268 \\
(0.00175)\end{array}$ \\
\hline Placebo Test & fail & pass & pass & pass \\
\hline Observations & $1,547,652$ & 164,464 & $1,547,652$ & 164,464 \\
\hline R-squared ${ }^{\ddagger}$ & 0.0574 & 0.0205 & 0.133 & 0.0608 \\
\hline
\end{tabular}


Table 40: Effect of choice on probability of committing a crime until age 22 and education and employment at age 25 for different parental education levels; choice radius $2 \mathbf{k m}$

\begin{tabular}{|c|c|c|c|c|c|c|}
\hline \multirow{2}{*}{$\begin{array}{l}\text { INDEPENDENT } \\
\text { VARIABLE } \\
\text { Parental education } \\
\text { is... }\end{array}$} & \multicolumn{2}{|c|}{ CRIME AGE 22} & \multicolumn{2}{|c|}{ UNIVERSITY DEGREE AGE 25} & \multicolumn{2}{|c|}{ EMPLOYED AGE 25} \\
\hline & $\begin{array}{l}\text { more than } \\
\text { compulsory }\end{array}$ & compulsory & $\begin{array}{c}\text { more than } \\
\text { compulsory } t\end{array}$ & compulsory & $\begin{array}{l}\text { more than } \\
\text { compulsory }\end{array}$ & compulsory \\
\hline \multicolumn{7}{|c|}{ Marginal effect of choice, relative to untreated cohorts for: } \\
\hline Cohorts 1985-1987 & $\begin{array}{c}0.000466 \\
(0.000605)\end{array}$ & $\begin{array}{l}0.000236 \\
(0.00218)\end{array}$ & & & & \\
\hline Cohorts 1982-1984 & $\begin{array}{c}0.000532 \\
(0.000647)\end{array}$ & $\begin{array}{l}-0.00328 * \\
(0.00196)\end{array}$ & $\begin{array}{c}0.00466 * * * \\
(0.00110)\end{array}$ & $\begin{array}{l}0.0139 * * * \\
(0.00209)\end{array}$ & $\begin{array}{c}0.00107 \\
(0.000883)\end{array}$ & $\begin{array}{l}0.0102 * * * \\
(0.00224)\end{array}$ \\
\hline Cohorts 1979-1981 & $\begin{array}{c}0.000552 \\
(0.000684)\end{array}$ & $\begin{array}{c}-0.0055^{* * *} \\
(0.00196)\end{array}$ & $\begin{array}{l}0.00183^{*} \\
(0.00109)\end{array}$ & $\begin{array}{c}0.00720 * * * \\
(0.00204)\end{array}$ & $\begin{array}{c}0.0000 \\
(0.000929)\end{array}$ & $\begin{array}{c}0.00826 * * * \\
(0.00223)\end{array}$ \\
\hline Cohorts 1977-1978 & $\begin{array}{l}0.00165^{* *} \\
(0.000820)\end{array}$ & $\begin{array}{l}-0.00168 \\
(0.00204)\end{array}$ & $\begin{array}{l}-0.000402 \\
(0.00127)\end{array}$ & $\begin{array}{l}0.00494 * * \\
(0.00222)\end{array}$ & $\begin{array}{l}0.000632 \\
(0.00106)\end{array}$ & $\begin{array}{l}0.00490 * * \\
(0.00240)\end{array}$ \\
\hline $\begin{array}{l}\text { Untreated cohorts } \\
(1972-1976)\end{array}$ & $\begin{array}{c}0.000335 \\
(0.000485)\end{array}$ & $\begin{array}{c}0.00135 \\
(0.00134)\end{array}$ & $\begin{array}{c}0.000711 \\
(0.000766)\end{array}$ & $\begin{array}{c}-0.00277^{* *} \\
(0.00138)\end{array}$ & $\begin{array}{l}-0.0048 * * * \\
(0.000705)\end{array}$ & $\begin{array}{c}-0.0078^{* * *} \\
(0.00159)\end{array}$ \\
\hline Placebo Test & pass & pass & fail & pass & fail & pass \\
\hline Observations & $1,255,800$ & 153,292 & 984,366 & 136,093 & 984,638 & 136,207 \\
\hline R-squared ${ }^{\ddagger}$ & 0.0364 & 0.0366 & 0.114 & 0.0375 & 0.0293 & 0.0340 \\
\hline
\end{tabular}

Notes: Robust standard errors in parentheses. Statistical significance at 1, 5 and $10 \%$ level is denoted by ***, **, *. For a complete list of included covariates see Table 5. The definition of the placebo tests is explained in Section 5.1.

$\ddagger$ Pseudo R-squared for binary outcomes. † For the outcome "receiving a high grade”, we left out household income and its squared term to achieve convergence. 
Table 41: Effect of choice on percentile rank in marks and cognitive skills for different parental migration backgrounds; choice radius $2 \mathbf{k m}$

\begin{tabular}{|c|c|c|c|c|}
\hline \multirow{2}{*}{$\begin{array}{l}\text { INDEPENDENT VARIABLE } \\
\text { Parental migration background }\end{array}$} & \multicolumn{2}{|c|}{$\underline{\text { PERCENTILE RANK MARKS }}$} & \multicolumn{2}{|c|}{ COGNITIVE SCORE } \\
\hline & $\begin{array}{l}\text { at least one } \\
\text { Swedish }\end{array}$ & $\begin{array}{c}\text { both } \\
\text { immigrants }\end{array}$ & $\begin{array}{l}\text { at least one } \\
\text { Swedish }\end{array}$ & $\begin{array}{c}\text { both } \\
\text { immigrants }\end{array}$ \\
\hline \multicolumn{5}{|c|}{ Marginal effect of choice, relative to untreated cohorts for: } \\
\hline Cohorts 1988-1990 & $\begin{array}{c}0.381 * * * \\
(0.0572)\end{array}$ & $\begin{array}{l}0.0352 \\
(0.177)\end{array}$ & & \\
\hline Cohorts 1985-1987 & $\begin{array}{c}0.104 \\
(0.0633)\end{array}$ & $\begin{array}{l}0.0675 \\
(0.177)\end{array}$ & $\begin{array}{c}0.0156 * * * \\
(0.00526)\end{array}$ & $\begin{array}{c}0.0512 * * * \\
(0.0185)\end{array}$ \\
\hline Cohorts 1982-1984 & $\begin{array}{l}-0.128 * * \\
(0.0629)\end{array}$ & $\begin{array}{l}-0.214 \\
(0.178)\end{array}$ & $\begin{array}{c}0.00507 \\
(0.00538)\end{array}$ & $\begin{array}{c}0.0239 \\
(0.0178)\end{array}$ \\
\hline Cohorts 1979-1981 & $\begin{array}{l}-0.118 * \\
(0.0656)\end{array}$ & $\begin{array}{l}0.0501 \\
(0.177)\end{array}$ & $\begin{array}{c}0.00284 \\
(0.00554)\end{array}$ & $\begin{array}{l}0.0360 * * \\
(0.0181)\end{array}$ \\
\hline Cohorts 1977-1978 & $\begin{array}{l}-0.147 * * \\
(0.0677)\end{array}$ & $\begin{array}{c}0.00338 \\
(0.194)\end{array}$ & $\begin{array}{l}0.0139 * * \\
(0.00631)\end{array}$ & $\begin{array}{l}0.00700 \\
(0.0197)\end{array}$ \\
\hline $\begin{array}{l}\text { Untreated cohorts } \\
(1972-1976)\end{array}$ & $\begin{array}{l}0.117 * * * \\
(0.0421)\end{array}$ & $\begin{array}{l}0.0868 \\
(0.138)\end{array}$ & $\begin{array}{c}-0.00834^{* *} \\
(0.00378)\end{array}$ & $\begin{array}{c}-0.0369 * * * \\
(0.0135)\end{array}$ \\
\hline Placebo Test & pass & pass & pass & pass \\
\hline Observations & $1,599,471$ & 115,950 & 575,487 & 34,695 \\
\hline R-squared ${ }^{\ddagger}$ & 0.190 & 0.139 & 0.139 & 0.150 \\
\hline
\end{tabular}


Table 42: Effect of choice on probability of receiving a high or passing grade in math for different parental migration backgrounds; choice radius $2 \mathbf{k m}$

\begin{tabular}{|c|c|c|c|c|}
\hline \multirow{2}{*}{$\begin{array}{l}\text { INDEPENDENT VARIABLE } \\
\text { Parental education is... }\end{array}$} & \multicolumn{2}{|c|}{$\underline{\text { HIGH GRADE MATH }}$} & \multicolumn{2}{|c|}{$\underline{\text { PASSING GRADE MATH }}$} \\
\hline & $\begin{array}{l}\text { at least one } \\
\text { Swedish }\end{array}$ & $\begin{array}{c}\text { both } \\
\text { immigrants }\end{array}$ & $\begin{array}{l}\text { at least one } \\
\text { Swedish }\end{array}$ & $\begin{array}{l}\text { both } \\
\text { immigrants }\end{array}$ \\
\hline \multicolumn{5}{|c|}{ Marginal effect of choice, relative to untreated cohorts for: } \\
\hline Cohorts $1988-1990$ & $\begin{array}{c}0.00877 * * * \\
(0.00108)\end{array}$ & $\begin{array}{c}0.00683 * * \\
(0.00288)\end{array}$ & $\begin{array}{l}-0.000227 \\
(0.000701)\end{array}$ & $\begin{array}{l}-0.00457 * \\
(0.00270)\end{array}$ \\
\hline Cohorts 1985-1987 & $\begin{array}{c}0.00506^{* * *} \\
(0.00111)\end{array}$ & $\begin{array}{c}0.00725^{* *} \\
(0.00293)\end{array}$ & $\begin{array}{c}-0.00179 * * \\
(0.000699)\end{array}$ & $\begin{array}{l}-0.00336 \\
(0.00266)\end{array}$ \\
\hline Cohorts 1982-1984 & $\begin{array}{c}0.00108 \\
(0.00118)\end{array}$ & $\begin{array}{c}0.00265 \\
(0.00298)\end{array}$ & $\begin{array}{c}-0.00155^{* *} \\
(0.000695)\end{array}$ & $\begin{array}{l}-0.00324 \\
(0.00272)\end{array}$ \\
\hline Cohorts 1979-1981 & $\begin{array}{c}-0.00330 * * * \\
(0.00117)\end{array}$ & $\begin{array}{l}-0.00161 \\
(0.00298)\end{array}$ & $\begin{array}{c}0.00103 \\
(0.000994)\end{array}$ & $\begin{array}{c}0.00355 \\
(0.00306)\end{array}$ \\
\hline Cohorts $1977-1978$ & $\begin{array}{c}-0.00284 * * \\
(0.00137) \\
\end{array}$ & $\begin{array}{l}0.000581 \\
(0.00321) \\
\end{array}$ & $\begin{array}{l}-0.00103 \\
(0.00117) \\
\end{array}$ & $\begin{array}{l}-0.00115 \\
(0.00361) \\
\end{array}$ \\
\hline $\begin{array}{l}\text { Untreated cohorts } \\
(1972-1976)\end{array}$ & $\begin{array}{c}0.000360 \\
(0.000820)\end{array}$ & $\begin{array}{l}-0.00178 \\
(0.00226)\end{array}$ & $\begin{array}{c}0.00103 \\
(0.000660)\end{array}$ & $\begin{array}{c}0.00333 \\
(0.00250)\end{array}$ \\
\hline Placebo Test & fail & pass & pass & pass \\
\hline Observations & $1,596,671$ & 115,445 & $1,596,671$ & 115,414 \\
\hline R-squared ${ }^{\ddagger}$ & 0.0605 & 0.0524 & 0.135 & 0.121 \\
\hline
\end{tabular}


Table 43: Effect of choice on probability of committing a crime until age 22 and education and employment at age 25 for different parental migration backgrounds; choice radius

$2 \mathbf{k m}$

\begin{tabular}{|c|c|c|c|c|c|c|}
\hline \multirow{2}{*}{$\begin{array}{l}\text { INDEPENDENT } \\
\text { VARIABLE } \\
\text { Parental migration } \\
\text { background }\end{array}$} & \multicolumn{2}{|c|}{$\underline{\text { CRIME AGE } 22}$} & \multicolumn{2}{|c|}{$\frac{\text { UNIVERSITY DEGREE AGE }}{\underline{25}}$} & \multicolumn{2}{|c|}{$\underline{\text { EMPLOYED AGE } 25}$} \\
\hline & $\begin{array}{l}\text { at least one } \\
\text { Swedish }\end{array}$ & $\begin{array}{c}\text { both } \\
\text { immigrants }\end{array}$ & $\begin{array}{l}\text { at least one } \\
\text { Swedish } t\end{array}$ & $\begin{array}{c}\text { both } \\
\text { immigrants }\end{array}$ & $\begin{array}{c}\text { at least } \\
\text { one } \\
\text { Swedish }\end{array}$ & $\begin{array}{c}\text { both } \\
\text { immigrants }\end{array}$ \\
\hline \multicolumn{7}{|c|}{ Marginal effect of choice, relative to untreated cohorts for: } \\
\hline Cohorts 1985-1987 & $\begin{array}{c}0.000781 \\
(0.000613)\end{array}$ & $\begin{array}{c}-0.00398 \\
(0.00251)\end{array}$ & & & & \\
\hline Cohorts 1982-1984 & $\begin{array}{c}0.000908 \\
(0.000647)\end{array}$ & $\begin{array}{c}-0.00555 * * \\
(0.00251)\end{array}$ & $\begin{array}{c}0.00283^{* * *} \\
(0.00108)\end{array}$ & $\begin{array}{c}0.0115 * * * \\
(0.00286)\end{array}$ & $\begin{array}{c}0.00134 \\
(0.000857)\end{array}$ & $\begin{array}{c}0.00672 * * \\
(0.00307)\end{array}$ \\
\hline Cohorts 1979-1981 & $\begin{array}{c}0.000726 \\
(0.000682)\end{array}$ & $\begin{array}{c}-0.0080 * * * \\
(0.00257)\end{array}$ & $\begin{array}{l}0.000992 \\
(0.00108)\end{array}$ & $\begin{array}{c}0.00818^{* * *} \\
(0.00296)\end{array}$ & $\begin{array}{c}0.000822 \\
(0.000905)\end{array}$ & $\begin{array}{c}0.00415 \\
(0.00309)\end{array}$ \\
\hline Cohorts 1977-1978 & $\begin{array}{c}0.00220 * * * \\
(0.000804)\end{array}$ & $\begin{array}{c}-0.00674^{* *} \\
(0.00280) \\
\end{array}$ & $\begin{array}{r}-0.000755 \\
(0.00127) \\
\end{array}$ & $\begin{array}{c}0.00882^{* * * *} \\
(0.00313)\end{array}$ & $\begin{array}{l}0.000575 \\
(0.00108)\end{array}$ & $\begin{array}{l}0.00619 * \\
(0.00335)\end{array}$ \\
\hline $\begin{array}{l}\text { Untreated cohorts } \\
(1972-1976)\end{array}$ & $\begin{array}{c}4.68 \mathrm{e}-05 \\
(0.000475)\end{array}$ & $\begin{array}{l}0.00372 * \\
(0.00200)\end{array}$ & $\begin{array}{l}0.00161 * * \\
(0.000759)\end{array}$ & $\begin{array}{c}-0.0057 * * * \\
(0.00211)\end{array}$ & $\begin{array}{l}-0.0052 * * * \\
(0.000679)\end{array}$ & $\begin{array}{l}-0.00373 \\
(0.00240)\end{array}$ \\
\hline Placebo Test & pass & pass & pass & pass & fail & pass \\
\hline Observations & $1,313,155$ & 95,925 & $1,045,998$ & 74,437 & $1,046,309$ & 74,523 \\
\hline R-squared $^{\ddagger}$ & 0.0355 & 0.0319 & 0.128 & 0.104 & 0.0291 & 0.0300 \\
\hline
\end{tabular}

Notes: Robust standard errors in parentheses. Statistical significance at 1, 5 and $10 \%$ level is denoted by ***, **, *. For a complete list of included covariates see Table 5. The definition of the placebo tests is explained in Section 5.1.

$\ddagger$ Pseudo R-squared for binary outcomes. † For the outcome "receiving a high grade”, we left out household income and its squared term to achieve convergence. 
Table 44: Effect of choice on the percentile rank in marks and cognitive skills for local areas with high or low/medium youth crime levels; choice radius $\mathbf{2 k m}$

\begin{tabular}{|c|c|c|c|c|}
\hline INDEPENDENT VARIABLE & \multicolumn{2}{|c|}{ PERCENTILE RANK MARKS } & \multicolumn{2}{|c|}{ COGNITIVE SCORE } \\
\hline $\begin{array}{l}\text { Local area characteristics } \\
\text { 1990-91 }\end{array}$ & $\begin{array}{l}\text { low/medium } \\
\text { crime }\end{array}$ & high crime & $\begin{array}{l}\text { low } / \text { medium } \\
\text { crime }\end{array}$ & high crime \\
\hline \multicolumn{5}{|c|}{ Marginal effect of choice, relative to untreated cohorts for: } \\
\hline Cohorts 1988-1990 & $\begin{array}{c}0.191^{* * *} \\
(0.0678)\end{array}$ & $\begin{array}{c}0.458^{* * *} \\
(0.107)\end{array}$ & & \\
\hline Cohorts $1985-1987$ & $\begin{array}{c}0.0364 \\
(0.0756)\end{array}$ & $\begin{array}{l}0.208^{*} \\
(0.111)\end{array}$ & $\begin{array}{c}0.00750 \\
(0.00622)\end{array}$ & $\begin{array}{c}0.0350 * * * \\
(0.0105)\end{array}$ \\
\hline Cohorts 1982-1984 & $\begin{array}{l}-0.185 * * \\
(0.0745)\end{array}$ & $\begin{array}{c}0.104 \\
(0.114)\end{array}$ & $\begin{array}{c}0.00362 \\
(0.00621)\end{array}$ & $\begin{array}{c}0.0133 \\
(0.0106)\end{array}$ \\
\hline Cohorts 1979-1981 & $\begin{array}{l}-0.126^{*} \\
(0.0738)\end{array}$ & $\begin{array}{l}0.00956 \\
(0.120)\end{array}$ & $\begin{array}{c}0.00378 \\
(0.00654)\end{array}$ & $\begin{array}{c}0.0140 \\
(0.0105)\end{array}$ \\
\hline Cohorts $1977-1978$ & $\begin{array}{c}-0.228 * * * \\
(0.0813)\end{array}$ & $\begin{array}{c}0.121 \\
(0.121)\end{array}$ & $\begin{array}{c}0.00561 \\
(0.00696)\end{array}$ & $\begin{array}{c}0.0176 \\
(0.0125)\end{array}$ \\
\hline $\begin{array}{l}\text { Untreated cohorts } \\
(1972-1976)\end{array}$ & $\begin{array}{l}0.217^{* * *} \\
(0.0494)\end{array}$ & $\begin{array}{l}-0.00310 \\
(0.0796)\end{array}$ & $\begin{array}{l}-0.0180 * * \\
(0.00774)\end{array}$ & $\begin{array}{l}-0.0180 * * \\
(0.00774)\end{array}$ \\
\hline Placebo Test & pass & fail & pass & pass \\
\hline Observations & $1,400,647$ & 275,140 & 502,933 & 92,384 \\
\hline R-squared ${ }^{\ddagger}$ & 0.185 & 0.194 & 0.142 & 0.171 \\
\hline
\end{tabular}


Table 45: Effect of choice on the probability of receiving a high or passing grade in math for local areas with high or low/medium youth crime levels; choice radius $\mathbf{2 k m}$

\begin{tabular}{|c|c|c|c|c|}
\hline \multirow{2}{*}{$\begin{array}{l}\text { INDEPENDENT VARIABLE } \\
\text { Local area characteristics } \\
\text { 1990-91 }\end{array}$} & \multicolumn{2}{|c|}{$\underline{\text { HIGH GRADE MATH }}$} & \multicolumn{2}{|c|}{$\underline{\text { PASSING GRADE }}$} \\
\hline & $\begin{array}{l}\text { low/medium } \\
\text { crime }\end{array}$ & high crime & $\begin{array}{l}\text { low/medium } \\
\text { crime }\end{array}$ & high crime \\
\hline \multicolumn{5}{|c|}{ Marginal effect of choice, relative to untreated cohorts for: } \\
\hline Cohorts 1988-1990 & $\begin{array}{c}0.00751^{* * *} \\
(0.00129)\end{array}$ & $\begin{array}{c}0.0136 * * * \\
(0.00209)\end{array}$ & $\begin{array}{c}-0.00118 \\
(0.000822)\end{array}$ & $\begin{array}{c}0.00102 \\
(0.00148)\end{array}$ \\
\hline Cohorts 1985-1987 & $\begin{array}{c}0.00520 * * * \\
(0.00127)\end{array}$ & $\begin{array}{c}0.00924 * * * \\
(0.00211)\end{array}$ & $\begin{array}{c}-0.00220 * * * \\
(0.000825)\end{array}$ & $\begin{array}{l}0.000486 \\
(0.00145)\end{array}$ \\
\hline Cohorts 1982-1984 & $\begin{array}{c}0.00213 \\
(0.00133)\end{array}$ & $\begin{array}{l}0.00411^{*} \\
(0.00232)\end{array}$ & $\begin{array}{l}-0.00198^{* *} \\
(0.000823)\end{array}$ & $\begin{array}{l}0.000938 \\
(0.00147)\end{array}$ \\
\hline Cohorts 1979-1981 & $\begin{array}{c}-0.00261^{* *} \\
(0.00126)\end{array}$ & $\begin{array}{c}0.00263 \\
(0.00242)\end{array}$ & $\begin{array}{l}0.000746 \\
(0.00107)\end{array}$ & $\begin{array}{c}0.00545^{* * *} \\
(0.00205)\end{array}$ \\
\hline Cohorts 1977-1978 & $\begin{array}{c}-0.00398 * * * \\
(0.00150)\end{array}$ & $\begin{array}{c}0.00547 * * \\
(0.00274)\end{array}$ & $\begin{array}{l}-0.00239 * \\
(0.00133)\end{array}$ & $\begin{array}{c}0.00384 \\
(0.00251)\end{array}$ \\
\hline $\begin{array}{l}\text { Untreated cohorts } \\
(1972-1976)\end{array}$ & $\begin{array}{l}-0.000168 \\
(0.000937)\end{array}$ & $\begin{array}{l}-0.00244 \\
(0.00161)\end{array}$ & $\begin{array}{c}0.00135^{*} \\
(0.000775)\end{array}$ & $\begin{array}{l}0.000197 \\
(0.00138)\end{array}$ \\
\hline Placebo Test & fail & fail & fail & pass \\
\hline Observations & $1,398,201$ & 274,338 & $1,398,201$ & 274,338 \\
\hline R-squared ${ }^{\ddagger}$ & 0.0588 & 0.0695 & 0.133 & 0.141 \\
\hline
\end{tabular}


Table 46: Effect of choice on the percentile rank in marks and cognitive skills for local areas with high or low/medium youth crime levels; choice radius $2 \mathbf{k m}$

\begin{tabular}{|c|c|c|c|c|c|c|c|c|}
\hline \multirow{3}{*}{$\begin{array}{l}\text { INDEPENDENT } \\
\text { VARIABLE } \\
\text { Local area } \\
\text { characteristics } \\
\text { 1990-91 }\end{array}$} & \multicolumn{4}{|c|}{ PERCENTILE RANK MARKS } & \multicolumn{4}{|c|}{ COGNITIVE SCORE } \\
\hline & \multicolumn{2}{|c|}{ low/medium crime } & \multicolumn{2}{|c|}{ high crime } & \multicolumn{2}{|c|}{ low/medium crime } & \multicolumn{2}{|c|}{ high crime } \\
\hline & non-urban & urban & non-urban & urban & $\begin{array}{l}\text { non- } \\
\text { urban }\end{array}$ & urban & $\begin{array}{l}\text { non- } \\
\text { urban }\end{array}$ & urban \\
\hline \multicolumn{9}{|c|}{ Marginal effect of choice, relative to untreated cohorts for: } \\
\hline $\begin{array}{l}\text { Cohorts 1988- } \\
1990\end{array}$ & $\begin{array}{c}-0.453^{* * *} \\
(0.123)\end{array}$ & $\begin{array}{l}0.254 * * * \\
(0.0791)\end{array}$ & $\begin{array}{l}-0.992 \\
(0.752)\end{array}$ & $\begin{array}{c}0.649 * * * \\
(0.116)\end{array}$ & & & & \\
\hline $\begin{array}{l}\text { Cohorts 1985- } \\
1987\end{array}$ & $\begin{array}{c}-0.378^{* * *} \\
(0.133)\end{array}$ & $\begin{array}{c}0.130 \\
(0.0897)\end{array}$ & $\begin{array}{l}-1.330 \\
(0.811)\end{array}$ & $\begin{array}{c}0.395^{* * *} \\
(0.120)\end{array}$ & $\begin{array}{c}0.0128 \\
(0.0137)\end{array}$ & $\begin{array}{c}0.00819 \\
(0.00740)\end{array}$ & $\begin{array}{l}0.00176 \\
(0.0753)\end{array}$ & $\begin{array}{c}0.0385 * * * \\
(0.0116)\end{array}$ \\
\hline $\begin{array}{l}\text { Cohorts 1982- } \\
1984\end{array}$ & $\begin{array}{c}-0.337 * * \\
(0.140)\end{array}$ & $\begin{array}{l}-0.0422 \\
(0.0873)\end{array}$ & $\begin{array}{l}-1.299 \\
(0.900)\end{array}$ & $\begin{array}{l}0.307^{* *} \\
(0.126)\end{array}$ & $\begin{array}{l}0.0255^{*} \\
(0.0137)\end{array}$ & $\begin{array}{c}0.00623 \\
(0.00747)\end{array}$ & $\begin{array}{l}0.00216 \\
(0.0842)\end{array}$ & $\begin{array}{c}0.0141 \\
(0.0116)\end{array}$ \\
\hline $\begin{array}{l}\text { Cohorts 1979- } \\
1981\end{array}$ & $\begin{array}{l}-0.133 \\
(0.128)\end{array}$ & $\begin{array}{l}-0.0569 \\
(0.0905)\end{array}$ & $\begin{array}{l}-0.728 \\
(0.660)\end{array}$ & $\begin{array}{c}0.106 \\
(0.132)\end{array}$ & $\begin{array}{l}0.00859 \\
(0.0129)\end{array}$ & $\begin{array}{c}0.00534 \\
(0.00805)\end{array}$ & $\begin{array}{c}0.0358 \\
(0.0688)\end{array}$ & $\begin{array}{l}0.0202 * \\
(0.0118)\end{array}$ \\
\hline $\begin{array}{l}\text { Cohorts 1977- } \\
1978\end{array}$ & $\begin{array}{l}-0.196 \\
(0.146) \\
\end{array}$ & $\begin{array}{c}-0.131 \\
(0.0967)\end{array}$ & $\begin{array}{l}-0.274 \\
(0.821) \\
\end{array}$ & $\begin{array}{l}0.0927 \\
(0.133) \\
\end{array}$ & $\begin{array}{c}0.0104 \\
(0.0149)\end{array}$ & $\begin{array}{c}0.00395 \\
(0.00819) \\
\end{array}$ & $\begin{array}{c}0.0770 \\
(0.0702) \\
\end{array}$ & $\begin{array}{l}0.00134 \\
(0.0137) \\
\end{array}$ \\
\hline $\begin{array}{l}\text { Untreated cohorts } \\
(1972-1976)\end{array}$ & $\begin{array}{l}0.339 * * * \\
(0.0858)\end{array}$ & $\begin{array}{l}0.139 * * \\
(0.0595)\end{array}$ & $\begin{array}{c}1.798 * * * \\
(0.460)\end{array}$ & $\begin{array}{c}-0.130 \\
(0.0849)\end{array}$ & $\begin{array}{l}-0.030 * * * \\
(0.00857)\end{array}$ & $\begin{array}{l}-0.00144 \\
(0.00533)\end{array}$ & $\begin{array}{c}0.0628 \\
(0.0448)\end{array}$ & $\begin{array}{l}-0.0186 * * \\
(0.00830)\end{array}$ \\
\hline Placebo Test & pass & pass & pass & pass & pass & pass & pass & fail \\
\hline Observations & 741,774 & 658,873 & 42,720 & 232,420 & 266,858 & 236,075 & 14,876 & 77,508 \\
\hline R-squared ${ }^{\ddagger}$ & 0.164 & 0.201 & 0.169 & 0.197 & 0.124 & 0.153 & 0.131 & 0.179 \\
\hline
\end{tabular}


Table 47 Effect of choice on probability of receiving a high or passing grade in math for local areas with high or low/medium youth crime levels; choice radius $2 \mathbf{k m}$

\begin{tabular}{|c|c|c|c|c|c|c|c|c|}
\hline \multirow{3}{*}{$\begin{array}{l}\text { INDEPENDENT } \\
\text { VARIABLE } \\
\text { Local area } \\
\text { characteristics } \\
\text { 1990-91 }\end{array}$} & \multicolumn{4}{|c|}{$\underline{\text { HIGH GRADE MATH }}$} & \multicolumn{4}{|c|}{$\underline{\text { PASSING GRADE }}$} \\
\hline & \multicolumn{2}{|c|}{ low/medium crime } & \multicolumn{2}{|c|}{ high crime } & \multicolumn{2}{|c|}{ low/medium crime } & \multicolumn{2}{|c|}{ high crime } \\
\hline & non-urban & urban & non-urban & urban & non-urban & urban & non-urban & urban \\
\hline \multicolumn{9}{|c|}{ Marginal effect of choice, relative to untreated cohorts for: } \\
\hline $\begin{array}{l}\text { Cohorts 1988- } \\
1990\end{array}$ & $\begin{array}{l}-0.00320 \\
(0.00249)\end{array}$ & $\begin{array}{c}0.00707 * * * \\
(0.00155)\end{array}$ & $\begin{array}{l}-0.00202 \\
(0.0125)\end{array}$ & $\begin{array}{c}0.0146^{* * *} \\
(0.00232)\end{array}$ & $\begin{array}{l}-0.005^{* * *} \\
(0.00157)\end{array}$ & $\begin{array}{c}0.000121 \\
(0.000949)\end{array}$ & $\begin{array}{l}-0.00636 \\
(0.0101)\end{array}$ & $\begin{array}{l}-0.00277 \\
(0.00176)\end{array}$ \\
\hline Cohorts 1985- & -0.000413 & $0.00499 * * *$ & 0.0125 & $0.0101 * * *$ & $-0.005 * * *$ & -0.000568 & -0.0158 & -0.00244 \\
\hline 1987 & $(0.00253)$ & $(0.00158)$ & $(0.0141)$ & $(0.00236)$ & $(0.00159)$ & $(0.000949)$ & $(0.0103)$ & $(0.00177)$ \\
\hline Cohorts 1982- & -0.00208 & 0.00264 & -0.0137 & $0.00568 * *$ & $-0.0039 * *$ & -0.000383 & -0.0144 & -0.00122 \\
\hline 1984 & $(0.00251)$ & $(0.00163)$ & $(0.0157)$ & (0.00259) & $(0.00155)$ & (0.000964) & $(0.0104)$ & $(0.00174)$ \\
\hline Cohorts 1979- & -0.000277 & -0.00229 & -0.00665 & $0.00493^{*}$ & -0.00233 & $0.00285^{* *}$ & -0.0140 & $0.00460 * *$ \\
\hline 1981 & $(0.00242)$ & $(0.00157)$ & $(0.0145)$ & $(0.00265)$ & $(0.00207)$ & $(0.00128)$ & $(0.0129)$ & $(0.00232)$ \\
\hline Cohorts 1977- & -0.00196 & -0.00261 & -0.0143 & $0.00686 * *$ & -0.00322 & -0.000404 & -0.00394 & 0.00226 \\
\hline 1978 & $(0.00276)$ & $(0.00183)$ & $(0.0166)$ & $(0.00305)$ & $(0.00247)$ & $(0.00159)$ & $(0.0144)$ & $(0.00270)$ \\
\hline Untreated cohorts & 0.00187 & -0.000362 & $0.0165 * *$ & $-0.00300 *$ & $0.00277^{*}$ & 0.0000985 & $0.0179 * *$ & $0.00328 * *$ \\
\hline (1972-1976) & $(0.00157)$ & $(0.00116)$ & (0.00733) & $(0.00175)$ & $(0.00142)$ & (0.000905) & $(0.00914)$ & $(0.00164)$ \\
\hline Placebo Test & fail & pass & pass & fail & pass & pass & pass & pass \\
\hline Observations & 740,459 & 657,742 & 42,609 & 231,729 & 740,459 & 657,742 & 42,609 & 231,729 \\
\hline R-squared ${ }^{\ddagger}$ & 0.0507 & 0.0657 & 0.0554 & 0.0731 & 0.127 & 0.140 & 0.126 & 0.145 \\
\hline
\end{tabular}

